\title{
Crystallization of Sodium Nitrate from Radioactive Waste
}

\author{
V. B. Krapukhin ${ }^{(a)}$ \\ E. P. Krasavina ${ }^{(a)}$ \\ A. K. Pikaev ${ }^{(2)}$
}

July 1997

Prepared for

the U.S. Department of Energy

under Contract DE-AC06-76RLO 1830

Pacific Northwest National Laboratory

Richland, Washington 99352

(a) Institute of Physical Chemistry, Russian Academy of Sciences, Moscow, Russia. 


\section{DISCLAMIER}

Portions of this document may be illegible in electronic image produetc. Images are produced from the best arailabie origion coeroment. 


\section{DISCLAIMER}

This report was prepared as an account of work sponsored by an agency of the United States Government. Neither the United States Government nor any agency thereof, nor any of their employees, makes any warranty, express or implied, or assumes any legal liability or responsibility for the accuracy, completeness, or usefulness of any information, apparatus, product, or process disclosed, or represents that its use would not infringe privately owned rights. Reference herein to any specific commercial product, process, or service by trade name, trademark, manufacturer, or otherwise does not necessarily constitute or imply its endorsement, recommendation, or favoring by the United States Government or any agency thereof. The views and opinions of authors expressed herein do not necessarily state or reflect those of the United States Government or any agency thereof. 


\section{Preface}

This final technical report was prepared by Dr. V. B. Krapukhin, Mrs. E. P. Krasavina, and Professor A. K. Pikaev for Westinghouse Hanford Company by a collaboration agreement made on August 1, 1996 between the United States Department of Energy and the Institute of Physical Chemistry of the Russian Academy of Sciences. 



\section{Executive Summary}

From the 1940s to the 1980s, the Institute of Physical Chemistry of the Russian Academy of Sciences (IPC/RAS) conducted research and development on processes to separate acetate and nitrate salts and acetic acid from radioactive wastes. The research objective was to decrease waste volumes and produce the separated decontaminated materials for recycle. This report presents an account of the IPC/RAS experience in this field. Details on operating conditions, waste and product compositions, decontamination factors, and process equipment are described.

Early industrial flowsheets generated neutralized radioactive wastes containing roughly equivalent concentrations of sodium nitrate and sodium acetate. Methods were developed to fractionally crystallize first one salt, then the other (the first being the one in abundance) under closed cyclic conditions. To identify optimum process conditions, the $\mathrm{CH}_{3} \mathrm{COONa}-\mathrm{NaNO}_{3}-\mathrm{H}_{2} \mathrm{O}$ phase diagram was studied extensively. Sodium acetate generally was crystallized at about $20^{\circ} \mathrm{C}$ as its trihydrate. Sodium nitrate solutions were concentrated to about $120^{\circ} \mathrm{C}$ boiling point and were crystallized at $70^{\circ} \mathrm{C}$. Recycling the mother solutions and blending them with fresh feed allowed nearly $100 \%$ recovery of both sodium nitrate and acetate. Decontamination factors of 30 to 50 were obtained from radioactive components for both salts over the single crystallization steps used. A tubular rotating crystallizer was developed and used to produce the separated salts.

Several approaches were attempted to attain better decontamination factors from product impurities. Impurities included both radioactive components (ruthenium, strontium, cesium) and bulk chemical waste components that affected crystallization and could carry radionuclides with the salt product (e.g., chromium, aluminum, silicic acid, carbonate, surfactants). Thus, barium and calcium were added to precipitate the chromate and carbonate and to carry radiostrontium. Radiocesium was removed by coprecipitation with ferrocyanide. These decontamination steps were performed at neutral to alkaline conditions. The partially decontaminated solution then was acidified, and the acetic acid was removed by distillation.

However, unprecipitated ferrocyanide could carry to the acid-side evaporators and partially decompose to form hydrogen cyanide gas and ferric ferrocyanide solids that would be retained, with captured fission products, in the crystallized sodium nitrate. Alternative flowsheets were developed that began with acidification and distillation of acetic acid. With this approach, chromate was reduced to $\mathrm{Cr}$ (III), and nonsorbing ruthenium complexes were partially destroyed. The nitrate-rich residue then was neutralized with fresh alkaline waste solution to produce a precipitate in which chromium(III) hydroxide captured aluminum and silicon, the radioactive strontium, and part of the ruthenium. By this sequence, the barium addition (to precipitate $\mathrm{BaCrO}_{4}$ ) could be avoided.

Cesium removal became more imperative as operating efficiencies increased, waste volumes decreased, and fission product concentrations rose. Cesium was removed by adding preformed iron and nickel ferrocyanide to the alkaline waste mixture, and process conditions ( $\mathrm{pH}$, temperature, time) were optimized. Because excess dissolved ferrocyanide was not present in solution, problems with hydrogen 
cyanide generation and ferric ferrocyanide post-precipitation in acid also were eliminated. Centrifuge filters and jet-spray crystal washers were developed to remove the various decontamination solids from the process solutions and product solids, respectively.

Bulk waste components accumulated in the waste solutions as they were stripped of acetate and sodium nitrate. Sodium sulfate was one such component. The influence of sodium sulfate on process conditions was, if anything, positive because it inhibited nitric acid codistillation with the acetic acid. If not removed by alkaline-side calcium precipitation, sulfate ultimately precipitated as the sodium salt with the sodium nitrate product. Because sodium sulfate did not carry radionuclides, it did not radioactively contaminate the product salt.

Other bulk waste components included carbonate, oxalate, and other organics; fluoride, chloride, and potassium. The deleterious effects of carbonate (because of the poor filtration of the carbonate solids, carbonate complexation of zirconium and niobium radionuclides, and carbonate solids' contamination of sodium nitrate product) could be avoided by acidification. Oxalate also could contaminate sodium nitrate product. However, process conditions such as alkaline-side precipitation with calcium and oxidation in hot nitric acid [especially if catalyzed by manganese(II)] eliminated oxalate from the sodium nitrate crystallization solutions and the product salt. Other organics (lactic acid, trihydroxyglutaric acid, thiourea) similarly were oxidized by heating the acidified nitrate solution. Fluoride was eliminated by alkaline-side precipitation with calcium (if calcium were present) or was partially removed by distillation and partly crystallized with sodium nitrate. Potassium and chloride were present in the sodium nitrate product as components of the interstitial liquor.

A single recrystallization step was used for further purification of sodium nitrate salt product in more recent process improvements for wastes containing no acetate. The recrystallization achieved decontamination by removing solid and interstitial contaminants. Generally, further decontaminations of strontium, ruthenium, cesium, and plutonium radioactivity were achieved by sorption on ferrocyanide, alkaline sulfide precipitation, and sorption on pyrolusite $\left(\mathrm{MnO}_{2}\right)$.

A detergent salt, sodium dodecylbenzenesulfonate (called sulfonol in Russia), that is present in more recent wastes proved to be the most difficult contaminant in sodium nitrate crystallization. Alkaline-side precipitation of the anion with calcium or iron did not completely remove this colloidal material. Acidside evaporation did not fully decompose sulfonol. Filtration was marginally successful, but the solids compressed and rapidly blocked the filter. Coprecipitation with calcium phosphate was the most effective single method to remove sulfonol. By using a combination of these approaches, the greatest success was achieved. 


\section{Acknowledgments}

We thank Dr. Kurt Gerdes, Program Manager of the Efficient Separations and Processing Crosscutting Program, for his active support of this work funded through the International Program administered by Dr. Jack Watson of the Oak Ridge National Laboratory. These programs are operated under the Office of Science and Technology of the United States Department of Energy, Office of Environmental Management.

The authors express their gratitude to Professor N. N. Krot of the Institute of Physical Chemistry for his useful discussions during the compilation of this report. We are grateful to Dr. James $\mathrm{R}$. Jewett and Dr. Daniel L. Herting of Westinghouse Hanford Company (now with Numatec Hanford Company) for their interest in the research of our Institute on crystallization of salts from radioactive wastes. Cal Delegard of Westinghouse Hanford Company (now with the Pacific Northwest National Laboratory) is thanked very much for the coordination of our work and the technical editing of this document. We gratefully acknowledge the efforts of Dr. T. E. Albert for rapid resolution of organizational and contract issues. 


\section{Contents}

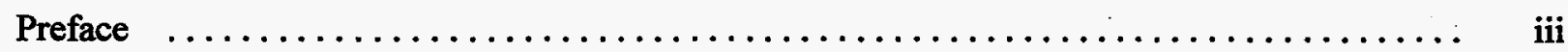

Executive Summary $\ldots \ldots \ldots \ldots \ldots \ldots \ldots \ldots \ldots \ldots \ldots \ldots \ldots \ldots \ldots \ldots \ldots \ldots \ldots$

Acknowledgments $\ldots \ldots \ldots \ldots \ldots \ldots \ldots \ldots \ldots \ldots \ldots \ldots \ldots \ldots \ldots \ldots \ldots \ldots \ldots$ vii

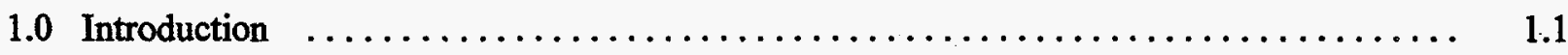

2.0 Isolation of Salts from Radioactive Wastes Containing Sodium Nitrate and

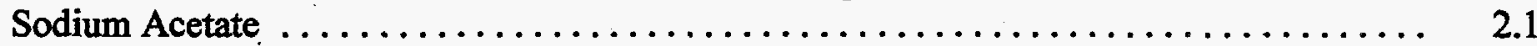

2.1 Compositions of Initial Solutions $: \ldots \ldots \ldots \ldots \ldots \ldots \ldots \ldots \ldots \ldots \ldots \ldots \ldots \ldots$

2.2 Flowsheet for Processing of Solutions Rich in Sodium Acetate $\ldots \ldots \ldots \ldots \ldots \ldots 2.2$

2.3 Flowsheet for Processing Solutions Rich in Sodium Nitrate $\ldots \ldots \ldots \ldots \ldots \ldots . . \ldots$

3.0 Isolation of Sodium Acetate and Nitrate Using a Tubular Rotating Crystallizer $\ldots \ldots \ldots \ldots$

4.0 Processing Acetate-Nitrate Radioactive Wastes with Purification in the Sodium Nitrate Crystallization Cycle $\ldots \ldots \ldots \ldots \ldots \ldots \ldots \ldots \ldots \ldots \ldots \ldots \ldots \ldots \ldots \ldots \ldots \ldots \ldots \ldots \ldots$

4.1 Flowsheet with Cesium and Strontium Removal by Chromate Precipitation $\ldots \ldots \quad 4.1$

4.2 Removal of Impurities by Crystallization $\ldots \ldots \ldots \ldots \ldots \ldots \ldots \ldots \ldots \ldots \ldots \ldots$

4.2.1 Study of the Formation of Insoluble Precipitates by Evaporation

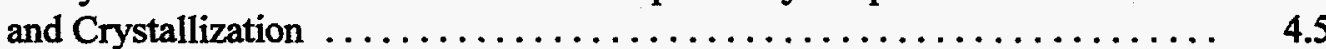

4.2.2 Purification from Strontium, Cesium, and Ruthenium $\ldots \ldots \ldots \ldots \ldots \ldots .4 .6$

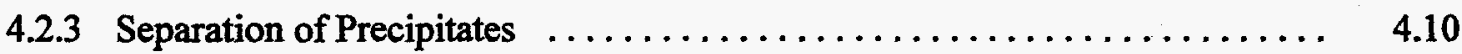

4.2.4 Cyclic Processing for Sodium Nitrate Crystallization $\ldots \ldots \ldots \ldots \ldots \ldots .4 .10$

5.0 Purification of Acetate-Nitrate Radioactive Waste with Removal of Ruthenium, Cesium, and Strontium Before Distillation of Acetic Acid .

5.1 Purification from Cesium, Strontium, and Ruthenium $\ldots \ldots \ldots \ldots \ldots \ldots \ldots . . \quad 5.1$

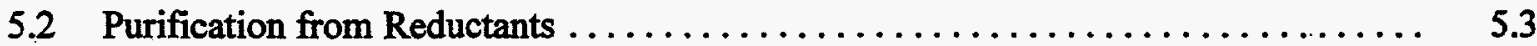


5.3 Cyclic Process to Purify Solutions of Radionuclides Before Acetic Acid Distillation

6.0 Influence of Sulfate on Acetic Acid Distillation and Sodium Nitrate Crystallization ......

6.1 Influence of Sulfate on Gas Phase Composition in Acetic Acid Distillation .......

6.2 Behavior of Sodium Sulfate in Sodium Nitrate Crystallization $\ldots \ldots \ldots \ldots \ldots \ldots .3$

6.3 Influence of Sodium Sulfate on ${ }^{106} \mathrm{Ru}$ Behavior $\ldots \ldots \ldots \ldots \ldots \ldots \ldots \ldots \ldots$

6.4 Materials of Construction for Acetic Acid Evaporators in the Presence of Sulfate and Chloride

7.0 Isolation of Sodium Acetate and Nitrate Salts by Separate Crystallization from Solutions Depleted in Sodium Acetate

8.0 Processing of Genuine Industrial Solutions

8.1 Description of Solutions

8.2 Steps in Cyclic Processing and Removal of Impurities $\ldots \ldots \ldots \ldots \ldots \ldots$

8.3 Crystallization Purification Factors $\ldots \ldots \ldots \ldots \ldots \ldots \ldots \ldots \ldots \ldots \ldots \ldots \ldots \ldots \ldots \ldots$

8.4 Evaporation and Crystallization of Sodium Nitrate $\ldots \ldots \ldots \ldots \ldots \ldots \ldots$

9.0 Behavior of Chemical Components at Various Stages in Cyclic Processing of Intermediate-Level Radioactive Wastes

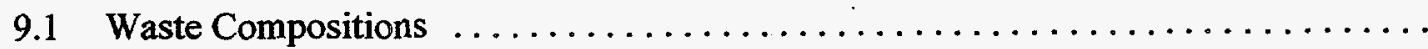

9.2 Techniques Applicable to Purification in Cyclic Sodium Nitrate Processing ......

9.3 Behavior of Chemical Cornponents During Processing of Intermediate-Level Radioactive Waste Solutions . .

9.3.1 Sodium Nitrate

9.3.2 Sodium Carbonate

9.3.3 Oxalate Salts

9.3.4 Fluoride

9.3.5 Sodium Sulfate

9.3.6 Chloride 
9.3.7 Calcium $\ldots \ldots \ldots \ldots \ldots \ldots \ldots \ldots \ldots \ldots \ldots \ldots \ldots \ldots \ldots \ldots \ldots \ldots \ldots \ldots, \quad 9.11$

9.3 .8 Potassium $\ldots \ldots \ldots \ldots \ldots \ldots \ldots \ldots \ldots \ldots \ldots \ldots \ldots \ldots \ldots \ldots, \quad 9.12$

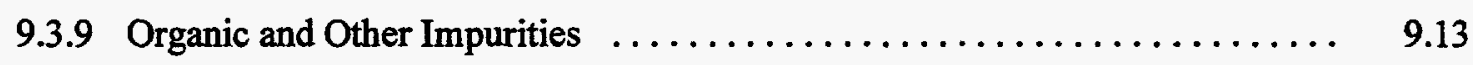

9.3 .10 Summary $\ldots \ldots \ldots \ldots \ldots \ldots \ldots \ldots \ldots \ldots \ldots \ldots \ldots \ldots \ldots \ldots \ldots \ldots, \quad 9.13$

10.0 Precipitate Volumes from Processing Intermediate Level Radioactive Solutions ....... 10.1

11.0 Results of Testing Variants for Processing Intermediate-Level Radioactive Waste

Solutions by Crystallization and Sorption Techniques $\ldots \ldots \ldots \ldots \ldots \ldots \ldots \ldots \ldots \ldots \ldots \ldots \ldots \ldots$

11.1 Test Facility, Test Objectives, and Solution Process Variants $\ldots \ldots \ldots \ldots \ldots \ldots \quad 11.1$

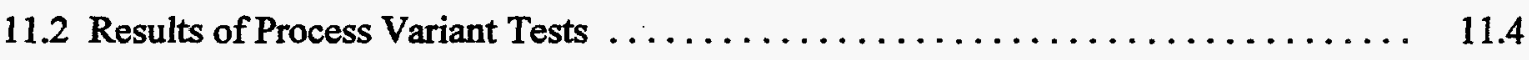

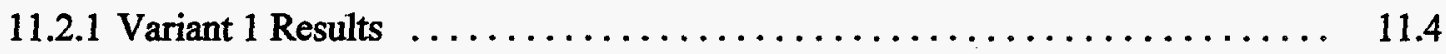

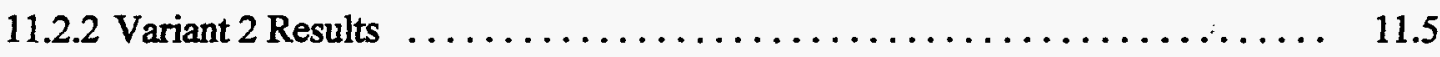

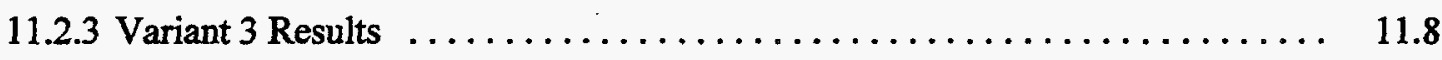

11.2.4 Variant 4 Results $\ldots \ldots \ldots \ldots \ldots \ldots \ldots \ldots \ldots \ldots \ldots \ldots \ldots \ldots \ldots \ldots \ldots \ldots \ldots \ldots, 11.8$

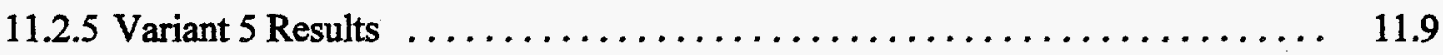

11.2.6 Summary of Variant Results $\ldots \ldots \ldots \ldots \ldots \ldots \ldots \ldots \ldots \ldots \ldots \ldots \ldots$

11.3 Influence of Accumulated Impurities in Sodium Nitrate on Its Purification by Sorption $\ldots \ldots \ldots \ldots \ldots \ldots \ldots \ldots \ldots \ldots \ldots \ldots \ldots \ldots \ldots \ldots \ldots \ldots \ldots \ldots \ldots \ldots, 11.11$

11.4 Behavior of Sulfonol in Sodium Nitrate Solutions $\ldots \ldots \ldots \ldots \ldots \ldots \ldots \ldots, 11.14$

11.5 Filtration of Sodium Nitrate Solutions $\ldots \ldots \ldots \ldots \ldots \ldots \ldots \ldots \ldots \ldots \ldots \ldots \ldots \ldots \ldots, 11.16$

12.0 Conclusions $\ldots \ldots \ldots \ldots \ldots \ldots \ldots \ldots \ldots \ldots \ldots \ldots \ldots \ldots \ldots \ldots \ldots \ldots \ldots \ldots \ldots \ldots \ldots, 12.1$ 


\section{Figures}

2.1 Phase Composition Diagram of System $\mathrm{NaNO}_{3}-\mathrm{CH}_{3} \mathrm{COONa}-\mathrm{H}_{2} \mathrm{O} \ldots \ldots \ldots \ldots \ldots \ldots \ldots$

2.2 Flowsheet for Separation of Sodium Acetate and Sodium Nitrate from Radioactive

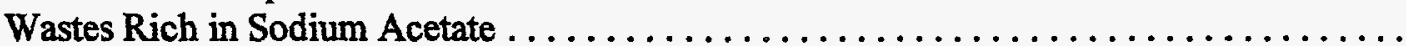

2.3 Schematic Diagram of Facility to Process Solutions Rich in Sodium Acetate $\ldots \ldots \ldots \ldots \quad 2.4$

2.4 Analysis of Phase Diagram of System $\mathrm{CH}_{3} \mathrm{COONa}-\mathrm{NaNO}_{3}-\mathrm{H}_{2} \mathrm{O} \ldots \ldots \ldots \ldots \ldots \ldots \ldots$

2.5 Schematic Diagram of Facility to Process Solutions Rich in Sodium Nitrate $\ldots \ldots \ldots \ldots$

3.1 Diagram of the Tubular Rotating Crystallizer Experimental Apparatus for Isolation of Sodium Acetate and Nitrate . . . . . . . . . . . . . . . . . . . . . . .

3.2 Dependence of Crystallization Temperature, Fraction of Crystallization, and Yield on Solution Feed Rate

3.3 Dependence of Crystallization T'emperature, Degree of Crystallization, and Yield on

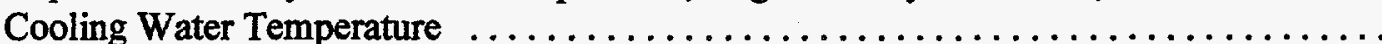

4.1 Influence of $\mathrm{pH}$ on Adsorption and Desorption of Ruthenium on Chromium Hydroxide . .

4.2 Influence of Alkalinity on Adsorption and Desorption of Ruthenium on Chromium Hydroxide

4.3 Cross-Section of Centrifuge Rotor with Packet of Separating Trays

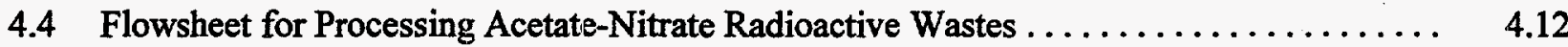

5.1 Process to Purify Solutions of Radionuclides Before Acetic Acid Distillation . . . . . . . $\quad 5.4$

6.1 Apparatus to Study the Influence of Sulfate on Gas Phase Composition in Distillation

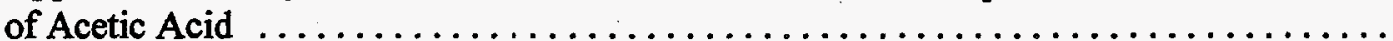

6.2 Nitric Acid Concentration Ratio in the Condensate and Solution as a Function of Sodium Nitrate Concentration at Various Sodium Sulfate Concentrations ...........

6.3 Acetic Acid Concentration Ratio in the Condensate and Solution as a Function of Sodium Sulfate Concentration at Various Distillation Temperatures . . . . . . . . . . .

6.4 Dependence of Sodium Sulfate Solubility on Sodium Nitrate Concentration at $40^{\circ} \mathrm{C} \ldots \ldots$

7.1 Phase Diagram of System $\mathrm{CH}_{3} \mathrm{COONa}-\mathrm{NaNO}_{3}-\mathrm{H}_{2} \mathrm{O}$ and Dilution Rays $\ldots \ldots \ldots \ldots \ldots$

7.2 Conceptual Flowsheet for Processing Acetate-Nitrate Solutions with $\alpha$ of $0.65 \ldots \ldots \ldots$ 
7.3 Dependence of Boiling Point and Sodium Nitrate Crystallization Temperature on Water Concentration

9.1 Dependence of Calcium Oxalate Precipitation on $\mathrm{pH} \ldots \ldots \ldots \ldots \ldots \ldots \ldots \ldots \ldots \ldots$

9.2 Dependence of Calcium Oxalate Precipitation on $\mathrm{NaOH}$ Concentration $\ldots \ldots \ldots \ldots \ldots .4$

9.3 Dependence of Calcium Oxalate Precipitation on the Calcium Ion Concentration $\ldots \ldots . \quad 9.5$

9.4 Dependence of Oxalic Acid Decomposition on Time at $120^{\circ} \mathrm{C}$, and $0.1 \mathrm{M}$ Nitric Acid

11.1 Test Facility for Processing Intermediate-Level Radioactive Waste Solution $\ldots \ldots \ldots \ldots \quad 11.2$

11.2 Sulfonol Solubility in Room Temperature Sodium Nitrate Solution as a Function of Time at Various Nitrate Concentrations

11.3 Filtration of Sodium Nitrate Solutions Containing Sulfonol Through a Pearlite Filter at Various Pressures . . . . . . . . . . . . . . . . . . . . . . . . . . . . . . .

11.4 Filtration of Sodium Nitrate Solution Without Sulfonol Through a Pearlite Filter . 


\section{Tables}

4.1 Chemical and Radiochemical Composition of Solutions $\ldots \ldots \ldots \ldots \ldots \ldots \ldots \ldots .2$

4.2 Precipitate Volumes for Solutions Containing $0.088 \mathrm{~g} \mathrm{Al} / \mathrm{L}$ and Silicic Acid $\ldots \ldots \ldots \quad 4.3$

4.3 Precipitate Volumes for Solutions Containing $0.1 \mathrm{~g} \mathrm{SiO}_{2} / \mathrm{L}$ and Aluminum $\ldots \ldots \ldots .3$

4.4 Dynamics of Increasing Solution Activity $\ldots \ldots \ldots \ldots \ldots \ldots \ldots \ldots \ldots \ldots \ldots \ldots$

4.5 Isotopic Composition of Active Impurities in Sodium Nitrate Salt $\ldots \ldots \ldots \ldots \ldots$

4.6 Cesium Sorption on Preformed Nickel Ferrocyanide Precipitate at Various

Potassium Nitrate Concentrations and Three Hours' Contact Time .............

4.7 Influence of Various Cations on Ruthenium Sorption During Alkaline Precipitation

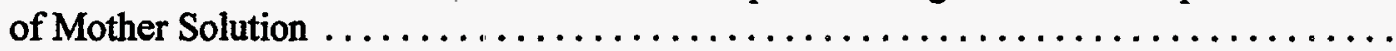

5.1 Purification Factors of ${ }^{137} \mathrm{Cs}$ for Nickel Ferrocyanide Precipitates as a Function of $\mathrm{pH} \quad \ldots \quad 5.2$

5.2 Conversion of Poorly Sorbed Ruthenium to the Well-Sorbed Form by Acetic Acid

Distillation in the Presence of Potassium Dichromate ....................

6.1 Sodium Sulfate Solubility in Saturated Sodium Nitrate Solutions $\ldots \ldots \ldots \ldots \ldots$

6.2 Influence of Sodium Sulfate on the Boiling Point of $985 \mathrm{~g} / \mathrm{L}$ Sodium Nitrate Solution $\quad \ldots \quad 6.5$

7.1 Comparison of Theoretical and Experimental Yields of Salts $\ldots \ldots \ldots \ldots \ldots \ldots \ldots$

8.1 Chemical and Radiochemical Composition of Industrial Solution I $\ldots \ldots \ldots \ldots \ldots$

8.2 Chemical and Radiochemical Composition of Industrial Solution II $\ldots \ldots \ldots \ldots \ldots . \quad 8.2$

8.3 Purification Factors for Fresh and Stored Solutions I after Two Precipitations ...... 8.3

9.1 Daily Salt and Impurity Additions to Intermediate-Level Radioactive Waste Solutions . . $\quad 9.2$

9.2 Solubility of Sodium Oxalate in Saturated Sodium Nitrate Solutions $\ldots \ldots \ldots \ldots$

9.3 Sodium Fluoride Solubility in Saturated Sodium Nitrate Solutions $\ldots \ldots \ldots \ldots \ldots$

9.4 Influence of Acidity on Sodium Fluoride Solubility in Saturated Sodium Nitrate

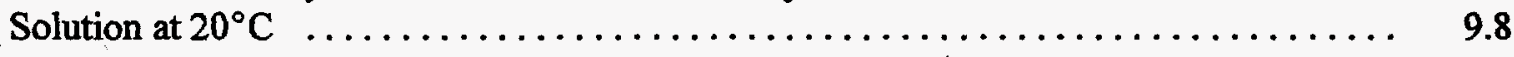

9.5 Calculated Fluoride Content in Process Products $\ldots \ldots \ldots \ldots \ldots \ldots \ldots \ldots \ldots \ldots$

9.6 Calcium Fluoride Solubility in Saturated Sodium Nitrate Solutions $\ldots \ldots \ldots \ldots$ 
9.7 Purification Factors for Salt from Fluoride and Chloride $\ldots \ldots \ldots \ldots \ldots \ldots \ldots \ldots \ldots$

9.8 Calcium Sulfate Solubility in Nitrate Solutions $\ldots \ldots \ldots \ldots \ldots \ldots \ldots \ldots \ldots \ldots \ldots$

9.9 Dependence of Equilibrium $\mathrm{NaCl}$ and $\mathrm{NaNO}_{3}$ Solution Composition

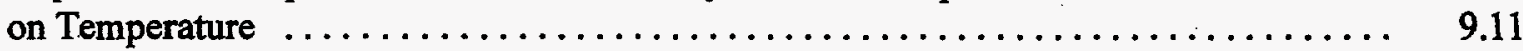

9.10 Solubility of Calcium Hydroxide in Sodium Nitrate Solutions at $20^{\circ} \mathrm{C} \ldots \ldots \ldots \ldots .12$

9.11 Solubility of Calcium Hydroxide in Saturated Sodium Nitrate Solutions

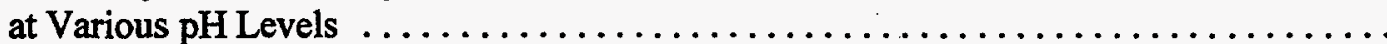

9.12 Concentrations of Impurities at Various Stages of Purification of Intermediate-Level

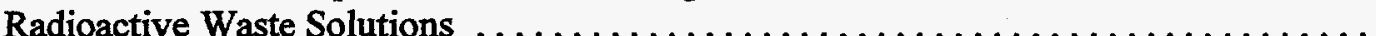

10.1 Magnesium Hydroxide Solubility in $200 \mathrm{~g} / \mathrm{L}$ Sodium Nitrate Solution at Various $\mathrm{pH}$ Levels

10.2 Effect of $\mathrm{Mg}^{2+}$ on Precipitate Volumes $\ldots \ldots \ldots \ldots \ldots \ldots \ldots \ldots \ldots \ldots \ldots \ldots \ldots \ldots \ldots \ldots . .2$

10.3 Volumes of Iron and Manganese Hydroxide Precipitates from Solution $\ldots \ldots \ldots \ldots$.

11.1 Experimental Conditions for Process Test Variants $\ldots \ldots \ldots \ldots \ldots \ldots \ldots \ldots \ldots \ldots$

11.2 Solution Composition for Preparation of Model Solutions $\ldots \ldots \ldots \ldots \ldots \ldots \ldots \ldots \ldots$

11.3 Concentrations of Impurities in Salt Solutions after Second Crystallization for

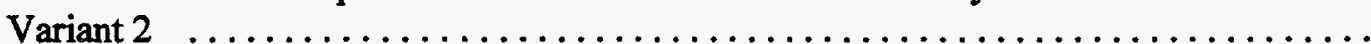

11.4 Concentrations of Calcium and Solid Phase in Solutions after Second Crystallization at Various $\mathrm{pH}$ for Variant 4

11.5 Solution Characteristics after First and Second Crystallization in Variant 5

11.6 Concentration of Impurities after Second Crystallization in Variant 5 Using Increased Nitric Acid

11.7 Summary of Results for Variants for Processing Intermediate-Level Radioactive Waste Solutions

11.8 Sorption of Radionuclides Under Static Conditions from Sodium Nitrate Solutions Obtained from Various Crystallization Cycles

11.9 Influence of Sodium Nitrate Concentration on Sulfonol Concentration

11.10 Behavior of Sulfonol During Sodium Nitrate Evaporation and Crystallization 


\subsection{Introduction}

Separation and purification of sodium nitrate from radioactive wastes by crystallization has been investigated extensively in the former Soviet Union and in Russia. Scientists at the Institute of Physical Chemistry of the Russian Academy of Sciences have conducted considerable research and development (R\&D) in this field. This report is a short review of the conclusions obtained by the scientists from the late 1940s through the early 1980s. These data were initially published as original reports of the Institute.

This report describes removal of sodium nitrate and sodium acetate salts from radioactive waste by crystallization. At the Institute of Physical Chemistry, the R\&D efforts related to these activities started in the late 1940 s with purification of radioactive wastes containing significant concentrations of sodium nitrate and acetate and also lower concentrations of potassium nitrate, sodium carbonate, and sodium hydroxide. The work performed required analysis and phase diagram studies of crystallization equilibria in the system $\mathrm{CH}_{3} \mathrm{COONa}-\mathrm{NaNO}_{3}-\mathrm{H}_{2} \mathrm{O}$. These studies were used to identify optimal conditions for selective crystallization of sodium acetate and sodium nitrate and to develop a cyclic process for waste treatment.

The $R \& D$ experience generally was related to the management of intermediate-level radioactive wastes (specific activity of $10^{-5}$ to $1 \mathrm{Ci} / \mathrm{L}$ ). The waste solutions resulted from recovery and processing of uranium, plutonium, and other valuable products from irradiated nuclear fuel, neutralization of nuclear process solutions after extractant recovery, regeneration of process nitric acid, equipment decontamination, and other radiochemical processes.

The wastes have large volumes and various compositions. Waste components include nitric acid, metal nitrate and acetate salts, organic impurities, and surfactants. Waste management operations generally consist of two stages: volume reduction and processing of the concentrates for storage, solidification, and disposal. Filtration, coprecipitation, coagulation, evaporation, and sorption are techniques used to reduce waste volume.

The composition of the radioactive wastes changed with the development of new flowsheets for processing irradiated nuclear fuel. Therefore, adaptation of cyclic waste processes, particularly for solutions with lower sodium acetate concentrations, became necessary.

Further changes in spent nuclear fuel processes produced wastes containing complex compounds of radionuclides. Process improvements also yielded wastes with increased concentrations of radioactivity. The effects of the waste composition changes on sodium nitrate decontamination factors compelled further research. Programs to study the behavior of individual fission product elements in processing, the influence of surfactants on the size of sodium nitrate crystals, the purification of solutions by sorption, and improvements in salt crystal washing and solution filtration were investigated. 
Because waste compositions can vary over a wide range, the crystallization technologies developed had to be relatively flexible and not strongly dependent on concentration variations of individual components. Therefore, the influence of impurities was determined, and the behaviors of these impurities were studied at various stages of cyclic processing (such as alkaline calcium precipitation, evaporation, crystallization, and sorption purification). 


\subsection{Isolation of Salts from Radioactive Wastes Containing Sodium Nitrate and Sodium Acetate}

Purification of radioactive wastes containing high concentrations of sodium nitrate and acetate by cyclic selective crystallization was investigated as a method to reduce the volume of disposed radioactive waste.

\subsection{Compositions of Initial Solutions}

Initial research was conducted with simulated waste solutions of two compositions. The first solution, relatively rich in sodium acetate $\left(\mathrm{CH}_{3} \mathrm{COONa} ; 72.25 \mathrm{~g} / \mathrm{L}\right)$, also contained sodium nitrate $\left(\mathrm{NaNO}_{3}\right.$; $41.4 \mathrm{~g} / \mathrm{L})$, potassium carbonate $(1.7 \mathrm{~g} / \mathrm{L})$, sodium carbonate $(0.2 \mathrm{~g} / \mathrm{L})$, chromium(III) $(6.005 \mathrm{~g} / \mathrm{L})$, barium(II) $(0.1 \mathrm{~g} / \mathrm{L})$, and had a $\mathrm{pH}$ of 7 to 8 . The second solution was relatively rich in sodium nitrate $(97 \mathrm{~g} / \mathrm{L})$ and also had sodium acetate $(64 \mathrm{~g} / \mathrm{L})$, sodium hydroxide $(1.5 \mathrm{~g} / \mathrm{L})$, and potassium nitrate $(2.0 \mathrm{~g} / \mathrm{L})$. About 90 to $95 \%$ of the solution activity was caused by ${ }^{106} \mathrm{Ru} ;{ }^{137} \mathrm{Cs}$ accounted for 5 to $10 \%$ of the activity.

To understand this system, the equilibria of $\mathrm{CH}_{3} \mathrm{COONa}-\mathrm{NaNO}_{3}-\mathrm{H}_{2} \mathrm{O}$ mixtures were investigated. The phase composition diagram for this system was constructed for the temperature range from 10 to $70^{\circ} \mathrm{C}$. The diagram is shown in Figure 2.1.

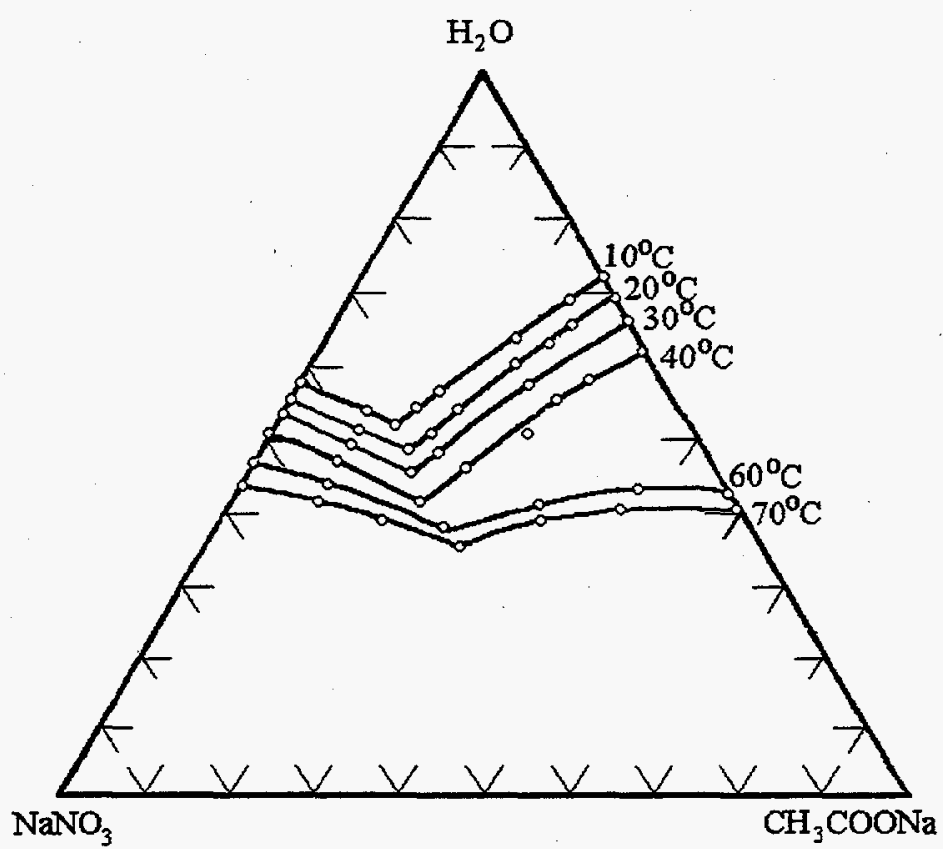

Figure 2.1. Phase Composition Diagram of System $\mathrm{NaNO}_{3}-\mathrm{CH}_{3} \mathrm{COONa}-\mathrm{H}_{2} \mathrm{O}$ (weight basis) 
Analysis of the phase diagram permitted optimal conditions for isolation of sodium nitrate and sodium acetate to be chosen. The order of separation of the salts depended on the ratio of their concentrations in the solution. For solutions with a salt weight concentration ratio $\left[\mathrm{CH}_{3} \mathrm{COONa} /\left[\mathrm{NaNO}_{3}\right], \alpha\right.$, greater than one, sodium acetate was initially separated, followed by separation of sodium nitrate. If $\alpha$ were less than one, the order was reversed.

The phase diagram shows that the yield of salt possible for a single crystallization is not more than 50 to $60 \%$ of the amount of salt contained in the initial solution. However, repeated recycling of the mother solutions from crystallization to the beginning of the process could produce yields near $100 \%$. This conclusion was verified experimentally for solutions with $\alpha$ greater than 1 in a pilot plant with metal equipment, and for solutions with $\alpha$ less than 1 in a small facility with glass equipment.

\subsection{Flowsheet for Processing of Solutions Rich in Sodium Acetate}

The flowsheet for separation of salts from radioactive wastes rich in sodium acetate is presented in Figure 2.2. In this flowsheet, acetate was separated before nitrate because the solution composition had $\alpha$ greater than 1.

The initial waste solution was concentrated by evaporation and then crystallized at $20^{\circ} \mathrm{C}$. The product sodium acetate trihydrate $\left(\mathrm{CH}_{3} \mathrm{COONa} \cdot 3 \mathrm{H}_{2} \mathrm{O}\right)$ crystals were separated from the mother solution by centrifugation. The mother solution, depleted in sodium acetate, then was evaporated further. Sodium nitrate crystallization from the concentrated solution occurred at $70^{\circ} \mathrm{C}$. The product sodium nitrate crystals were separated by centrifugation and the second mother solution returned to the beginning of the process for mixing with a fresh portion of the initial solution.

The product sodium nitrate was washed with $70^{\circ} \mathrm{C}$ saturated sodium nitrate solution. The spent wash solution was added to the first-cycle mother solution entering the second evaporation. The saturated sodium nitrate crystal wash solutions were prepared from salt isolated in the preceding cycle. The return of nitrate wash solution to the beginning of the process would have been deleterious because it would have shifted the concentration ratio to the side unfavorable for initial crystallization of sodium acetate.

A schematic diagram of the facility is shown in Figure 2.3. The evaporator (1) was equipped with manometer (13), thermometer (9), outlet for discharge of concentrated product solution (14), and outlet for discharge of the salt-depleted solutions for solidification in grout (15). The evaporator also had compressed air, evacuation, and gas pressure relief service lines. The evaporator was heated through an air bath (2) by a gas burner (3). To prevent local overheating, the temperature of the hottest point of the evaporator bottom was monitored by a thermometer (10). The condensates from the cooled condenser (16) entered the collection vessel (17).

The concentrated solution left the evaporator (1) through the outlet (14) and entered the metalconstructed crystallizer (4) by gas pressure. The crystallizer was thermostatted by a water bath (5). The solution/crystal slurry was stirred constantly by an agitator (6) during crystallization. The solution and bath 


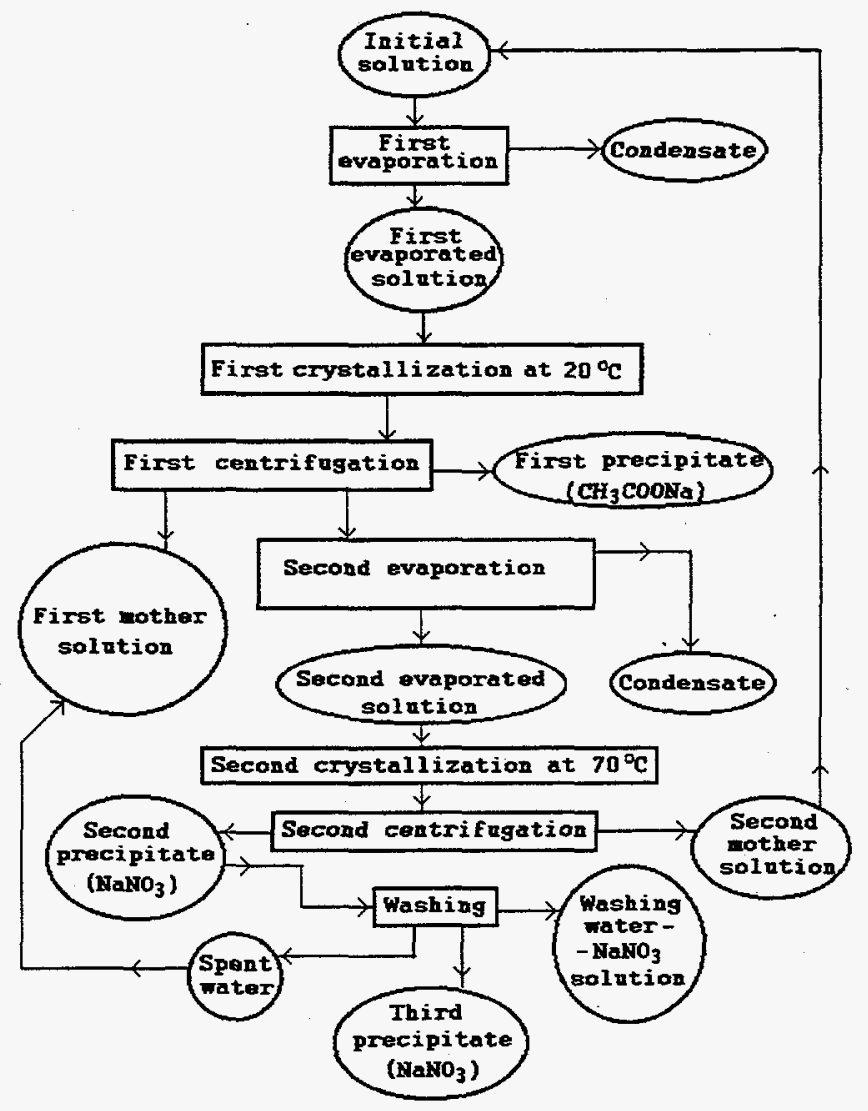

Figure 2.2. Flowsheet for Separation of Sodium Acetate and Sodium Nitrate from Radioactive Wastes Rich in Sodium Acetate

temperatures were measured by thermometers (11 and 12). After crystallization, the crystals were separated by a centrifuge filter (7) operated batch-wise. The mother solution was collected in the vessel (8). The sodium nitrate crystals were washed in the same centrifuge filter (7) while the drum was rotated. The centrifuge filter enclosure was heated to control the temperature of the exiting mother solution to be the same as the crystallization temperature.

The evaporators had 10-L capacity for the first evaporation and $5 \mathrm{~L}$ for the second evaporation. Each evaporator was cylindrical, with a conical bottom, and was made of stainless steel. The crystallizer (2-L capacity) also was cylindrical. Both the crystallizer and the propeller-type agitator were constructed of stainless steel. The centrifuge filter rotated at $53.3 \mathrm{~Hz}(3200 \mathrm{rpm})$ on a vertical shaft and was unloaded manually. The $160-\mathrm{mm}$ diameter, $140-\mathrm{mm}$ high centrifuge drum and centrifuge enclosure were constructed of carbon steel. 


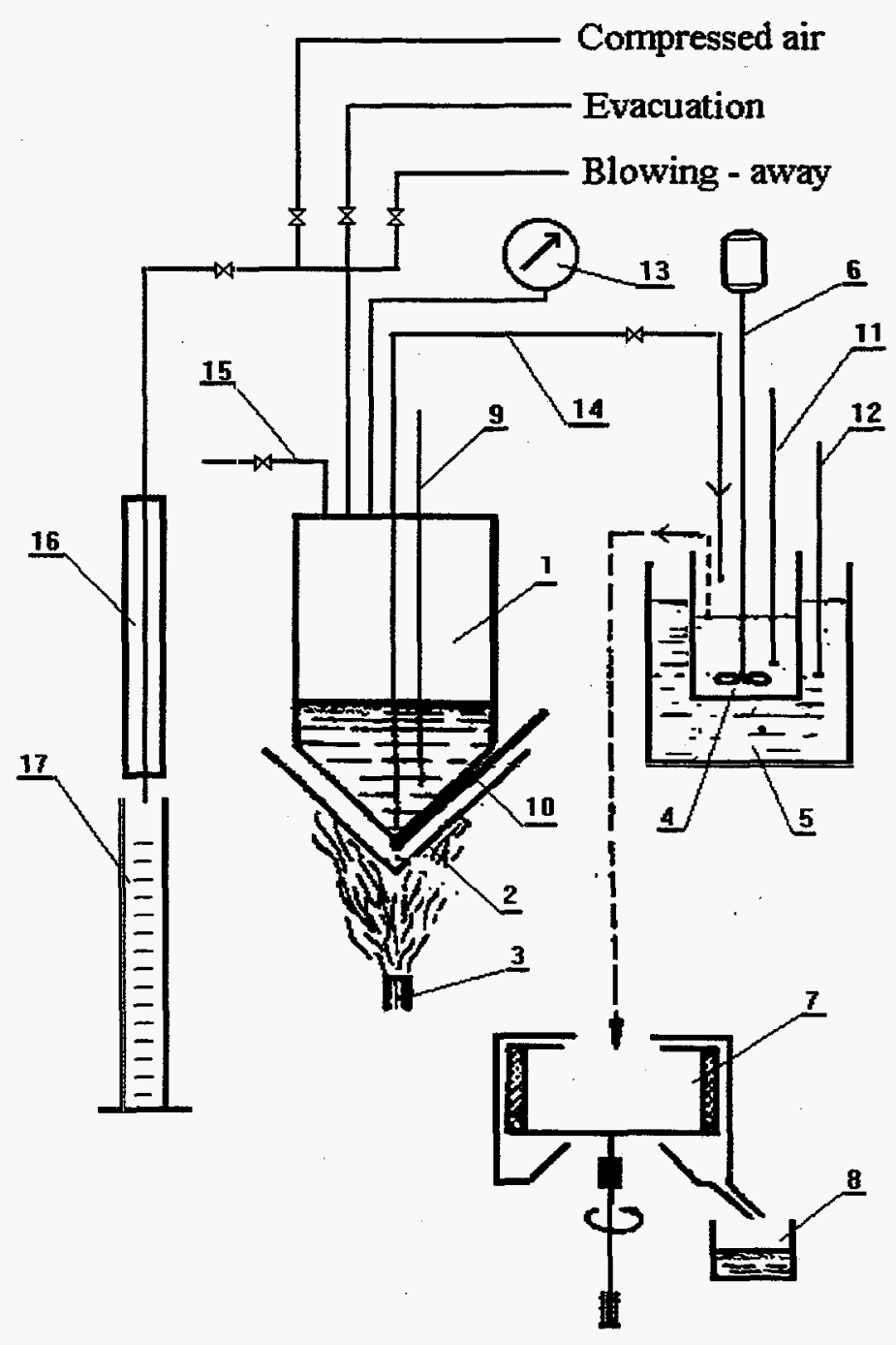

Figure 2.3. Schematic Diagram of Facility to Process Solutions Rich in Sodium Acetate

Eight successive crystallization cycles were conducted. The product sodium acetate contained no more than $10 \%$ sodium nitrate; sodium acetate in sodium nitrate product was no more than 1.5 to $2 \%$. Most of the radioactivity remained in solution. The activities present in the acetate and nitrate crystals were each 2 to $3 \%$ of the initial activity.

No systematic accumulation of impurities was found in the two product salts. The joint crystallization of potassium nitrate with sodium nitrate did not occur. The concentration of impurities in the mother solution increased in proportion to the number of cycles. 


\subsection{Flowsheet for Processing Solutions Rich in Sodium Nitrate}

Analysis of the phase diagram for the system $\mathrm{CH}_{3} \mathrm{COONa}-\mathrm{NaNO}_{3}-\mathrm{H}_{2} \mathrm{O}$ (Figure 2.4) showed that the separation of sodium acetate and sodium nitrate was also possible for solutions rich in sodium nitrate $(\alpha<1)$. One such solution was the second composition described in Section 2.1. The fields of crystallization of sodium acetate $\left(\right.$ at $20^{\circ} \mathrm{C}$ ) and sodium nitrate $\left(\right.$ at $70^{\circ} \mathrm{C}$ ) are indicated in Figure 2.4. The initial solution composition corresponds to point $\mathrm{P}_{1}$. With evaporation of water, the salt concentrations increased and the mixture composition proceeded along ray $\mathrm{OM}$. At point $\mathrm{F}$ and $70^{\circ} \mathrm{C}$, the solution became saturated with $\mathrm{NaNO}_{3}$. Further removal of water precipitated $\mathrm{NaNO}_{3}$ salt. The solution composition changed (along line $\mathrm{n}_{2} \mathrm{Q}$ ) and the relative concentration of sodium acetate increased. After sodium nitrate crystallization, the mother solution had the composition described at point $\mathrm{Q}$.

To separate sodium acetate, it was then necessary to move the system to the crystallization field of sodium acetate trihydrate. By adding water, the system was shifted from point $Q$ along ray $O N$ to point $A$. To precipitate sodium acetate, the solution was cooled to $20^{\circ} \mathrm{C}$. With cooling, the solution became saturated and sodium acetate trihydrate precipitated. The composition of the solution again changed, the relative solution concentration of sodium acetate increased, and the aqueous system went from point $A$ to point $\mathrm{C}$.

The flowsheet of the process is shown in Figure 2.5. The initial solution was evaporated, and sodium nitrate crystallized at $70^{\circ} \mathrm{C}$. The crystals were separated from the mother solution by centrifugation and washed by saturated $70^{\circ} \mathrm{C}$ sodium nitrate solution. The spent washing solution joined the initial solution.

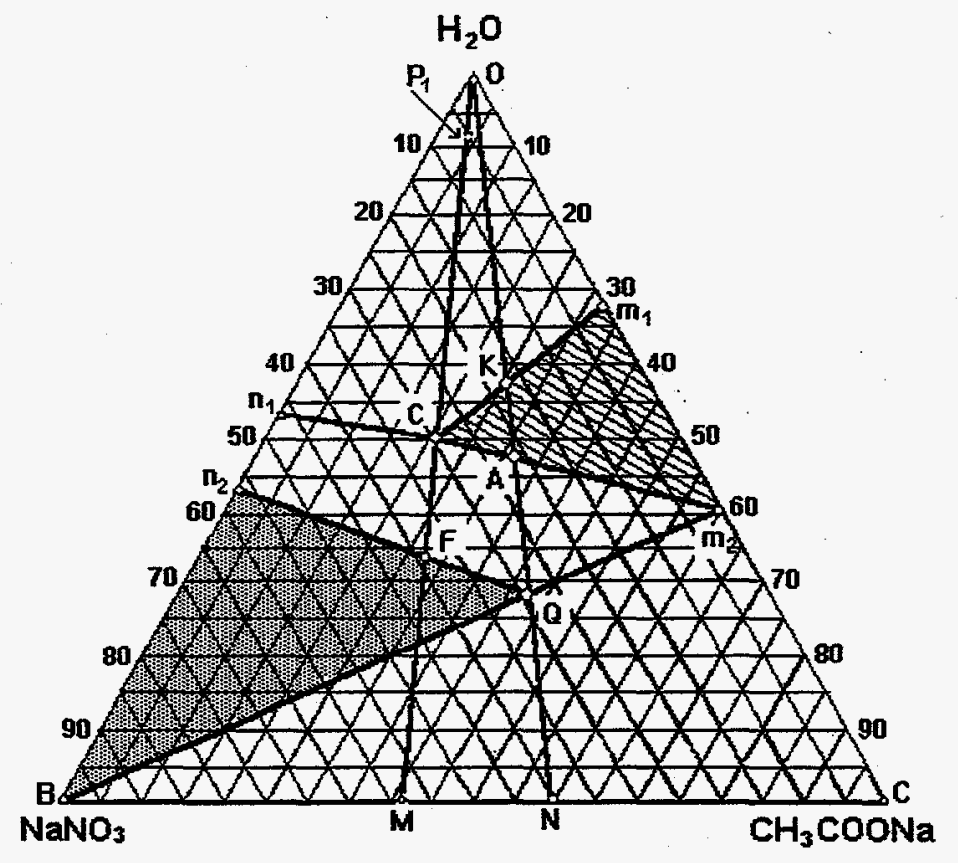

Figure 2.4. Analysis of Phase Diagram of System $\mathrm{CH}_{3} \mathrm{COONa}-\mathrm{NaNO}_{3}-\mathrm{H}_{2} \mathrm{O}$ (weight basis) 


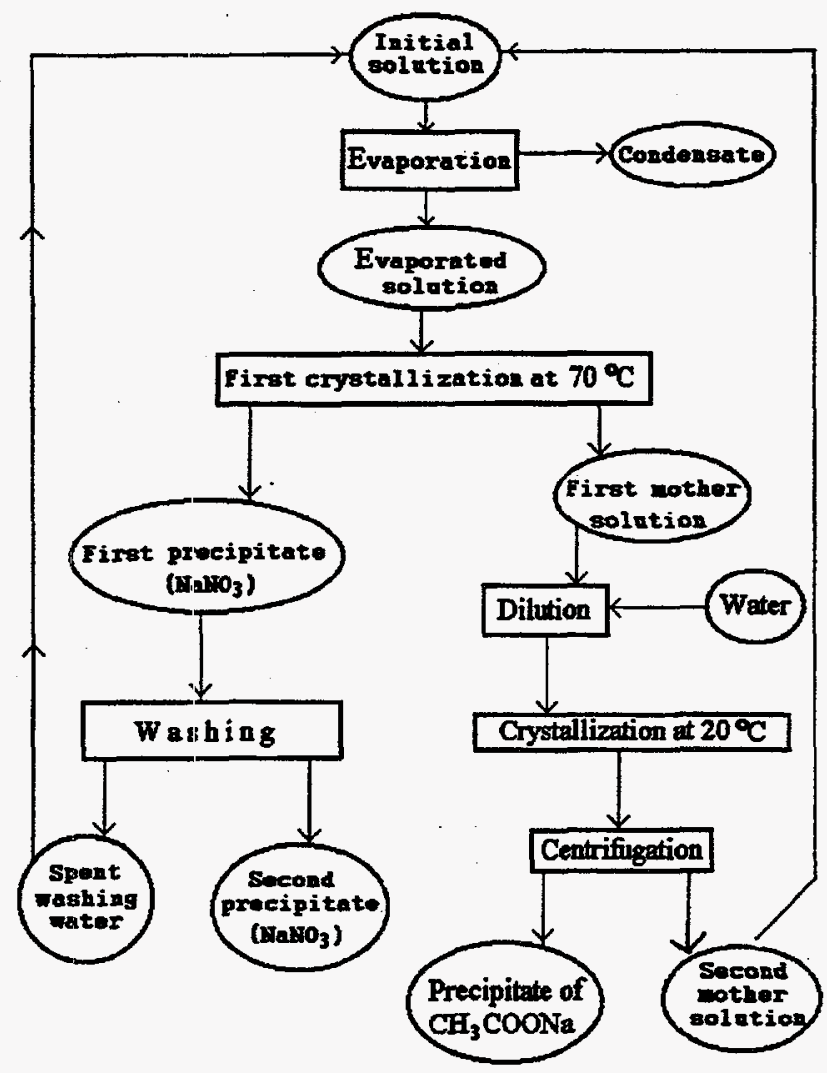

Figure 2.5. Schemátic Diagram of Facility to Process Solutions Rich in Sodium Nitrate

The mother solution was diluted with water and crystallized at $20^{\circ} \mathrm{C}$. The sodium acetate trihydrate crystals were separated from the second mother solution by centrifugation, and the mother solution was also added to the initial solution entering the next cycle.

Seven crystallization cycles were conducted. The impurity of sodium nitrate in sodium acetate was less than $5 \%$; the content of sodium acetate in sodium nitrate was less than $1.4 \%$. Most radioactivity remained in the crystallization mother solution. The activity of purified salts was 2 to $3 \%$ of the initial solution activity.

In conclusion, for both waste compositions, sodium nitrate and sodium acetate crystallizations were demonstrated by closed cyclic processing. The purity of product sodium acetate without washing was $\mathbf{8 8}$ to $95 \%$, and that of sodium nitrate with washing was 96 to $98 \%$. Accumulations of impurities in salts were not observed for the first eight cycles. The activity of the separated crystals was 2 to $3 \%$ of the initial activity of the radioactive wastes. 


\subsection{Isolation of Sodium Acetate and Nitrate Using \\ a Tubular Rotating Crystallizer}

Separation of sodium acetate and sodium nitrate by selective crystallization in a tubular rotating crystallizer was conducted at an initial sodium acetate/sodium nitrate weight ratio, $\alpha$, of 1.2. The radioactive waste solution first was evaporated and sodium acetate trihydrate crystallized at $20^{\circ} \mathrm{C}$. The resulting mother solution was evaporated further, and sodium nitrate was crystallized from it at $70^{\circ} \mathrm{C}$.

Increasing the sodium nitrate fraction in the solution only varied the order of separation of salts. In this case, sodium nitrate initially was separated at $70^{\circ} \mathrm{C}$, and then sodium acetate trihydrate was crystallized from the mother solution at $20^{\circ} \mathrm{C}$. The increased sodium nitrate concentration did not affect the choice of equipment. Separation of salts by other methods (distillation of acetic acid with subsequent crystallization of sodium nitrate from the evaporated solution) also did not influence the choice of equipment used for crystallization of sodium nitrate.

The tubular crystallizer ( $120 \mathrm{~mm}$ diameter, $1200 \mathrm{~mm}$ long) was constructed of carbon steel. It was rotated on roller supports at various slope angles and speeds (ranging from $0.0117 \mathrm{~Hz}$ to $0.8 \mathrm{~Hz}$ or $0.7 \mathrm{rpm}$ to $48 \mathrm{rpm}$ ). The external surface of the crystallizer was cooled by a water jacket at temperatures ranging from 14 to $70^{\circ} \mathrm{C}$.

The crystallizer was tested under flowsheet conditions. The test apparatus is depicted in Figure 3.1. Simulated solution, prepared in the make-up vessel (1), was passed to the thermostat (2) and then fed at constant rate to the crystallizer (3). A mixture of mother solution and crystals leaving the crystallizer passed to the centrifuge (7). The mother solution was collected in the reservoir vessel (8). Water for cooling was fed to the jacket directly by pipeline or by pump (5) from another thermostat (6) controlled to the desired temperature.

Excessive cooling of the crystallizer surface caused the crystals to stick to the crystallizer walls; the buildup, in turn, substantially decreased convective heat transfer. To remove sticking salts from the crystallizer walls, two rods were placed in the crystallizer drum. One of the rods was round in cross-section, and the second was hexahedral. The rods were of the same length as the crystallizer drum and were placed so that the leading rod (meeting the adhering crystals as the drum rotated) was the hexahedral one. The round rod prevented rotation of the hexahedral rod on its axis and caused it to slide along the crystallizer wall, scraping off the adhering salts. The rods required no further mounting.

The rate of crystallizer output depended on the rate of solution feed, the cooling rate (i.e., on the cooling water feed rate and temperature), the crystallizer rotation speed, and the crystallizer angle. The influence of the solution feed rate on the output rate and crystallization conditions is shown in Figure 3.2. Increasing the solution feed rate increased the crystallization temperature but decreased the fraction of 


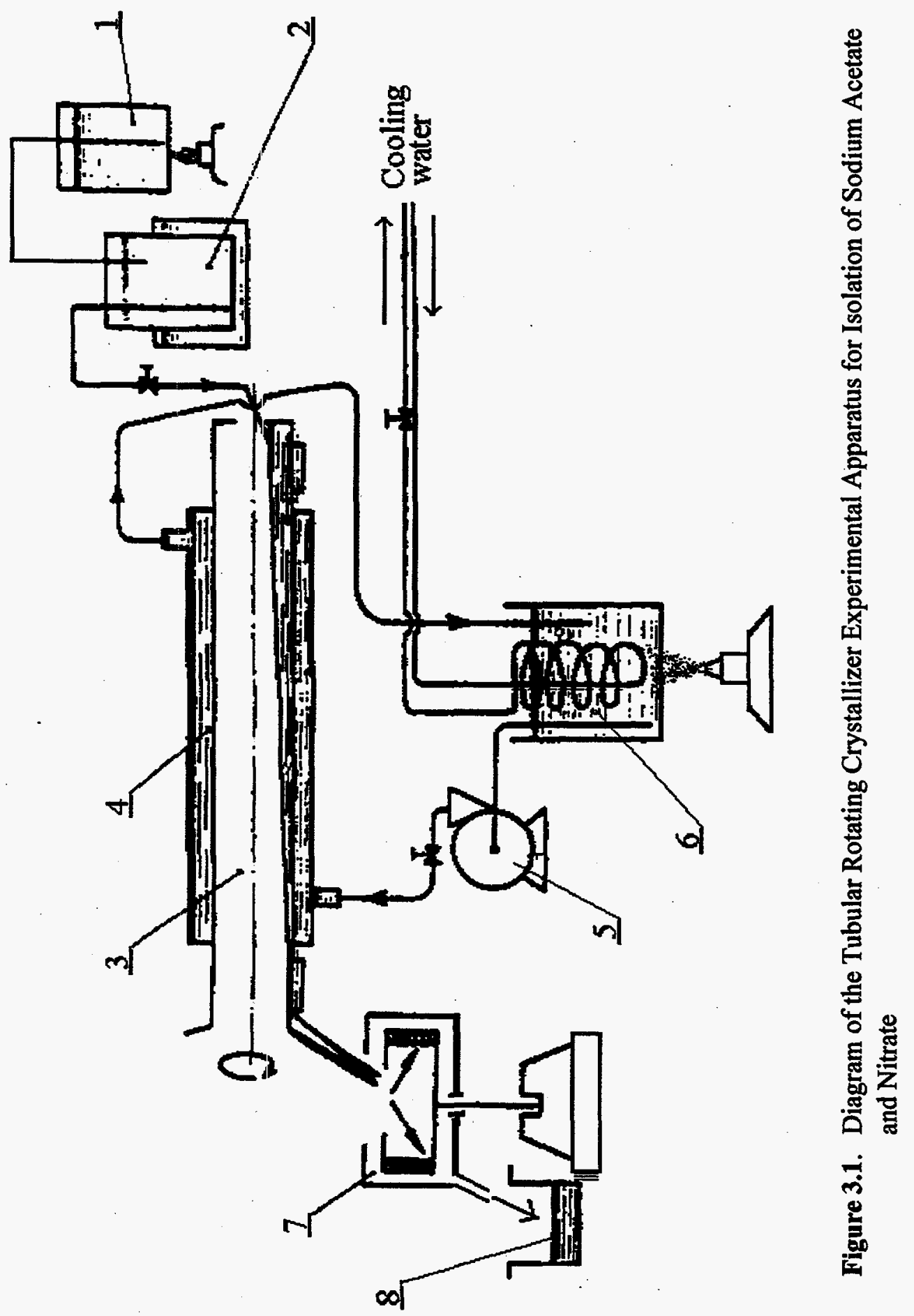




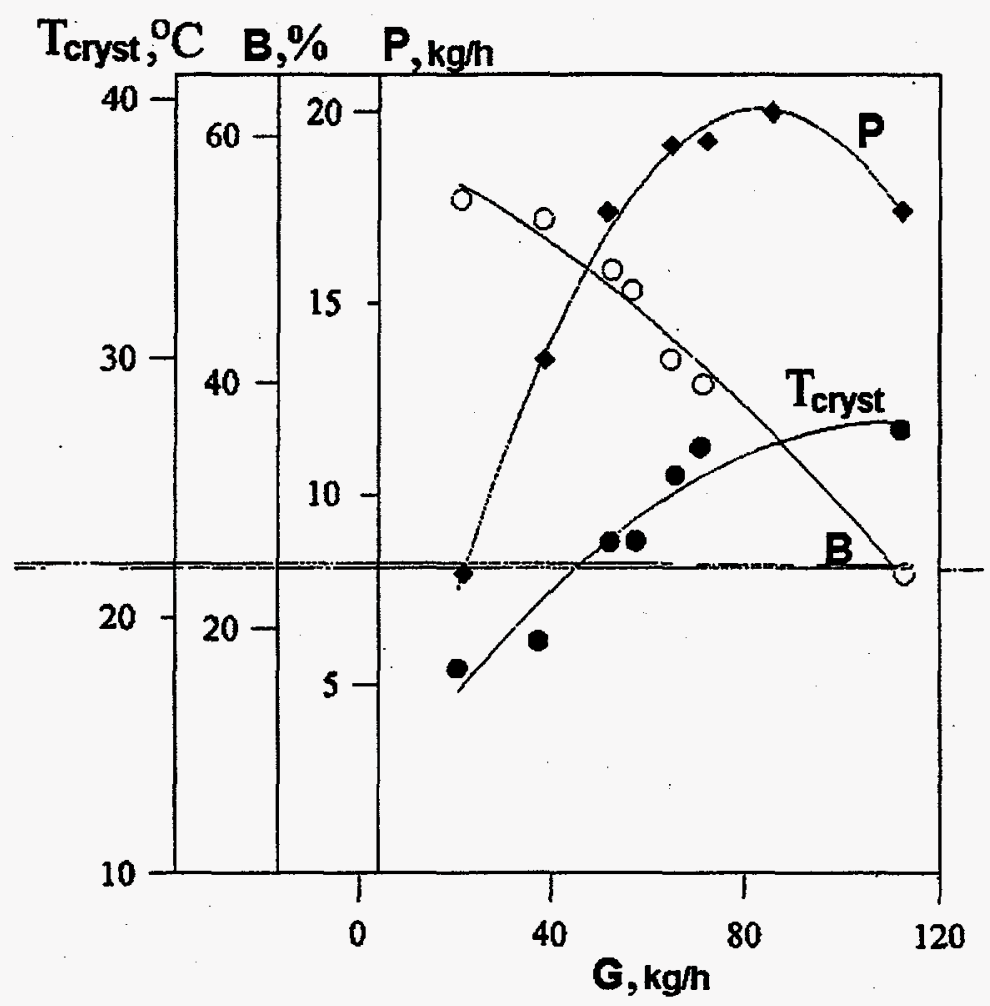

Figure 3.2. Dependence of Crystallization Temperature $\left(T_{\text {cryst }}\right)$, Fraction of Crystallization (B), and Yield (P) on Solution Feed Rate (G)

sodium acetate crystallized. As shown in Figure 3.2, a five-fold increase in solution feed rate decreased the crystallized fraction two-fold. However, the overall output increased with increasing solution feed rate, reaching a maximum value at a feed rate of 80 to $90 \mathrm{~kg} / \mathrm{h}$ before decreasing at higher feed rates.

The fraction crystallized and the crystallizer output strongly depended on cooling water temperature. Decreasing the cooling water temperature from 19 to $11.7^{\circ} \mathrm{C}$ decreased the crystallization temperature from 30 to $25^{\circ} \mathrm{C}$, increased the salt crystallization percentage from 30 to $44 \%$, and increased output from $14 \mathrm{~kg} / \mathrm{h}$ to $18 \mathrm{~kg} / \mathrm{h}$ (Figure 3.3). Because of the increase in the tubular crystallizer surface cooling rate, it was possible to increase sodium acetate yield 1.5 times.

Increasing the rotation speed from 0.0119 to $0.8 \mathrm{~Hz}$ increased the convective heat transfer rate. As a result, the crystallization temperature continuously decreased, but the increase in the output and yield of sodium acetate only increased to certain limit. Further increasing the rotation speed only slightly increased the yield.

Increasing the crystallizer slope angle from 1 to $5^{\circ}$ slightly decreased the output and the salt yield. The decreases were because solution residence time in the apparatus decreased. A $1^{\circ}$ change in the slope angle had negligible effect on the crystallization process parameters. 


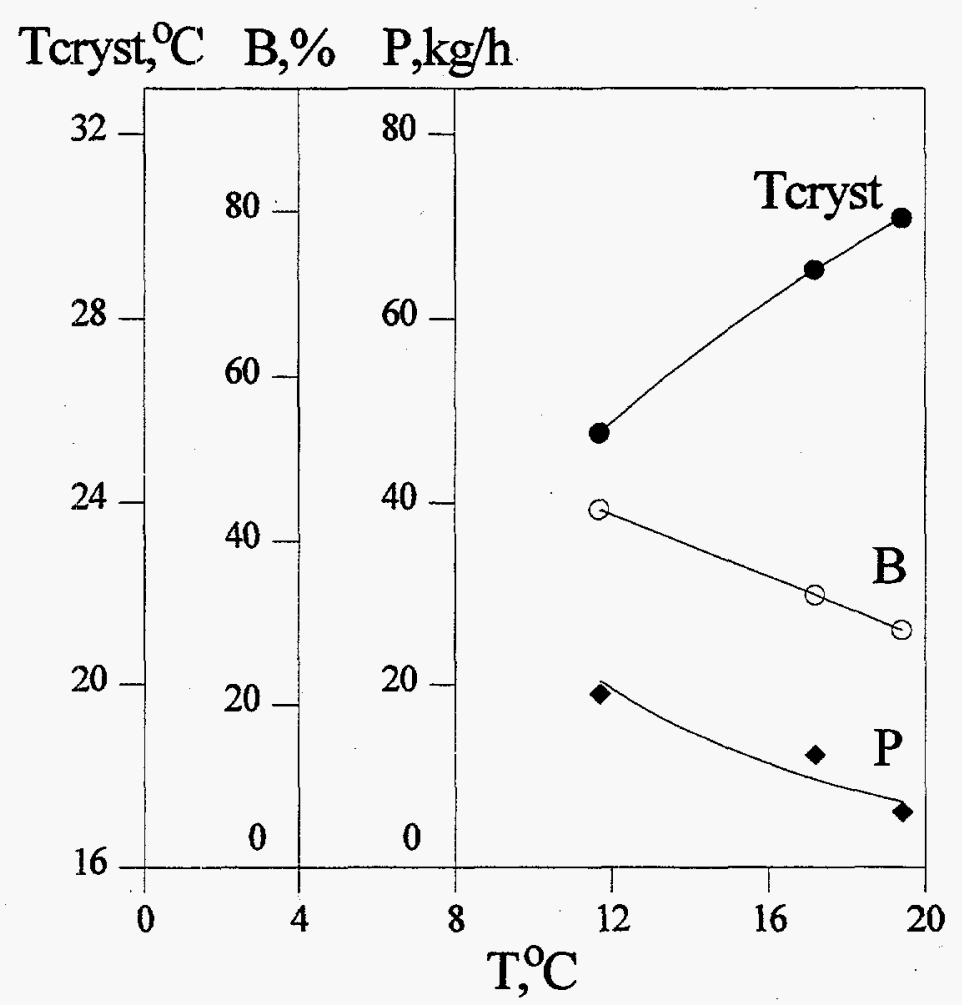

Figure 3.3. Dependence of Crystallization Temperature $\left(\mathrm{T}_{\text {cryst }}\right)$, Degree of Crystallization (B), and Yield (P) on Cooling Water Temperature

Crystallization behavior of sodium nitrate in the tubular crystallizer was similar to that of sodium acetate, differing only in crystallization temperature. For sodium nitrate crystallization, the cooling water was maintained at 45 to $60^{\circ} \mathrm{C}$.

Overall, the experiments showed that the tubular rotating crystallizer with water cooling was equally suitable for crystallization of sodium acetate trihydrate and sodium nitrate. 


\subsection{Processing Acetate-Nitrate Radioactive Wastes with Purification in the Sodium Nitrate Crystallization Cycle}

Alternative techniques were investigated to remove radioactive and chemical contaminants from the acetate and nitrate products.

\subsection{Flowsheet with Cesium and Strontium Removal by Chromate Precipitation}

One flowsheet considered for processing acetate-nitrate radioactive waste consisted of the following stages:

1. Alkaline precipitation of tin and tellurium and their recovery from the product alkaline sludges.

2. Chromate-ferrocyanide-soda precipitation of the alkaline decantate at $\mathrm{pH} 7$ to 9 to remove hexavalent chromium, cesium, and strontium.

3. Subsequent ferrocyanide-soda precipitation of the decantate from stage 2 at $\mathrm{pH} 8.5$ to 9.5 to remove residual cesium and strontium.

4. Acidification of the purified solution (to convert acetate to acetic acid) and distillation of the acetic acid.

5. Cyclic crystallization of sodium nitrate from the distillation bottoms.

6. Removal of radioactive mother solution after 10 to 15 crystallization cycles to perform additional purification or to discharge to storage.

Two solution compositions (I and II in Table 4.1) were treated by this flowsheet. Barium chromate precipitation at stage 2 was used to remove $\mathrm{Cr}(\mathrm{VI})$. To remove the excess barium, a small amount of soda (sodium carbonate) was added. The barium chromate/carbonate precipitation stage purified the solution of $\mathrm{Cr}(\mathrm{VI})$, removed certain fission product elements by adsorption, and decreased strontium concentration 50 -fold by coprecipitation. Sedimentation of the barium precipitates also removed a radioactive slime found in the process solution that was present because of equipment imperfections and insufficient sedimentation.

Precipitation of nickel ferrocyanide in the $\mathrm{pH}$ range 6 to 9.5, used in stages 2 and 3 to remove cesium, required acidification of solution I by nitric acid. Barium carbonate precipitation in stage 3 separated strontium. 
Table 4.1. Chemical and Radiochemical Composition of Solutions

\begin{tabular}{|c|c|c|c|}
\hline \multirow[b]{2}{*}{ Component } & \multirow[b]{2}{*}{ Unit } & \multicolumn{2}{|c|}{ Mean Concentration } \\
\hline & & Solution I & Solution II \\
\hline $\mathrm{NaNO}_{3}$ & $g / L$ & 150 & 165 \\
\hline $\mathrm{CH}_{3} \mathrm{COONa}$ & $g / L$ & 90 & 88 \\
\hline $\mathrm{Cr}(\mathrm{VI})$ & $g / L$ & 0.85 & -- \\
\hline $\mathrm{NaOH}$ & $g / L$ & 9.0 & 10 \\
\hline Total $\gamma$-Activity & $\mathrm{mCi} / \mathrm{L}$ & 475 & 4.6 \\
\hline${ }^{106} \mathrm{Ru}$ & $\mathrm{mCi} / \mathrm{L}$ & $360-370$ & -- \\
\hline${ }^{137} \mathrm{Cs}$ & $\mathrm{mCi} / \mathrm{L}$ & 121.2 & -- \\
\hline
\end{tabular}

The behaviors of aluminum and silicic acid during acidification of a solution I simulant were investigated, and decreasing $\mathrm{pH}$ to the range 6 to 9 gave virtually complete aluminum precipitation. By increasing alkali concentration to $2 \mathrm{~g} / \mathrm{L}, 0.125 \mathrm{~g}$ aluminum $/ \mathrm{L}$ remained in solution. To retain $0.6 \mathrm{~g}$ aluminum $/ \mathrm{L}$ in solution, sodium hydroxide to at least $5 \mathrm{~g} / \mathrm{L}$ was required.

Silicic acid concentration up to $0.2 \mathrm{~g} / \mathrm{L}$ remained in the solution over the range from $\mathrm{pH} 5$ to $5 \mathrm{~g} / \mathrm{L}$ free sodium hydroxide. The dependence of aluminum and silicic acid precipitate volumes on solution $\mathrm{pH}$ and alkalinity was determined (Tables 4.2 and 4.3). With both aluminum and silicic acid present, precipitate volumes under otherwise similar conditions were several times higher than in the presence of these components individually. The precipitate volume reached $18 \%$ of the total volume when the concentrations of aluminum and silicic acid were 0.08 to 0.1 and $0.1 \mathrm{~g} / \mathrm{L}$, respectively.

In general, the aluminum hydroxide precipitates settled poorly and were easily resuspended. The precipitates often rose to the surface initially. Additional stirring followed by settling caused the precipitates to sink and reach constant volume after 3 to 4 hours. However, the silicic acid precipitate showed a crumbly gelatinous structure that sometimes did not settle.

The behaviors of aluminum and silicic acid during chromate-carbonate precipitation also were studied. In alkaline media, aluminum and silicic acid were found to have no noticeable effect on barium chromate precipitate volume. Precipitate volumes decreased 10- to 50-fold when $\mathrm{pH}$ was decreased to between 7 and 8. 
Table 4.2. Precipitate Volumes for Solutions Containing $0.088 \mathrm{~g} \mathrm{Al} / \mathrm{L}$ and Silicic Acid

\begin{tabular}{||c|c|c|c|c|c|c|c||}
\hline \multicolumn{2}{|c|}{ Acidity/Alkalinity } & \multicolumn{5}{c||}{ Precipitate Volume, \% } \\
\hline $\begin{array}{c}\text { Excess, } \\
\mathrm{g} / \mathrm{L}\end{array}$ & $\mathrm{pH}$ & $\begin{array}{c}\mathrm{CH}_{3} \mathrm{COOH} \\
\mathrm{g} / \mathrm{L}\end{array}$ & $\begin{array}{c}0 \mathrm{~g} \\
\mathrm{SiO}_{2} / \mathrm{L}\end{array}$ & $\begin{array}{c}0.1 \mathrm{~g} \\
\mathrm{SiO}_{2} / \mathrm{L}\end{array}$ & $\begin{array}{c}0.2 \mathrm{~g} \\
\mathrm{SiO}_{2} / \mathrm{L}\end{array}$ & $\begin{array}{c}0.5 \mathrm{~g} \\
\mathrm{SiO}_{2} / \mathrm{L}\end{array}$ & $\begin{array}{c}1.0 \mathrm{~g} \\
\mathrm{SiO}_{2} / \mathrm{L}\end{array}$ \\
\hline 5 & -- & -- & 0 & $\begin{array}{c}\text { Small } \\
\text { amount } \\
\text { slime }\end{array}$ & 3.0 & 16.0 & 28.0 \\
\hline-2 & -- & - & 0 & 2.5 & 8.0 & 16.0 & 21.0 \\
\hline 1 & -- & -- & $\mathrm{Trace}$ & 8.0 & 20.0 & 22.0 & 28.0 \\
\hline-- & 9.0 & -- & 5.0 & -- & -- & 18.0 & 20.0 \\
\hline- & 8.0 & -- & -- & 15.0 & 15.0 & 20.0 & 20.0 \\
\hline-- & 7.0 & -- & 12.0 & 18.0 & 14.0 & 20.0 & 20.0 \\
\hline-- & 6.0 & -- & -- & -- & -- & 15.0 & 17.0 \\
\hline-- & -- & 3 & -- & 9.0 & 12.0 & 16.0 & 17.0 \\
\hline
\end{tabular}

Table 4.3. Precipitate Volumes for Solutions Containing $0.1 \mathrm{~g} \mathrm{SiO}_{2} / \mathrm{L}$ and Aluminum

\begin{tabular}{||c|c|c|c|c|c|c||}
\hline \hline \multicolumn{1}{||c|}{ Acidity/Alkalinity } & \multicolumn{5}{|c||}{ Precipitate Volume, \% } \\
\hline $\begin{array}{c}\mathrm{NaOH} \\
\text { Excess, } \\
\mathrm{g} / \mathrm{L}\end{array}$ & $\mathrm{pH}$ & $\begin{array}{c}0 \mathrm{~g} \\
\mathrm{Al} / \mathrm{L}\end{array}$ & $\begin{array}{c}0.025 \mathrm{~g} \\
\mathrm{Al} / \mathrm{L}\end{array}$ & $\begin{array}{c}0.088 \mathrm{~g} \\
\mathrm{Al} / \mathrm{L}\end{array}$ & $\begin{array}{c}0.125 \mathrm{~g} \\
\mathrm{Al} / \mathrm{L}\end{array}$ & $\begin{array}{c}0.25 \mathrm{~g} \\
\mathrm{Al} / \mathrm{L}\end{array}$ \\
\hline 5 & -- & 0 & 0 & Traces & Traces & Traces \\
\hline 2 & -- & 0 & Traces & 3.0 & 3.0 & 7.0 \\
\hline 1 & -- & 0 & 0.3 & 8.0 & 8.0 & 10.0 \\
\hline- & 9.0 & 0 & 8.0 & 9.0 & 13.0 & 32.0 \\
\hline- & 8.0 & 0 & 18.0 & 18.0 & 26.0 & 40.0 \\
\hline- & 7.0 & 0 & 5.0 & 17.0 & 23.0 & 38.0 \\
\hline- & 6.0 & 0 & 3.5 & 9.0 & 17.0 & 30.0 \\
\hline
\end{tabular}


The influence of aluminum and silicic acid on nickel ferrocyanide and barium carbonate precipitations also depended strongly on solution alkalinity. Increasing alkalinity increased the fraction of ferrocyanide remaining in solution. Over $70 \%$ of the ferrocyanide remained in solution at around $\mathrm{pH} 10$. To increase the degree of precipitation, it was necessary to decrease the initial solution $\mathrm{pH}$ to between 6 and 7 . However, use of the lower $\mathrm{pH}$ precluded two-stage precipitation. To precipitate ferrocyanide from solutions containing low concentrations of aluminum and silicic acid, it was expedient to combine the ferrocyanide and chromate-soda precipitations to one stage (chromate-ferrocyanide-soda).

The behaviors of aluminum and silicic acid during acidification of acetate with nitric acid were also investigated. Aluminum and silicic acid were almost completely removed from solution with precipitates of barium chromate and nickel ferrocyanide at a $\mathrm{pH}$ less than 9. Therefore, no precipitates formed by acidification of supernatant liquids remaining after ferrocyanide-soda precipitation and the subsequent distillation of acetic acid.

Some amount of free potassium ferrocyanide always remained in solution after nickel ferrocyanide precipitation. The amount increased with increasing $\mathrm{pH}$. At least 15 to $20 \%$ of the potassium ferrocyanide remained in solution after ferrocyanide precipitation at $\mathrm{pH}$ from 9 to 10 . From research of ferrocyanide behavior during acetic acid distillation, it was found that ferrocyanide partially decomposed to form hydrogen cyanide ( $\mathrm{HCN}$ ) in acid both in the presence and absence of an oxidant. The decomposition rate increased with increasing temperature and acidity.

To evaluate the influence of small amounts of ferrocyanide on the sodium nitrate quality, a series of experiments was performed on sodium nitrate crystallization. It was found that ferrocyanide decomposition products contaminated the sodium nitrate. Thus, part of the ferrocyanide decomposed and precipitated as Berlin blue (ferric ferrocyanide, $\left.\mathrm{Fe} \mathrm{e}_{4} \mid \mathrm{Fe}(\mathrm{CN})_{6}\right]_{3}$ ), which was captured during sodium nitrate crystallization and contaminated the product with its scavenged radioactivity. To implement the complete flowsheet successfully (including ferrocyanide decontamination, acidification, and distillation of acetic acid), the ferrocyanide had to be prevented from entering the evaporators. To avoid the problems caused by ferrocyanide, a variant of the process flowsheet was developed.

\subsection{Removal of Impurities by Crystallization}

The new flowsheet began with acidification of the alkaline supernatant liquid and distillation of acetic acid. In this way, $\mathrm{Cr}$ (VI) was reduced to $\mathrm{Cr}$ (III) during acetic acid distillation, which in turn oxidized most of the other reductants. Ruthenium was partially converted to an adsorbable form. The mother solution, that remaining after subsequent crystallization of sodium nitrate, had a volume 2.5 to 3 times smaller than the volume of the initial solution and was decontaminated by one of the methods known for acid media.

The resulting decontaminated supernate then was blended with a portion of the initial alkaline solution I, and reverse alkaline precipitation occurred. The alkaline chromium precipitate captured technological slime, strontium, and ruthenium during sedimentation. Aluminum and silicic acid, if present, were also captured by the precipitate. The flowsheet thereby avoided the chromate-soda precipitation step. 


\subsubsection{Study of the Formation of Insoluble Precipitates by Evaporation and Crystallization}

Twelve crystallization cycles were conducted to study the formation of insoluble precipitates by evaporation and crystallization and to refine crystallization decontamination factors. One liter of initial solution, prepared by chromate-soda purification, was used in each cycle. The solution was composed of sodium nitrate $(141 \mathrm{~g} / \mathrm{L})$, sodium acetate $(92 \mathrm{~g} / \mathrm{L})$, and sodium carbonate $(2 \mathrm{~g} / \mathrm{L})$ and contained $6 \mathrm{mCi} / \mathrm{L}$ total $\beta$-activity. Because of the decontamination achieved by the chromate-soda step, the solution contained $44.8 \%$ of its original ${ }^{137} \mathrm{Cs}$ activity, $0.96 \%$ of the original ${ }^{90} \mathrm{Sr}$, and $74.3 \%$ of the ${ }^{106} \mathrm{Ru}$.

Each crystallization cycle included acidification, evaporation, crystallization, and centrifugation stages. Crystal washing also was conducted for some cycles.

Experiments showed that, on average, $2.7 \%$ of the total activity was retained in the sodium nitrate crystals. The sodium nitrate salt yield ranged from 44 to $62 \%$ in the individual cycles. The increase in activity of the solutions and salt products is shown in Table 4.4. These data indicated that solution purification wass required to keep activity from increasing. The radioactivity remaining in the sodium nitrate product was caused solely by interstitial retention of mother solution during crystallization, because the radioactivity distributions of the initial and mother solutions and the product salt were the same (Table 4.5).

Table 4.4. Dynamics of Increasing Solution Activity (total activity of initial solution is $100 \%$ )

\begin{tabular}{|c|c|c|c|c|c|c||}
\hline & \multirow{2}{*}{$\begin{array}{c}\text { Relative } \\
\text { Activity } \\
\text { of Mother } \\
\text { Cycle }\end{array}$} & $\begin{array}{c}\text { Relative } \\
\text { Activity of } \\
\text { Solution for } \\
\text { Soluporation, \% }\end{array}$ & $\begin{array}{c}\text { Temperature } \\
\text { of Incipient }\end{array}$ & \multirow{2}{*}{$\begin{array}{c}\text { Salt } \\
\text { Crystallization, }{ }^{\circ} \mathrm{C}\end{array}$} & $\begin{array}{c}\text { Activity Captured, \%, } \\
\text { Yelative to }\end{array}$ \\
\cline { 6 - 8 } & $\begin{array}{c}\text { Crystallization } \\
\text { Solution }\end{array}$ & $\begin{array}{c}\text { Initial } \\
\text { Solution }\end{array}$ \\
\hline 1 & -- & -- & 82 & 44.5 & 1.9 & 4.26 \\
\hline 2 & 90.7 & 190.7 & 96 & 52.5 & 2.8 & 5.34 \\
\hline 3 & 183.2 & 283.2 & 87 & 49.9 & 2.1 & 5.95 \\
\hline 4 & 219.7 & 319.7 & 97 & 56.5 & 2.3 & 7.35 \\
\hline 5 & 348.7 & 448.7 & 98 & 54.8 & 2.0 & 9.0 \\
\hline 6 & 418.0 & 518.0 & 92 & 53.8 & 2.6 & 13.5 \\
\hline 7 & 457.1 & 557.1 & 94 & 55.3 & 2.5 & 13.3 \\
\hline 8 & 523.9 & 623.9 & 92 & 44.0 & 2.1 & 13.1 \\
\hline 9 & 568.0 & 668.0 & 107 & 60.9 & 2.5 & 16.7 \\
\hline 10 & 668.5 & 768.0 & 108 & 62.5 & 2.9 & 22.3 \\
\hline 11 & 764.0 & 864.0 & 105 & 62.2 & 2.5 & 21.6 \\
\hline 12 & 816.8 & 916.8 & 106.3 & 52.2 & 2.3 & 21.1 \\
\hline
\end{tabular}


Table 4.5. Isotopic Composition of Active Impurities in Sodium Nitrate Salt (total activity for each radionuclide in initial solution is $100 \%$ )

\begin{tabular}{||c|c|c|c||}
\hline \multirow{2}{*}{ Product } & \multicolumn{3}{|c|}{ Activity, \% } \\
\cline { 2 - 4 } & ${ }^{137} \mathrm{Cs}$ & ${ }^{90} \mathrm{Sr}$ & ${ }^{106} \mathrm{Ru}$ \\
\hline Initial solution after chromate-soda & 44.8 & 0.96 & 74.3 \\
\hline Mother solution after crystallization & 49.1 & 0.86 & - \\
\hline Washed salt crystals after $12^{\text {th }}$ cycle & 46.9 & 0.81 & - \\
\hline
\end{tabular}

\subsubsection{Purification from Strontium, Cesium, and Ruthenium}

To attain consistently low activity in the sodium nitrate and acetate products, it was necessary to decontaminate the crystallization mother solutions. The required decontamination factors depended on the sodium nitrate crystallization yield. With increasing yield, the volume of mother solution returned to the beginning of the process decreased but had higher relative activity and thus required a higher decontamination factor. In cyclic processing, the activity of the salt product thus depended on the activity of the initial solution and the decontamination factor for the mother solution.

The initial activity of solution I varied over a wide range (Table 8.2). The activity range depended on the age (cooling time) of the solution, the concentration of active slime, and the alkalinity. The activity caused by solid suspensions could reach $30 \%$ of the total activity. The fraction of dissolved ruthenium increased and of strontium decreased with increasing alkalinity. The dissolved strontium activity at $\mathrm{pH} 9$ to 10 was 25 to $30 \%$ of the total solution activity. If the alkalinity was raised to 5 to $10 \mathrm{~g} / \mathrm{L}$ sodium hydroxide, the dissolved strontium activity decreased to 2 to $3 \%$ of the total. For a total activity of industrial solution I of $7.67 \mathrm{GBq} / \mathrm{L}(0.21 \mathrm{Ci} / \mathrm{L}), 2.30,0.67,0.38$, and $4.32 \mathrm{GBq} / \mathrm{L}$ was because of suspensions (slime), cesium, zirconium/niobium, and ruthenium, respectively.

\subsubsection{Separation of Slime and Strontium from Solution}

Strontium was found to adsorb on precipitates produced by alkaline treatment of solutions containing large amounts (i.e., over 1 to $1.5 \mathrm{~g} / \mathrm{L}$ ) of chromium(III). Analyses showed that decontamination factors over 1,000 and up to 2,000 were reached. Two process variants were investigated to separate strontium from solution by cyclic chromium hydroxide precipitation.

In the first variant, acidic mother solution with chromium(III) was added directly to the initial alkaline solution to achieve reverse alkaline precipitation. The resulting precipitate captured active slime and adsorbed strontium and some ruthenium. In the second variant, alkaline precipitation of the mother solution was performed in a special unit. 


\subsubsection{Separation of Cesium from Solution}

To purify mother solutions of cesium, preformed iron and nickel ferrocyanide precipitates were used. Tests showed that these precipitates adsorbed radioactivity both at room and elevated temperatures, but adsorption factors increased with increasing temperature. Near-equilibrium was reached in 1 to 2 hours. Decontamination factors increased with increasing ferrocyanide concentrations. For iron ferrocyanide, the decontamination factor was 1.0 at $1 \mathrm{~g} / \mathrm{L}$ and 5.8 at $20 \mathrm{~g} / \mathrm{L}$. For nickel ferrocyanide, the decontamination factor was 1.7 at $1 \mathrm{~g} / \mathrm{L}$ and 3.6 at $10 \mathrm{~g} / \mathrm{L}$. Selective sorption of cesium by nickel ferrocyanide was higher than by iron ferrocyanide.

At ferrocyanide concentrations of $2 \mathrm{~g} / \mathrm{L}$, the volumes of both ferrocyanide precipitates were approximately $2 \%$ of the solution volume. Nickel ferrocyanide settled considerably faster (in 5 to 6 hours) than iron ferrocyanide (12 to 15 hours). As shown in Table 4.6, the cesium decontamination factor with nickel ferrocyanide was only slightly affected by potassium concentrations ranging from 0 to $40 \mathrm{~g} / \mathrm{L}$. Nickel ferrocyanide was slightly soluble (less than $0.01 \mathrm{~g} / \mathrm{L}$ ) in acid salt solution.

Solution decontamination factors from cesium were about 3. This level was achieved at 75 to $80^{\circ} \mathrm{C}$ using $2 \mathrm{~kg}$ ferrocyanide per $\mathrm{m}^{3}$ mother solution to produce a precipitate volume of about $0.5 \%$ of that of the mother solution.

Another method, based on co-crystallization of cesium phosphotungstate with potassium or ammonium phosphotungstate, could be used for cesium separation. In this case, decontamination factors of about 5 were attained with $0.75 \mathrm{~kg}$ precipitate per $\mathrm{m}^{3}$ of mother solution and 10 to $100 \mathrm{~g}$ potassium per liter. The phosphotungstate precipitate method was successful over a wide range of acidity ( $\mathrm{pH} 2$ to 0$)$ and produced a small precipitate volume.

Table 4.6. Cesium Sorption on Preformed Nickel Ferrocyanide Precipitate ( $2 \mathrm{~g} / \mathrm{L})$ at Various Potassium Nitrate Concentrations, 75 to $80^{\circ} \mathrm{C}$, and Three Hours' Contact Time (solution composition: $367 \mathrm{~g} \mathrm{NaNO}_{3} / \mathrm{L}, 13 \mathrm{~g} \mathrm{CH}_{3} \mathrm{COONa} / \mathrm{L}, 6.7 \mathrm{~g} \mathrm{HNO}_{3} / \mathrm{L}$, $\left.3.3 \mathrm{~g} \mathrm{Cr}^{3+} / \mathrm{L}, 3.3 \mathrm{~g} \mathrm{Al}^{3+} / \mathrm{L}\right)$

\begin{tabular}{|c|c|c||}
\hline $\begin{array}{c}{\left[\mathrm{KNO}_{3}\right],} \\
\mathrm{g} / \mathrm{L}\end{array}$ & $\begin{array}{c}\text { Residual } \\
\text { Activity of } \\
\text { Decantate, \% }\end{array}$ & $\begin{array}{c}\text { Purification } \\
\text { Factor }\end{array}$ \\
\hline 0 & 27.4 & 3.6 \\
\hline 15 & 27.4 & 3.6 \\
\hline 60 & 33.4 & 3.0 \\
\hline 80 & 35.3 & 2.8 \\
\hline 100 & 35.9 & 2.8 \\
\hline
\end{tabular}




\subsubsection{Separation of Ruthenium from Solution}

Purification of solutions from ruthenium is more complicated than purification from cesium and strontium and is affected by the following two features:

1. Ruthenium adsorption on hydroxide precipitates during alkaline precipitation strongly depends on the final solution $\mathrm{pH}$.

2. Well-adsorbed and poorly adsorbed forms of ruthenium exist. The poorly adsorbed anionic form originates from reactions of ruthenium with sodium acetate and nitrate radiolysis products.

Experiments were conducted with mother solution obtained from industrial solution I after acetic acid distillation and sodium nitrate crystallization. As shown in Figures 4.1 and 4.2, maximum adsorption (about 94\%) was observed by precipitation on chromium hydroxide at $\mathrm{pH} 7$ to 8 over the tested $\mathrm{pH}$ range of 8.5 to 5.5 . Less than $50 \%$ of the ruthenium was adsorbed on chromium hydroxide at $1 \mathrm{~g} / \mathrm{L}$ sodium hydroxide. Note that the sorption was irreversible. If the ruthenium were adsorbed on chromium hydroxide at an optimal $\mathrm{pH}$, desorption by exposure of the precipitate to higher alkalinity was small.

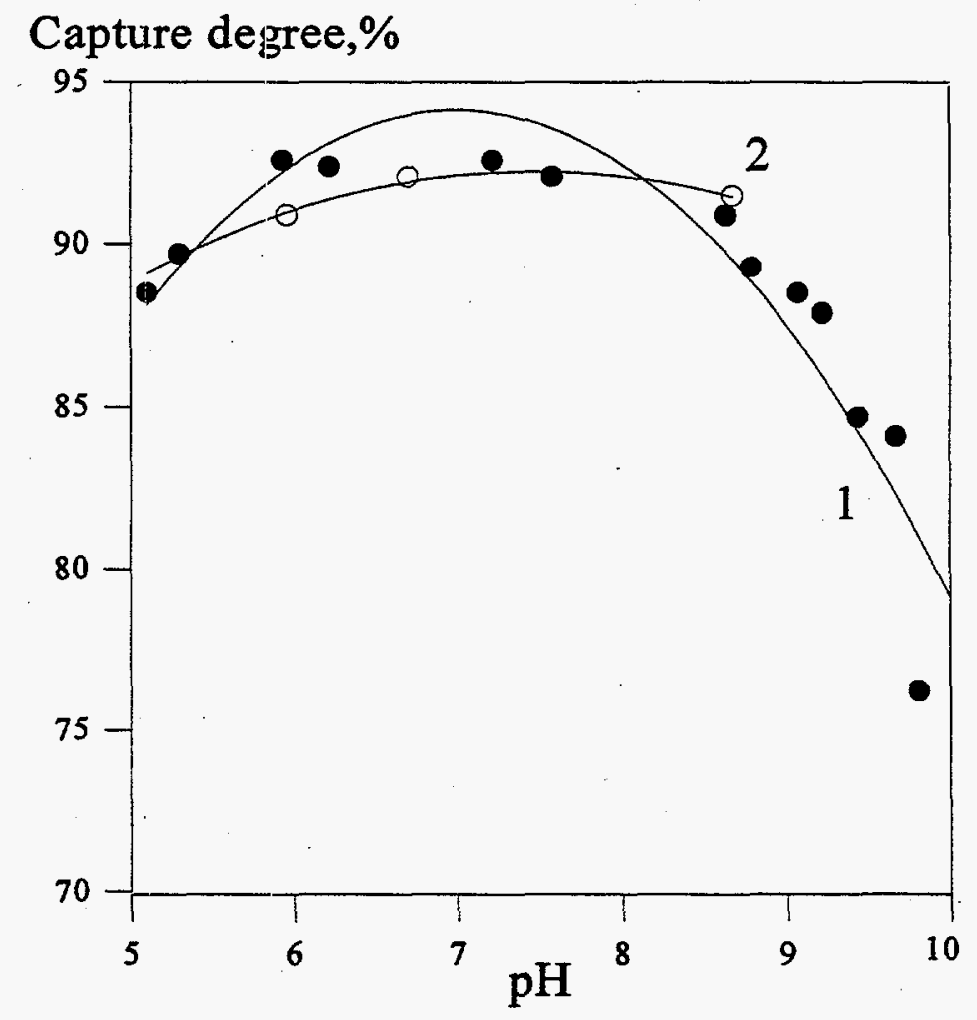

Figure 4.1. Influence of $\mathrm{pH}$ on Adsorption (1) and Desorption (2) of Ruthenium on Chromium Hydroxide 


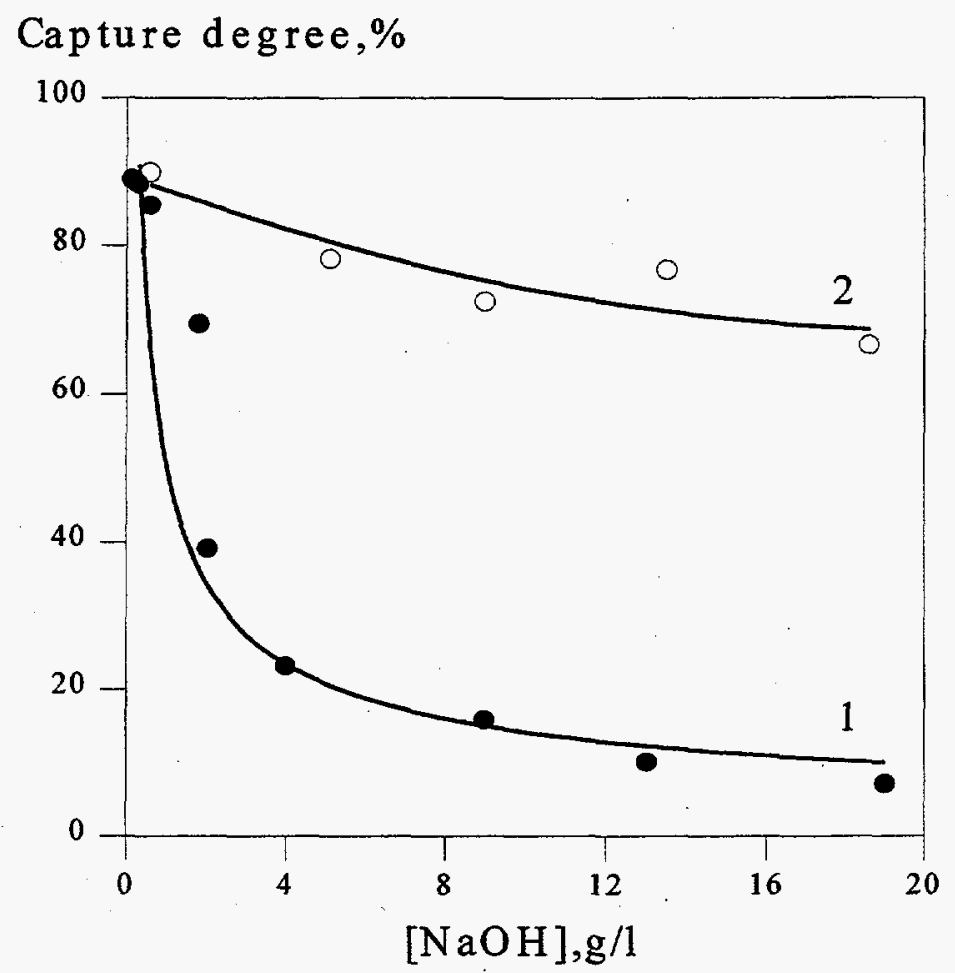

Figure 4.2. Influence of Alkalinity on Adsorption (1) and Desorption (2) of Ruthenium on Chromium Hydroxide

Addition of various cations (e.g., nickel, copper, manganese) increased ruthenium adsorption on $\mathrm{Cr}$ (III) hydroxide precipitates (Table 4.7). Precipitation with added cations was tested under alkaline conditions using mother solution remaining after acidification and crystallization of solution I. As shown in Table 4.7, the best results were obtained for a mixture of chromium, copper, and nickel.

Table 4.7. Influence of Various Cations on Ruthenium Sorption During Alkaline Precipitation of Mother Solution ( $\mathrm{pH} 7.1$ to 9.4)

\begin{tabular}{||l|c|c|}
\hline \multirow{2}{*}{\multicolumn{1}{|c|}{ Cations }} & \multicolumn{2}{c|}{ Purification Factor } \\
\cline { 2 - 3 } & $\begin{array}{c}\text { Cr(VI) Reduction } \\
\text { by Bisulfite }\end{array}$ & $\begin{array}{c}\text { Without } \\
\text { Reduction }\end{array}$ \\
\hline $\mathrm{Cr}(\mathrm{III})$ & 20.4 & 22.1 \\
\hline $\mathrm{Cr}(\mathrm{III})+\mathrm{Ni}(\mathrm{II})$ & 22.8 & 31.4 \\
\hline $\mathrm{Cr}(\mathrm{III})+\mathrm{Cu}(\mathrm{II})$ & 26.9 & 41.9 \\
\hline $\mathrm{Cr}(\mathrm{III})+\mathrm{Cu}(\mathrm{II})+\mathrm{Ni}(\mathrm{II})$ & 47.0 & 95.3 \\
\hline $\mathrm{Cr}(\mathrm{III})+\mathrm{Mn}(\mathrm{II})$ & 27.4 & 27.6 \\
\hline $\mathrm{Cr}(\mathrm{III})+\mathrm{Fe}(\mathrm{II})$ & 25.0 & 31.4 \\
\hline
\end{tabular}


Tests also showed that preliminary reduction of chromate by sodium bisulfite $\left(\mathrm{NaHSO}_{3}\right)$ in acid did not increase sorption (Table 4.7). By avoiding the unnecessary reduction step, sulfate did not accumulate in the cyclic process solutions, but chromate and dichromate (hexavalent chromium) concentrations increased. However, the increased dichromate concentrations in the acid distillation promoted oxidation of reductants in the waste, destroyed the poorly adsorbed form of ruthenium, and produced Cr(III) for mother solution decontamination by chromium hydroxide precipitation. Because of the benefits provided by hexavalent chromium, its removal from solution by precipitation as barium chromate $\left(\mathrm{BaCrO}_{4}\right)$ was not pursued.

Recycle of the acidic mother solution to the strongly alkaline initial solution I also decreased alkali consumption for chromium hydroxide precipitation and decreased acid required for the initial solution. Tests showed that chromium hydroxide precipitation from mother solution at a final $\mathrm{pH}$ of 5.5 to 8.5 increased ruthenium separation by a factor of 10 to 20 .

\subsubsection{Separation of Precipitates}

Because most of the flowsheets required separation of large volumes of precipitates obtained in alkaline processes, appropriate phase separation methods were necessary. A sedimentation type centrifuge with a packet of separating trays was developed. A cross-sectional diagram of the centrifuge is shown in Figure 4.3. The cover (1), separating trays (2), clamping ring (3), shell (4), radial partitions (5) leading to a directing device (6), rotor bottom (7), suspension feed tube (8), precipitate removal tube (9), and decantate overflow route $(10)$ are depicted.

The suspension entered the feed tube (8) and was accelerated to the centrifuge shell (4). The precipitate settled to the gently sloped shell wall, where it was drawn off by the movable tube ( 9 ). The supernate traveled through the perforated separating trays (2), which reduced suspension turbulence and thus provided better solid/liquid partition. The clarified decantate exited the centrifuge through the overflow (10).

\subsubsection{Cyclic Processing for Sodium Nitrate Crystallization}

The test results support the proposed cyclic process shown in Figure 4.4 for sodium nitrate crystallization from industrial solutions.

Beginning at the upper right corner of Figure 4.4 in this cyclic process, acidic mother solution produced after sodium nitrate crystallization [and containing up to $2.5 \mathrm{~g} / \mathrm{L} \mathrm{Cr}(\mathrm{III})$ ] was blended with the initial solution I (containing 5 to $10 \mathrm{~g} / \mathrm{L}$ sodium hydroxide). Neutralization of the acidic mother solution by solution I caused chromium to precipitate as the hydroxide. Most of the aluminum and silicic acid also precipitated with the chromium hydroxide. These precipitates captured radioactive slimes and purified the solution of strontium and ruthenium, residues of niobium/zirconium, and the rare earth radioelements. 


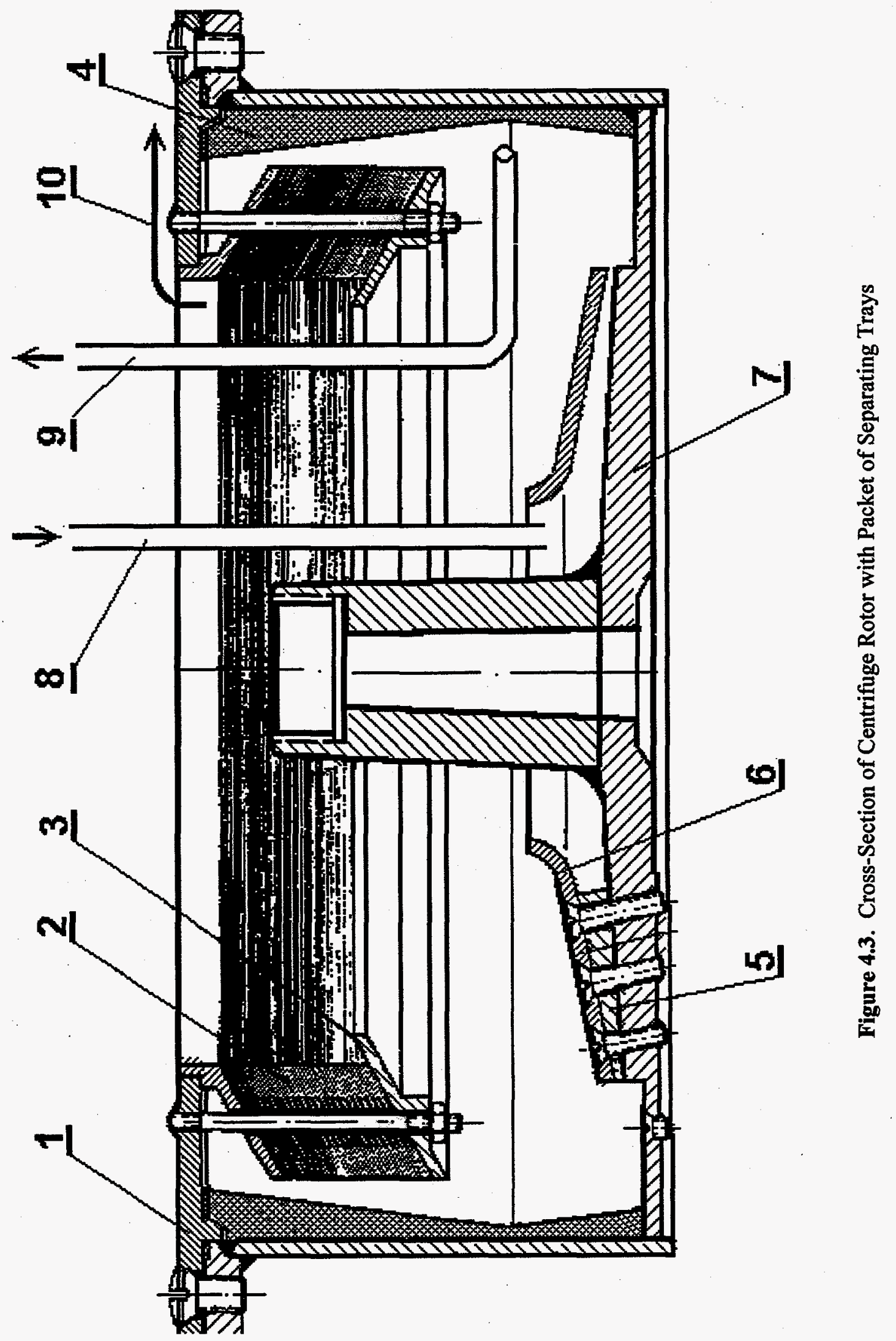

4.11 


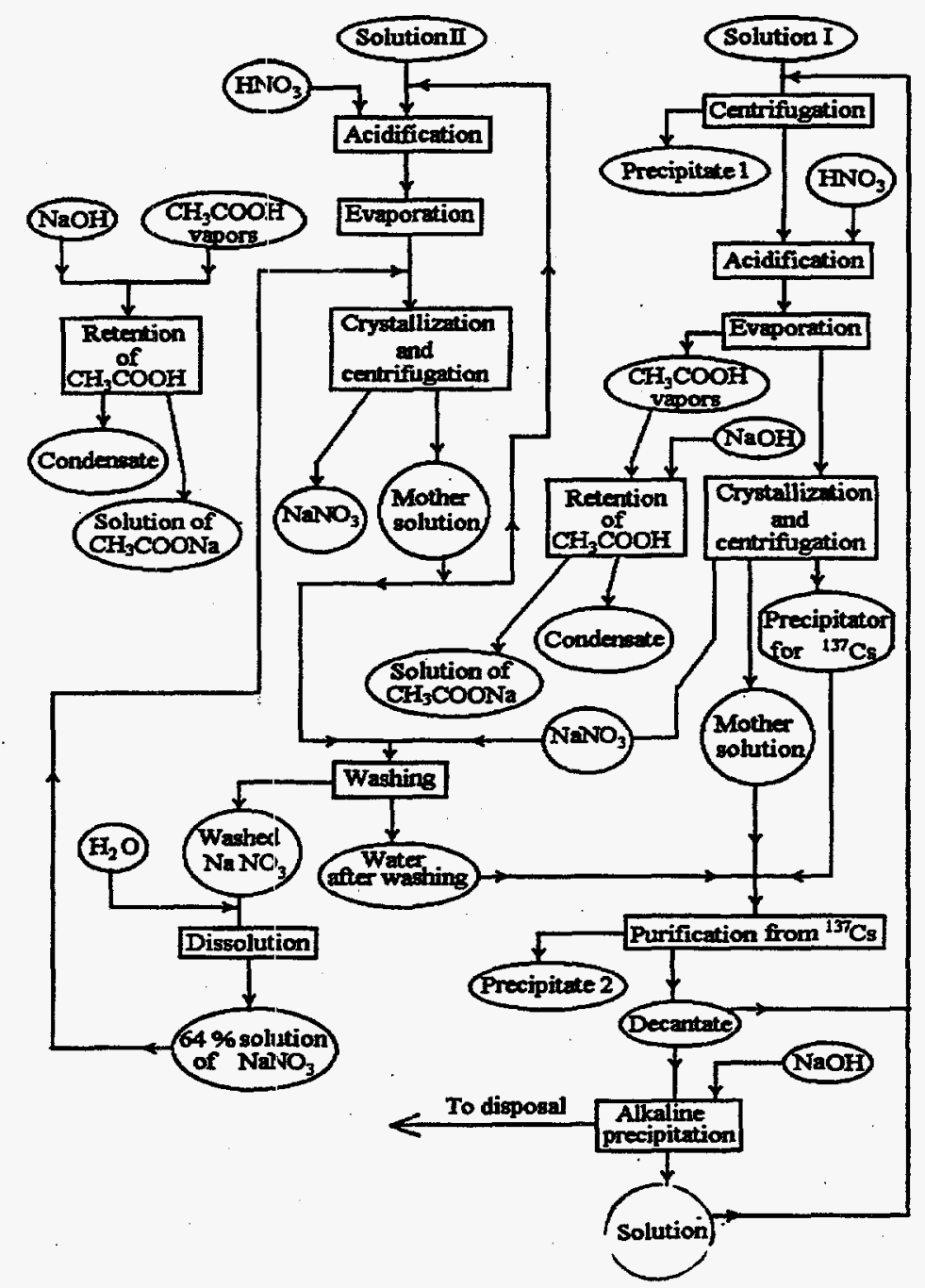

Figure 4.4. Flowsheet: for Processing Acetate-Nitrate Radioactive Wastes

The product suspension was separated by use of the sedimentation centrifuge with separating trays. The solids (designated precipitate 1) made up volumes 1 to $2 \%$ of the feed volume and were collected for storage. The clarified solution then was acidified and evaporated. Hexavalent chromium was reduced in the evaporator by oxidation of the solution reductants. The poorly sorbed ruthenium complex also was decomposed by reaction with dichromate. Acetic acid vapors were scrubbed by alkali in a hot trapping column to produce sodium acetate.

The concentrated solution then was allowed to crystallize sodium nitrate. The crystals were washed and the washed crystals were dissolved to make $64 \% \mathrm{NaNO}_{3}$ solution. In the meantime, the less radioactive solution II was undergoing acidification and removal of acetic acid by distillation. Following acetic acid removal, the sodium nitrate solution generated from solution II was blended with the $64 \%$ sodium nitrate from solution I and allowed to crystallize. The sodium nitrate arising from this crystallization constituted the separated product and was removed. 
The mother solution remaining after the room temperature sodium nitrate crystallization was used to wash the solution I sodium nitrate crystals. The spent wash solution was blended with mother solution remaining from solution I sodium nitrate crystallization. The blended solution was purified of cesium using preformed nickel ferrocyanide or potassium phosphotungstate. The ferrocyanide or phosphotungstate solids were collected for disposal as precipitate 2. The mother solution, purified of cesium, then was blended with solution I for alkaline precipitation, and the cycle was repeated. 


\subsection{Purification of Acetate-Nitrate Radioactive Waste with Removal of Ruthenium, Cesium, and Strontium Before Distillation of Acetic Acid}

Use of ferrocyanide to purify solutions of cesium required complete removal of ferrocyanide from the solution before distillation. As discussed in Section 4.1, removal was required because residual ferrocyanide decomposed in the evaporator, contaminating acetic acid with vapors of hydrogen cyanide and sodium nitrate crystals with radioactive Berlin blue. These problems were eliminated if the cesium purification was conducted in the solution after crystallization (see Section 4.2.2). However, postponing cesium removal after crystallization caused solution activities in the evaporator and crystallizer to be relatively high. To address this problem, additional studies of cesium removal before acetic acid distillation were conducted.

\subsection{Purification from Cesium, Strontium, and Ruthenium}

The study was conducted with solution I (Table 4.1). Tests showed that the concentration of free ferrocyanide arising from in-situ precipitation of nickel ferrocyanide was considerably higher than that arising using preformed precipitates under the same conditions. Most of the ferrocyanide remained in solution in the case of in-situ precipitation at $\mathrm{pH} 8$ to 8.5. At this $\mathrm{pH}$, however, aluminum precipitated well. At higher $\mathrm{pH}(8.5$ to 9$)$, sorption on the in-situ precipitate was severely diminished. In contrast, the preformed precipitate kept good sorption properties up to $\mathrm{pH} 9$ to 9.5 .

Results of the study on $\mathrm{pH}$ effects on ${ }^{137} \mathrm{Cs}$ decontamination from simulant solution I with preformed nickel ferrocyanide are shown in Table 5.1. The experiments were conducted at $80^{\circ} \mathrm{C}$ with sodium nitrate $(300 \mathrm{~g} / \mathrm{L})$, sodium acetate $(70 \mathrm{~g} / \mathrm{L})$, and trace ${ }^{137} \mathrm{Cs}$ concentrations. Good adsorption was demonstrated for the preformed precipitates over the $\mathrm{pH}$ range 4.5 to 8.8 ; higher $\mathrm{pH}$ (sodium hydroxide concentration) decreased adsorption significantly.

The effect of nickel ferrocyanide precipitate concentration on ${ }^{137} \mathrm{Cs}$ adsorption was investigated. Changing the precipitate concentration from 0.2 to $2 \mathrm{~g} / \mathrm{L}$ had no noticeable influence on decontamination factors. In all further experiments, the nickel ferrocyanide concentration used was $0.5 \mathrm{~g} / \mathrm{L}$. Application of preformed nickel ferrocyanide at $\mathrm{pH} 8.5$ to 9.0 in cyclic processing of radioactive sodium nitrate and acetate solution prevented contamination of sodium acetate with cyanide compounds.

It was shown that the concentration of added chromium $(0.2$ to $0.6 \mathrm{~g} / \mathrm{L})$ had no effect on the strontium decontamination factor. The strontium decontamination factor only depended on $\mathrm{pH}$, increasing from 1.2 to 72 as $\mathrm{pH}$ increased from 5.55 to 9.9 .

Under process conditions, and starting with industrial solution I, the poorly adsorbed form of ruthenium was converted to the well-adsorbed form when acetic acid was distilled in the presence of 
Table 5.1. Purification Factors of ${ }^{137} \mathrm{Cs}$ for Nickel Ferrocyanide Precipitates as a Function of pH

\begin{tabular}{|c|c|c|c|}
\hline \multicolumn{2}{|c|}{ Acidity/Alkalinity } & \\
\hline $\begin{array}{c}\mathrm{pH} \text { before Nickel } \\
\text { Ferrocyanide Addition }\end{array}$ & {$\left[\mathrm{CH}_{3} \mathrm{COOH}\right], \mathrm{g} / \mathrm{L}$} & $\mathrm{NNaOH}], \mathrm{g} / \mathrm{L}$ & $\mathrm{K}_{\text {pur }}{ }^{(\mathrm{a})}$ \\
\hline 4.53 & 23.55 & -- & 180 \\
\hline 5.00 & 13.05 & -- & 180 \\
\hline 6.00 & 2.19 & -- & 180 \\
\hline 7.00 & 0.3 & -- & 198 \\
\hline 8.80 & -- & - & 60 \\
\hline- & - & 0.96 & 5.62 \\
\hline- & -- & 3.30 & 1.23 \\
\hline- & -- & 5.40 & 1.39 \\
\hline- & - & 10.50 & 1.21 \\
\hline
\end{tabular}

potassium dichromate. The well-adsorbed form of ruthenium was captured (90 to $95 \%)$ at $\mathrm{pH} 6$ to 8 by the chromium hydroxide precipitate. Cyclic repetition of the oxidation and precipitation stages almost completely removed ruthenium.

Ruthenium removal was confirmed by experiments with a solution that initially did not contain cesium, strontium, and chromate but otherwise was similar in composition to solution I. Chromate was added to this solution prior to the experiment. Part of the solution was acidified to an excess nitric acid concentration of 2 to $3 \mathrm{~g} / \mathrm{L}$; acetic acid then was distilled in the presence of potassium dichromate $(5 \mathrm{~g} / \mathrm{L})$. The evaporated residual solution was diluted to the initial volume, and chromium hydroxide was precipitated by alkali, capturing ruthenium. The solution separated from the chromium hydroxide precipitate was again acidified, potassium dichromate added to the target concentration, and the evaporation repeated. A second part of the solution underwent similar testing but without the acetic acid distillation step.

The results of these experiments on ${ }^{106} \mathrm{Ru}$ removal are given in Table 5.2 . Only 5 to $10 \%$ of the ${ }^{106} \mathrm{Ru}$ was removed at each chromium hydroxide precipitation step in tests without heating. After four precipitations, the cumulative ruthenium decontamination factor was only 1.25. However, in experiments including distillation of acetic acid in the presence of potassium dichromate, the decontamination factor after four precipitations was 800 . The results confirmed that acetic acid distillation converts poorly adsorbed ruthenium completely to a form that can be removed from chromium hydroxide precipitate by cyclic processing. 
Table 5.2. Conversion of Poorly Sorbed Ruthenium to the Well-Sorbed Form by Acetic Acid Distillation in the Presence of Potassium Dichromate

\begin{tabular}{|c|c|c||}
\hline \multirow{2}{*}{ Precipitation Number } & \multicolumn{2}{|c|}{$\begin{array}{c}\text { Ruthenium } \\
\text { Purification Factors }\end{array}$} \\
\cline { 2 - 3 } & Without Heating & $\begin{array}{c}\text { After } \\
\text { Distillation }\end{array}$ \\
\hline 1 & 1.04 & 12 \\
\hline 2 & 1.10 & 127 \\
\hline 3 & 1.33 & 381 \\
\hline 4 & 1.25 & 800 \\
\hline
\end{tabular}

\subsection{Purification from Reductants}

From 50 to $70 \%$ of the process solutions' reductant concentration was sodium nitrite. Methods tested to remove the reductants included gas phase purging and oxidations by potassium dichromate, hydrogen peroxide, and ozone.

Purging was achieved by air bubbling at various temperatures and acidities. It was found that the nitrite removal rate increased with increasing temperature and acidity. Sodium nitrite concentrations in solutions containing $3 \mathrm{~g}$ nitric acid per liter decreased from $0.8 \mathrm{~g} / \mathrm{L}$ initially to $0.03 \mathrm{~g} / \mathrm{L}$ (more than 25-fold) by bubbling air at $0.05 \mathrm{~L} / \mathrm{min}$ for 1 hour at $100^{\circ} \mathrm{C}$. However, nitrite could be regenerated by acetic acid reduction of nitric acid during distillation in the absence of an oxidant. Therefore, the acetic acid distillation had to be conducted with an oxidant present.

Potassium dichromate can oxidize most of the reductants during the distillation of acetic acid; however, some reductants distill with the acetic acid without oxidation. To oxidize these reductants, it was necessary to use relatively high $(10 \mathrm{~g} / \mathrm{L})$ potassium dichromate concentrations or treat the solution before heating with potassium dichromate. Storage with potassium dichromate at 80 to $100^{\circ} \mathrm{C}$ for 1 to 2 hours decreased the reductant concentrations 4- to 5-fold.

Ozone and hydrogen peroxide oxidation of reductants in prepared sodium acetate solutions was investigated in acid and alkaline media at 20,70 , and $100^{\circ} \mathrm{C}$. In both acid and alkaline media, hydrogen peroxide, at $100 \%$ excess, oxidized neither sodium nitrite nor other reductants. In acid media, 70 to $80 \%$ of the sodium nitrite oxidized in 2 hours with ten-fold excess of hydrogen peroxide. In alkaline media, oxidation with hydrogen peroxide under similar time and temperature conditions did not occur. Hydrogen peroxide, therefore, was not successful removing reductants from sodium acetate solution. 
Ozone oxidized sodium nitrite both in acid and alkaline media. However, to achieve complete oxidation, alkaline media required longer times than acid media. Higher temperatures increased the oxidation rate. Efficiency of ozone use in acid was greater than $50 \%$ by stoichiometry.

\subsection{Cyclic Process to Purify Solutions of Radionuclides Before Acetic Acid Distillation}

The process to purify solutions of radionuclides before acetic acid distillation is presented in Figure 5.1. Mother solution produced from the preceding cycle was fed by a metering pump to a fresh portion of solution $\mathrm{I}$ heated to $95^{\circ} \mathrm{C}$, and the resulting precipitates (mostly chromium and aluminum hydroxides) were removed. The hot solution then was acidified to $\mathrm{pH} 7$ to 8 , and preformed nickel ferrocyanide, mixed with a small amount of water, was added. After heating at $95^{\circ} \mathrm{C}$ for one-half hour with air bubbler stirring, the suspension was settled for 10 hours. The transparent decantate then was acidified to 3 to $5 \mathrm{~g} / \mathrm{L}$ excess nitric acid, evaporated at $117^{\circ} \mathrm{C}$, and fed for sodium nitrate crystallization on the centrifuge rotor. After crystallization, the mother solution was separated by centrifugation, blended with a fresh portion of solution $I$, and precipitated.

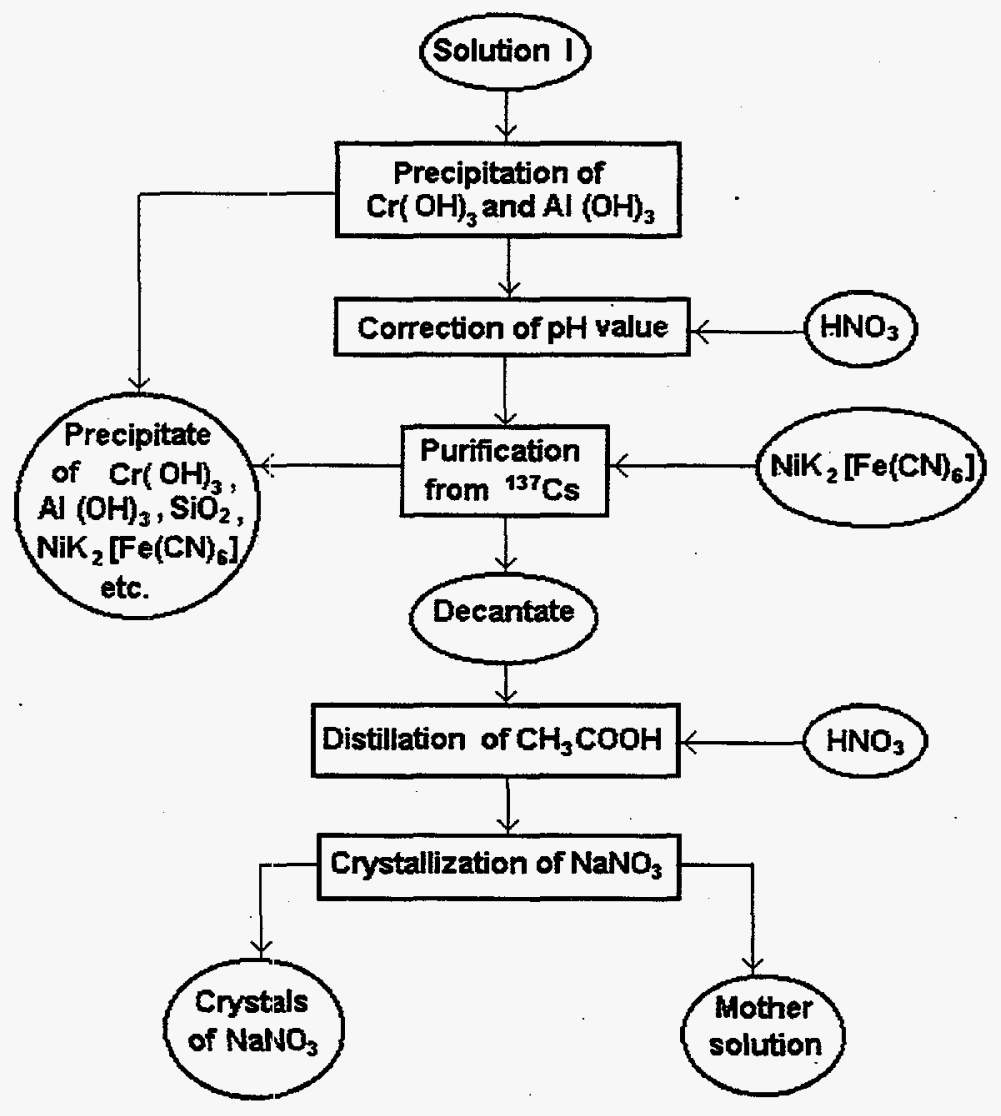

Figure 5.1. Process to Purify Solutions of Radionuclides Before Acetic Acid Distillation 
The preformed nickel ferrocyanide and chromium hydroxide precipitation gave total purification factors of 3 to 4 for $\beta$-activity and 3, on average, for $\gamma$-activity. Purification factors for individual radioelements were 2 to 3 for ruthenium, 50 to 100 for cesium, and 2 to 3 for strontium. The radioactivity of unwashed sodium nitrate did not increase from cycle to cycle and was constant within experimental error. 


\subsection{Influence of Sulfate on Acetic Acid Distillation and Sodium Nitrate Crystallization}

Sulfate concentrations in industrial solutions reached $1.5 \mathrm{~g} / \mathrm{L}$. Despite partial removal of sulfate by precipitation with chromium and iron hydroxides, large sulfate concentrations accumulated in recycle solutions arising in cyclic processing.

Because of the sulfate accumulation, studies were performed on the influence of sulfate on acetic acid distillation and mother solution composition in the equilibrium cycle, on the behavior of ruthenium during evaporation, and on the corrosion of evaporator equipment in the presence of sulfate with chloride. Based on these studies, it was judged that purification of recycle acetate-nitrate solutions from sulfate by barium sulfate precipitation was not required.

\subsection{Influence of Sulfate on Gas Phase Composition in Acetic Acid Distillation}

Gas phase compositions were determined for solutions containing sodium nitrate, nitric acid, and various concentrations of sodium sulfate and acetic acid. Experiments were conducted with a reflux apparatus as depicted in Figure 6.1. Condensate from the distillation flask could be removed for analysis by means of the drain cock or could be returned to the distillation flask. With sufficient reflux, the composition of the condensate corresponded to the equilibrium composition of the vapor phase.

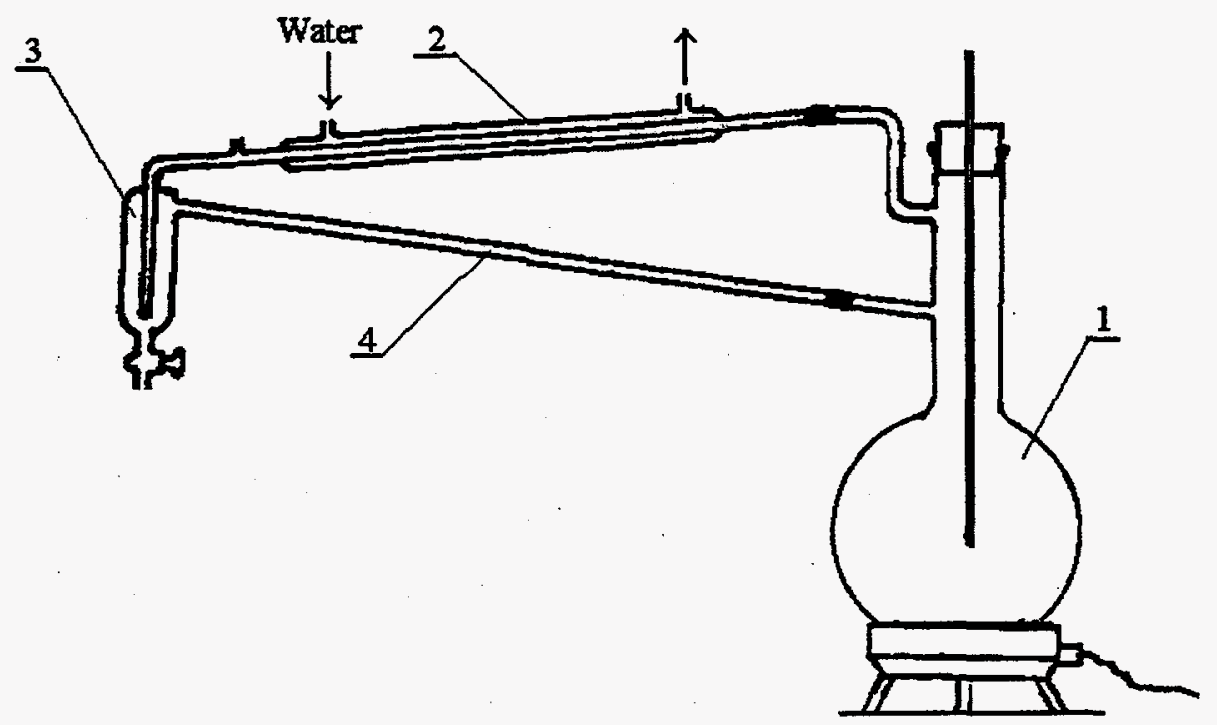

Figure 6.1. Apparatus to Study the Influence of Sulfate on Gas Phase Composition in Distillation of Acetic Acid: (1) Distillation Flask [1L], (2) Water-Cooled Condenser, (3) Condensate Collector, (4) Condensate Overflow Return 
All experiments began with solutions containing sodium nitrate at $600 \mathrm{~g} / \mathrm{L}$ and nitric acid at $10 \mathrm{~g} / \mathrm{L}$. The effect of sodium sulfate at conceritrations up to $50 \mathrm{~g} / \mathrm{L}$ on the ratio of nitric acid in the condensate and solution $\left(\mathrm{C}_{4} / \mathrm{C}_{3}\right)$ was investigated. The results are shown in Figure 6.2. It was found that at 25 to $30 \mathrm{~g} / \mathrm{L}$ sodium sulfate concentration, nitric acid volatility decreased almost 10 -fold.

Further experiments investigated the influence of sodium sulfate on acetic acid volatility (i.e., the ratio of acetic acid concentrations in vapor and liquid phases, $C_{2} / C_{1}$ ). The $C_{2} / C_{1}$ ratio as a function of sodium sulfate concentration at different temperatures, shown in Figure 6.3, depended little on sodium sulfate concentration; that is, sodium sulfate had negligible effect on acetic acid distillation (volatility).

In summary, the presence of sodium sulfate in acetic acid distillation did not affect acetic acid yield but improved acetic acid purity by decreasing the volatility of nitric acid.

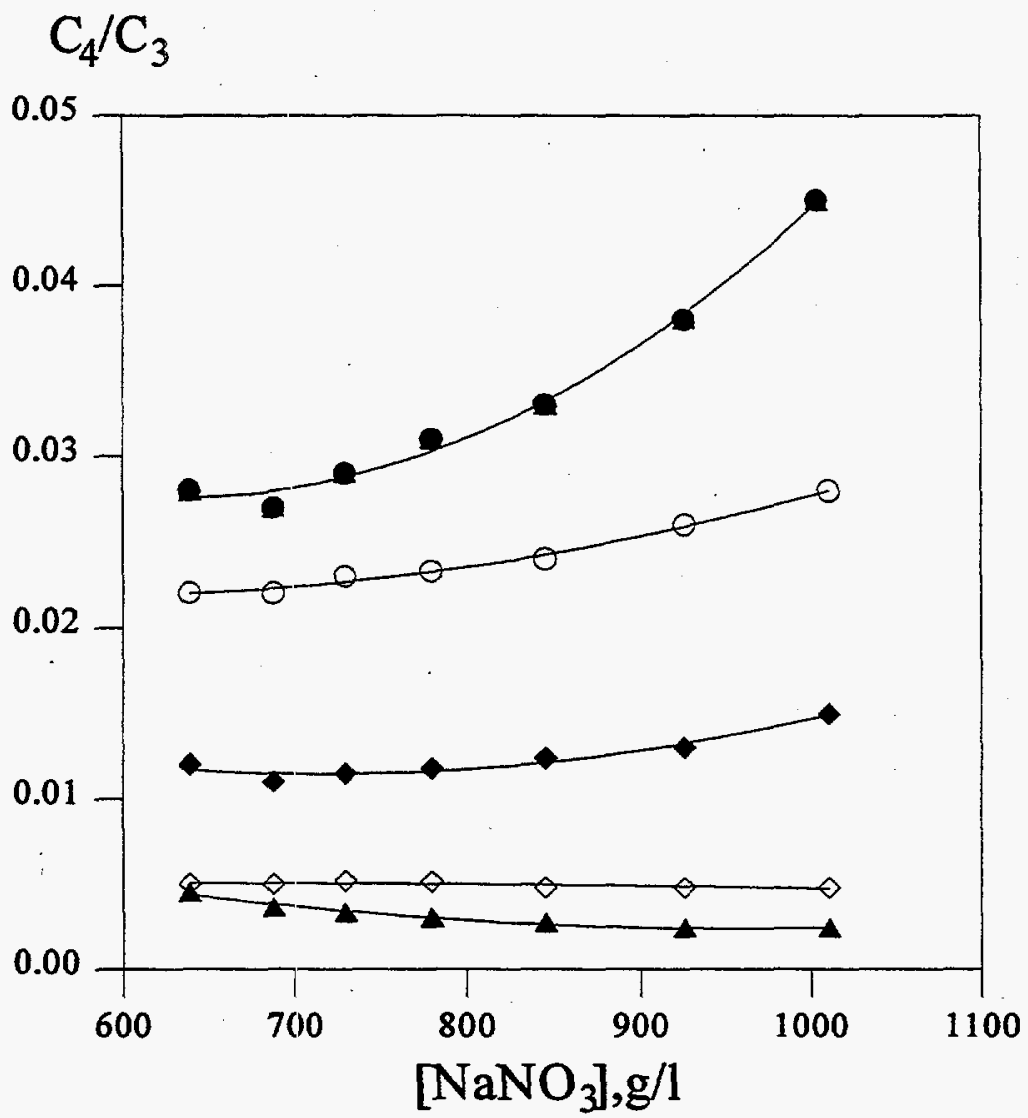

Figure 6.2. Nitric Acid Concentration Ratio in the Condensate and Solution $\left(C_{4} / C_{3}\right)$ as a Function of Sodium Nitrate Concentration at Various Sodium Sulfate Concentrations (from top in $\mathrm{g} \mathrm{Na}_{2} \mathrm{SO}_{4} / \mathrm{L}: 1-0,2-11,3-20,4-30,5-50$ ) 


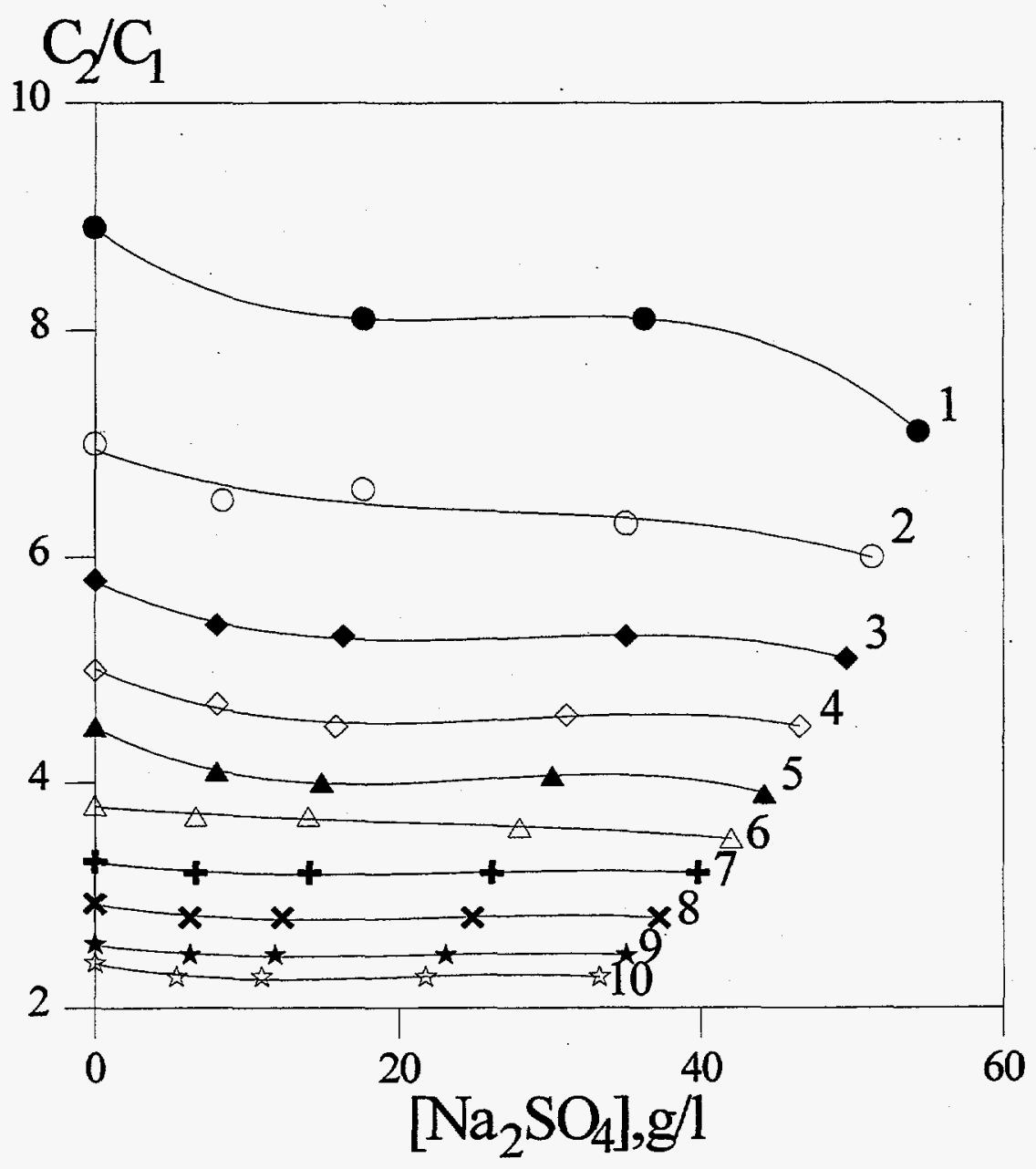

Figure 6.3. Acetic Acid Concentration Ratio in the Condensate and Solution $\left(\mathrm{C}_{2} / \mathrm{C}_{1}\right)$ as a Function of Sodium Sulfate Concentration at Various Distillation Temperatures in ${ }^{\circ} \mathrm{C}: 1-118$, $2-117,3-116,4-115,5-114,6-113,7-112,8-111,9-110,10-109$

\subsection{Behavior of Sodium Sulfate in Sodium Nitrate Crystallization}

The solubility of sodium sulfate was determined in sodium nitrate solutions at 20 to $120^{\circ} \mathrm{C}$. The dependence of sodium sulfate solubility on sodium nitrate concentration at $40^{\circ} \mathrm{C}$ is shown in Figure 6.4. Data on sodium sulfate solubility in saturated sodium nitrate solutions are presented in Table 6.1. In saturated sodium nitrate solutions, sodium sulfate solubility decreased with increasing temperature. In a separate experiment, a solution containing sodium nitrate $(625 \mathrm{~g} / \mathrm{L})$ and sodium sulfate $(30 \mathrm{~g} / \mathrm{L})$ was evaporated to $1000 \mathrm{~g} / \mathrm{L}$ sodium nitrate concentration and cooled to $20^{\circ} \mathrm{C}$. Concentrations of sodium nitrate and sulfate in the mother solution were 617 and $44.3 \mathrm{~g} / \mathrm{L}$, respectively, and corresponded well with the data given in Table 6.1. Sodium sulfate diminished the solubility of sodium nitrate to a small extent. 


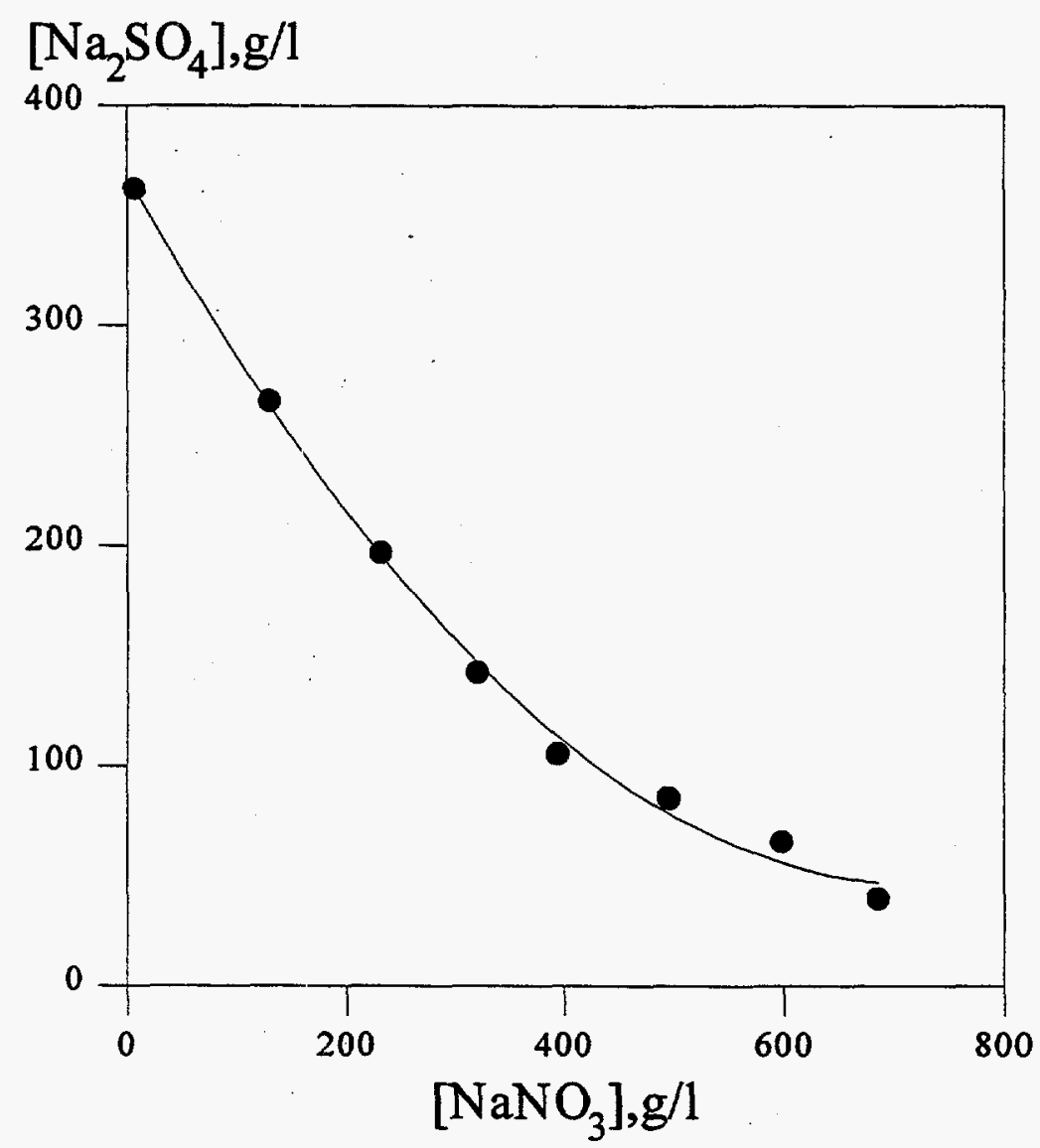

Figure 6.4. Dependence of Sodium Sulfate Solubility on Sodium Nitrate Concentration at $40^{\circ} \mathrm{C}$

Table 6.1. Sodium Sulfate Solubility in Saturated Sodium Nitrate Solutions

\begin{tabular}{||c|c|c|c|c|c||}
\hline \multirow{2}{*}{ Temperature, ${ }^{\circ} \mathrm{C}$} & $\begin{array}{r}\left.\mathrm{NaNO}_{3}\right] \text { in Saturated } \\
\text { Solution }\end{array}$ & \multicolumn{4}{|c|}{$\mathrm{Na}_{2} \mathrm{SO}_{4}$ Solubility Concentration, $\mathrm{g} / \mathrm{L}$} \\
\cline { 2 - 6 } & $\mathrm{g} / \mathrm{L}$ & $\mathrm{Wt} \%$ & At Heating & At Cooling & Mean Value \\
\hline 20 & 613 & 44.6 & 46.9 & 46.6 & 46.8 \\
\hline 40 & 713 & 46.8 & 39.2 & 38.4 & 38.8 \\
\hline 60 & 800 & 51.3 & 33.2 & 33.6 & 33.4 \\
\hline 80 & 883 & 58.0 & 27.5 & 27.4 & 27.5 \\
\hline 100 & 962 & 60.0 & 23.6 & 24.6 & 24.1 \\
\hline 120 & 1150 & -- & 15.9 & 16.0 & 16.0 \\
\hline
\end{tabular}


The influence of sodium sulfate on $985 \mathrm{~g} / \mathrm{L}$ sodium nitrate solution boiling point was investigated (Table 6.2). Because the solution boiling point increased only slightly with increasing sodium sulfate concentration, adaptations of the process conditions were unnecessary.

Based on the solubility studies, sodium sulfate concentrations in cyclic process solutions were found to be solubility limited to tolerably low levels in saturated sodium nitrate solutions. Sodium sulfate solubility decreased with temperature $\left(46.8 \mathrm{~g} / \mathrm{L}\right.$ at $20^{\circ} \mathrm{C} ; 24.1 \mathrm{~g} / \mathrm{L}$ at $100^{\circ} \mathrm{C} ; 16.0 \mathrm{~g} / \mathrm{L}$ at $\left.120^{\circ} \mathrm{C}\right)$ in saturated sodium nitrate solution.

Table 6.2. Influence of Sodium Sulfate on the Boiling Point of $985 \mathrm{~g} / \mathrm{L}$ Sodium Nitrate Solution

\begin{tabular}{|c|c|}
\hline$\left[\mathrm{Na}_{2} \mathrm{SO}_{4}\right], \mathrm{g} / \mathrm{L}$ & Boiling Point, ${ }^{\circ} \mathrm{C}$ \\
\hline 0 & 116.1 \\
\hline 5.0 & 116.2 \\
\hline 10.0 & 116.4 \\
\hline 20.0 & 116.6 \\
\hline 30.0 & 116.7 \\
\hline 40.0 & 116.9 \\
\hline 43.2 & 117.0 \\
\hline
\end{tabular}

\subsection{Influence of Sodium Sulfate on ${ }^{106} \mathrm{Ru}$ Behavior}

During acetic acid distillation and in the presence of nitric acid (1 to $4 \mathrm{~g} / \mathrm{L})$ and potassium dichromate $(5 \mathrm{~g} / \mathrm{L})$, it has been shown that the poorly adsorbed form of ruthenium is oxidized and converted to a welladsorbed form (see Section 5.1). The oxidized, well-adsorbed ruthenium then coprecipitates readily on chromium hydroxide and other solid phases. In the absence of dichromate, the remaining mixed acetic/ nitric acids were found to be much less oxidizing. The oxidizing power increased, however, with increasing nitric acid concentration.

Because sulfate removal from industrial solutions was difficult, the effect of sodium sulfate on oxidation of poorly adsorbed ruthenium was studied under distillation conditions. It was found that sodium sulfate, in concentrations equivalent to those of nitric acid, had no influence on ruthenium oxidation. However, without nitric acid acidification and subsequent acetic acid distillation, $50.4 \%$ of the ${ }^{106} \mathrm{Ru}$ remained in solution as the poorly adsorbed form. 


\subsection{Materials of Construction for Acetic Acid Evaporators in the Presence of Sulfate and Chloride}

Types of steel suitable for acetic acid evaporators were identified. The influence of sulfate and chloride on candidate metals' corrosion was determined. High-temperature alloyed stainless steels were found suitable in this environment. 


\subsection{Isolation of Sodium Acetate and Nitrate Salts by Separate Crystallization from Solutions Depleted in Sodium Acetate}

Changes in waste-generating process operations produced solutions with higher proportions of sodium nitrate. Because of the changes, it was necessary to investigate in detail the isolation of salts from such solutions to determine the effects on process parameters. Research was performed with solution of the composition: sodium nitrate ( $9 \mathrm{wt} \%)$, potassium nitrate $(0.2 \%)$, sodium acetate $(5.8 \%)$, sodium hydroxide $(0.1 \%)$, and water $(84.9 \%)$. Traces of barium chromate, sodium carbonate, and sodium chloride also were present in this $\mathrm{pH}-10.4$ solution.

Based on the $\mathrm{CH}_{3} \mathrm{COONa}-\mathrm{NaNO}_{3}-\mathrm{H}_{2} \mathrm{O}$ phase diagram (Figure 7.1) and the waste composition, the conceptual flowsheet presented in Figure 7.2 for acetate-nitrate solutions with $\alpha$ (sodium acetate/sodium nitrate weight ratio) of 0.65 was designed.

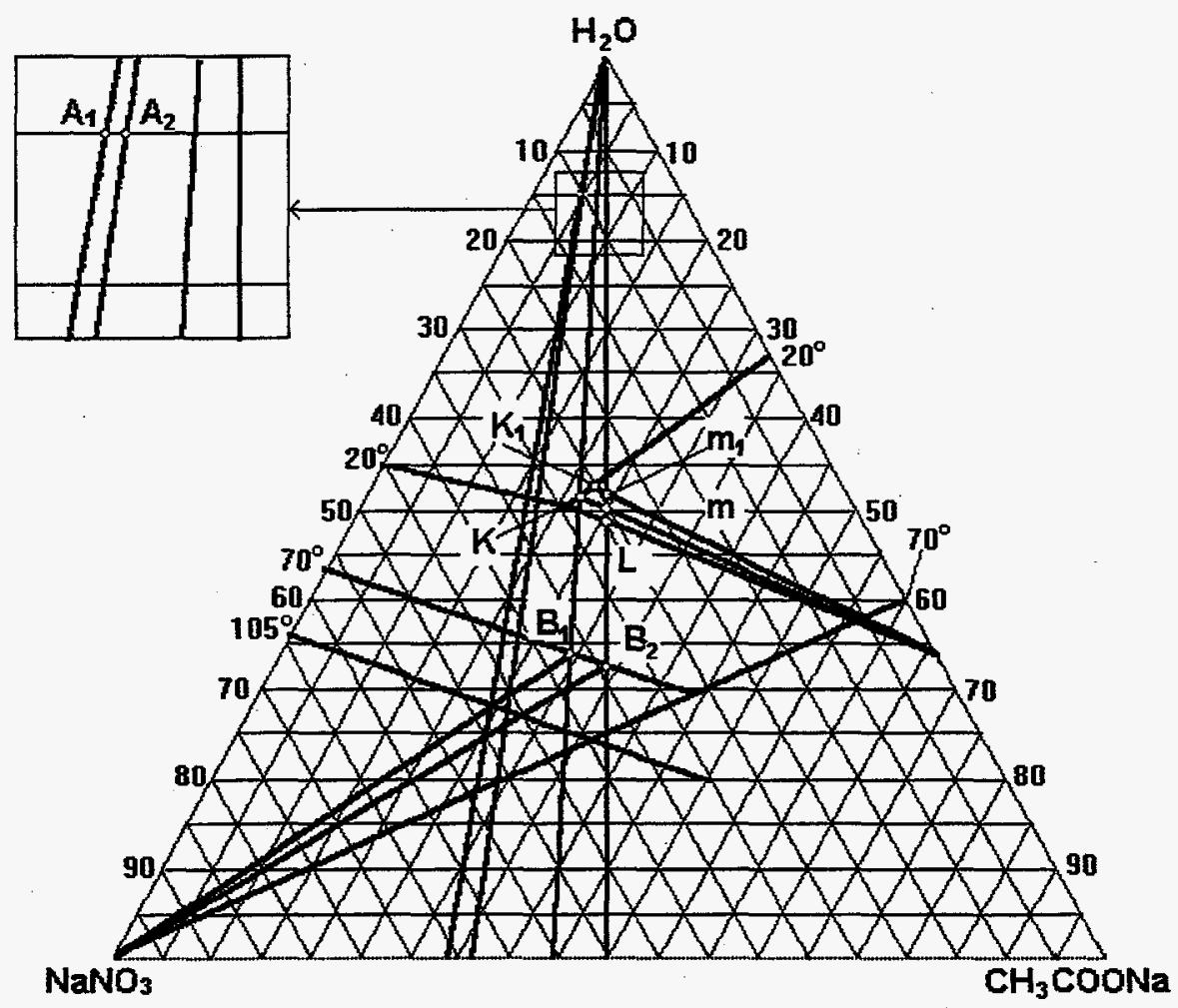

Figure 7.1. Phase Diagram of System $\mathrm{CH}_{3} \mathrm{COONa}-\mathrm{NaNO}_{3}-\mathrm{H}_{2} \mathrm{O}$ (weight basis) and Dilution Rays 


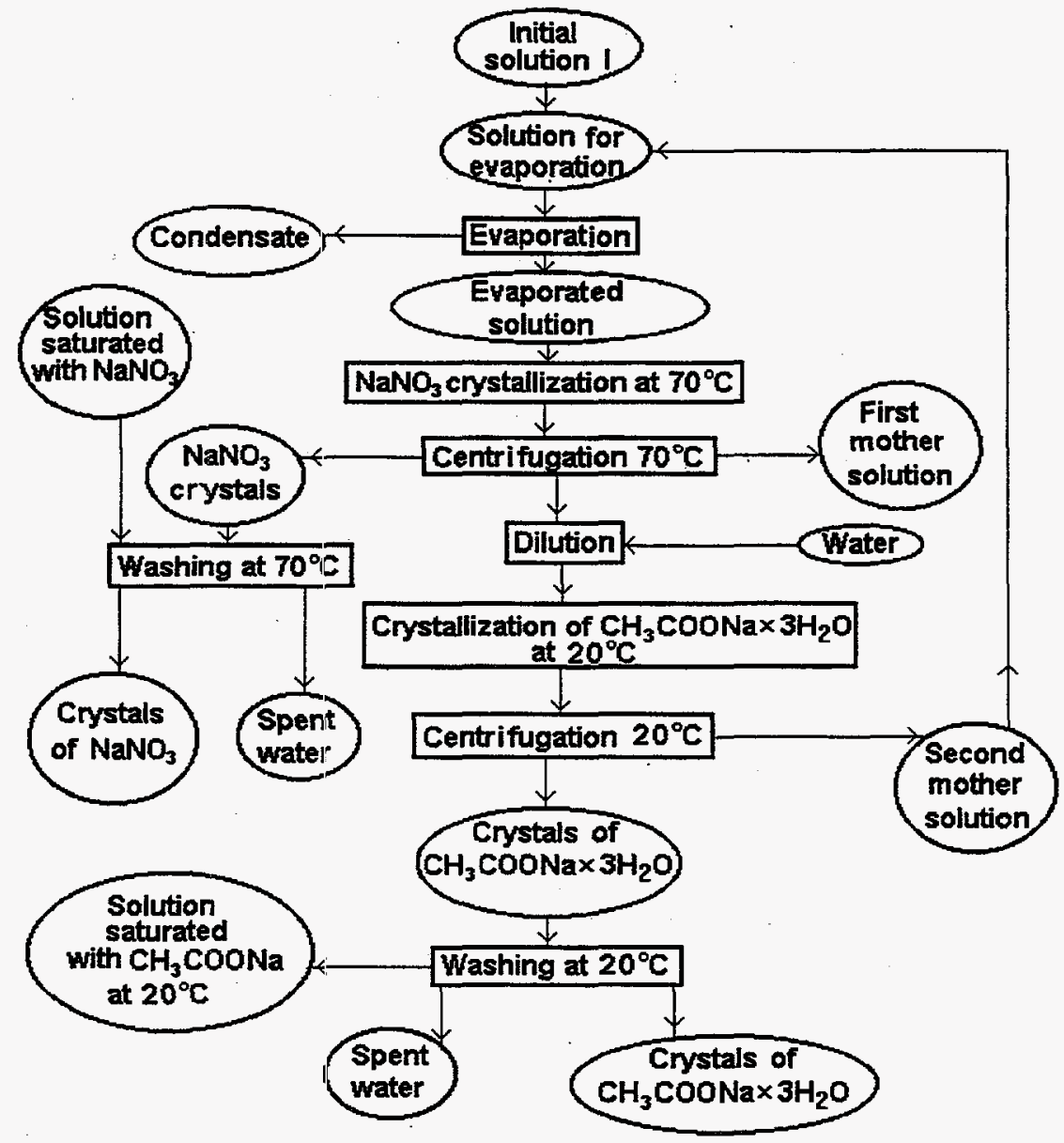

Figure 7.2. Conceptual Flowsheet for Processing Acetate-Nitrate Solutions with $\alpha$ of 0.65

The solution was evaporated to a boiling point of $128^{\circ} \mathrm{C}$ and cooled to $105^{\circ} \mathrm{C}$ to begin sodium nitrate crystallization. Further cooling and sodium nitrate crystallization continued to $70^{\circ} \mathrm{C}$. The mother solution from crystallization then was diluted with water (in an amount calculated according to the phase diagram) for subsequent crystallization of sodium acetate at $20^{\circ} \mathrm{C}$. The mother solution from the sodium acetate crystallization was mixed with the initial feed solution to conduct the next crystallization cycle.

Evaporation and crystallization were conducted in glass equipment. Crystals were separated from solution in a vertical filtering batch centrifuge with a drum rotation rate of $63.3 \mathrm{~Hz}(3800 \mathrm{rpm})$. The filter drum was unloaded manually. The dependence of solution boiling point and sodium nitrate crystallization temperature on the water concentration is shown in Figure 7.3. The amount of water added to the mother solutions in each cycle was calculated based on the theoretical process material balance. 


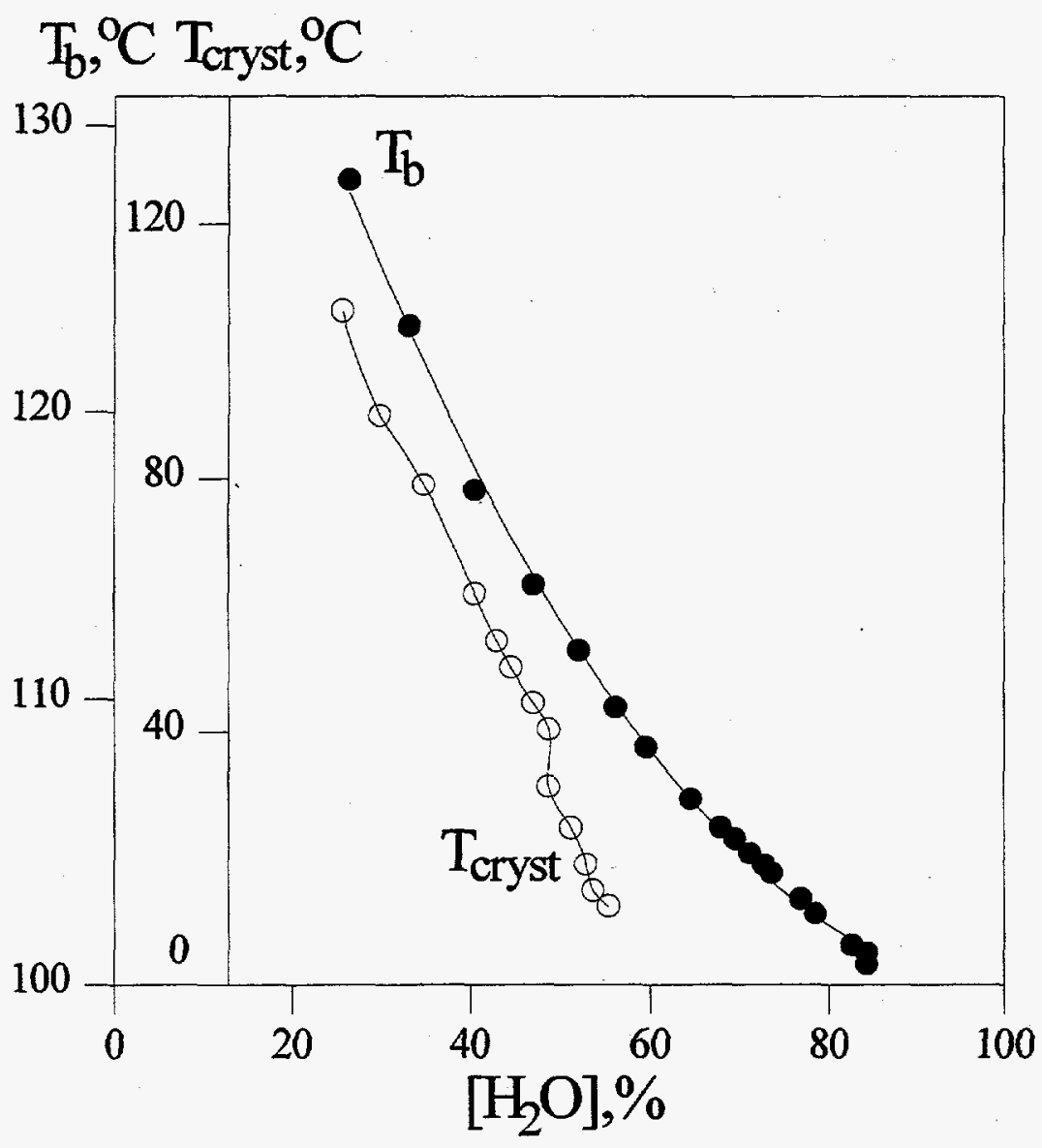

Figure 7.3. Dependence of Boiling Point $T_{b}$ and Sodium Nitrate Crystallization Temperature $T_{\text {cryst }}$ on Water Concentration

Five salt crystallization cycles were conducted. Salts of sufficient purity were obtained by these single fractional crystallizations with each salt slightly contaminated with vestiges of the other. Sodium acetate concentration in sodium nitrate crystals was not more than 1.5 to $2 \%$. Sodium nitrate in sodium acetate was, on the average, $1.2 \%$. However, unwashed crystals containing interstitial saturated mother solution were contaminated with about $6 \%$ impurity of the second salt.

The most important parameters influencing the yield and purity of salts were the weight ratio, $\alpha$, of sodium acetate to sodium nitrate in the initial solution; the boiling point of the evaporated solution; and the amount of water dilution of the first mother solution.

Analysis of the process by means of the phase diagram (Figure 7.1) has shown that selective crystallization according to the process flowsheet given in Figure 7.2 was possible only if the ratio $\alpha$ was not less than 0.6. Selective crystallization from solution with an $\alpha$ of 0.5 , for example, was impossible. The feed solution with a ratio of 0.5 corresponds to point $A_{1}$ (Figure 7.1). Concentration of the feed solution and crystallization of sodium nitrate produces a mother solution with composition $B_{1}$. Crystallization of 
sodium acetate by water dilution and cooling of the mother solution $B_{1}$ is impossible because the cooled diluted mother solution composition is near the eutectic point. The process can be achieved at $\alpha$ values greater than 0.65 . Higher $\alpha$ values increased the sodium nitrate yield by $2 \%$ and increased the sodium acetate yield by $14 \%$.

The temperature to begin sodium nitrate crystallization of evaporated solution with $\alpha$ of 0.65 was $105^{\circ} \mathrm{C}$. The corresponding solution boiling point was $128^{\circ} \mathrm{C}$ and was equivalent to a concentration factor of about 4. Salt yields increased with further increases in evaporative concentration, but the respective temperatures of incipient crystallization and boiling approached one another. For process operation reasons, this temperature difference should be at least $20^{\circ} \mathrm{C}$.

Crystallization of sodium nitrate can be conducted at 60 to $80^{\circ} \mathrm{C}$. However, as shown in the phase diagram, the sodium nitrate yield at an $80^{\circ} \mathrm{C}$ crystallization temperature can decrease by $14 \%$. Sodium nitrate crystallization at $60^{\circ} \mathrm{C}$ is hampered by increased contamination with sodium acetate. At and below this temperature, anhydrous sodium acetate converts to the less soluble hydrated form.

Water dilution of the mother solution remaining after sodium nitrate crystallization was performed along the line $\mathrm{B}_{2} \mathrm{~L}$ (phase diagram, Figure 7.1). To guarantee sodium acetate crystal purity, the dilution was continued to point $\mathrm{m}$, located above point $\mathrm{L}$. At this dilution, the sodium acetate yield was determined by the segment mk (32.2\%) originating at the $\mathrm{CH}_{3} \mathrm{COONa} \cdot 3 \mathrm{H}_{2} \mathrm{O}$ crystal composition. In the same way, dilution to point $m_{1}$ would produce a yield determined by segment $m_{1} k_{1}(27.4 \%)$. Thus a decrease in sodium acetate concentration at crystallization resulted in diminished salt yields.

Salt yields from cycle to cycle continuously increased and corresponded well with theoretical data in most cases (Table 7.1). The observed deviations could be ascribed to temperature variations in the centrifuge.

Based on these studies, selective sodium acetate and nitrate crystallizations were possible from initial solution with $\alpha$ of 0.65 if sodium nitrate crystallization preceded that of sodium acetate.

Table 7.1. Comparison of Theoretical and Experimental Yields of Salts

\begin{tabular}{||c|c|c|c|c||}
\hline \multirow{2}{*}{$\begin{array}{c}\text { Cycle } \\
\text { Number }\end{array}$} & \multicolumn{2}{|c|}{ Sodium Nitrate Yield, \% } & \multicolumn{2}{c|}{ Sodium Acetate Yield, \% } \\
\cline { 2 - 5 } & Experimental & Theoretical & Experimental & Theoretical \\
\hline 1 & 53.9 & 42.2 & 23.5 & 37.9 \\
\hline 2 & 45.7 & 45.8 & 29.2 & 43.6 \\
\hline 3 & 41.3 & 46.2 & 36.7 & 44.1 \\
\hline 4 & 44.1 & 47.2 & 30.1 & 45.0 \\
\hline 5 & 42.0 & 45.2 & 35.3 & 44.4 \\
\hline
\end{tabular}




\subsection{Processing of Genuine Industrial Solutions}

Further changes in irradiated nuclear fuel processing technology led to corresponding changes in liquid radioactive waste composition. Materials capable of forming chemical complexes with radionuclides appeared in the wastes and the initial solutions' radioactivities increased. Because of these changes, studies of the influence of the new parameters on salt purification were required.

\subsection{Description of Solutions}

The compositions of two types of industrial solution are shown in Tables 8.1 and 8.2. As shown in Table 8.1, component concentrations changed with storage. Long-term solution storage allowed radioactive precipitates containing most of the zirconium, strontium, and rare earth element radioactivity to settle. Storage also strongly decreased ${ }^{106} \mathrm{Ru}$ activity because of radioactive decay. For example, a 13.3-fold decrease in ruthenium $\gamma$-activity and 7.5-fold decrease of $\beta$-activity occurred after 200 days of storage.

Table 8.1. Chemical and Radiochemical Composition of Industrial Solution I

\begin{tabular}{|c|c|c|c|c|c|c|c|c|}
\hline \multirow[b]{2}{*}{ Component } & \multirow{2}{*}{$\begin{array}{c}\text { Measurement } \\
\text { Unit }\end{array}$} & \multicolumn{7}{|c|}{ Concentration } \\
\hline & & Fresh & Tank 1 & Tank 2 & Tank 3 & Tank 4 & Tank 5 & Tank 6 \\
\hline $\mathrm{NaNO}_{3}$ & $\mathrm{~g} / \mathrm{L}$ & 67.7 & 103 & 116 & 143.6 & 101 & 96.6 & 94.5 \\
\hline $\mathrm{CH}_{3} \mathrm{COONa}$ & $g / L$ & 113.1 & 78.9 & 47.7 & 73.2 & 80.4 & 91.3 & 83.6 \\
\hline $\mathrm{Cr}(\mathrm{VI})$ & $g / L$ & $0.2-0.3$ & 0.15 & 0.2 & 0.19 & $<0.02$ & 0.19 & 0.15 \\
\hline $\mathrm{NaOH}$ & $g / L$ & 10.1 & 5.9 & 4.8 & 6.4 & 7.5 & 4.4 & 5.4 \\
\hline $\mathrm{SiO}_{2}$ & $\mathrm{~g} / \mathrm{L}$ & 0.02 & 0.02 & 0.3 & 0.012 & 0.014 & 0.016 & 0.025 \\
\hline Al(III) & $g / L$ & - & 0.01 & - & 0.025 & 0.015 & 0.02 & 0.01 \\
\hline $\begin{array}{l}\text { Reductants } \\
\text { (based on } \mathrm{NO}_{2}^{-} \text {) }\end{array}$ & $\mathrm{g} / \mathrm{L}$ & $0.5-0.64$ & - & 0.64 & 0.78 & 0.92 & 0.69 & \\
\hline Total activity & $\mathrm{mCi} / \mathrm{L}$ & $627-2130$ & 39 & 55 & 77 & 109 & 514 & 161 \\
\hline Ruthenium & $\mathrm{mCi} / \mathrm{L}$ & $589-2060$ & 7.3 & 31 & 33 & 68 & 462 & 127 \\
\hline Cesium & $\mathrm{mCi} / \mathrm{L}$ & $32-63$ & 32 & 24 & 44 & 41 & 51 & 34 \\
\hline $\begin{array}{l}\text { Zirconium and } \\
\text { Niobium }\end{array}$ & $\mathrm{mCi} / \mathrm{L}$ & $5.9-12$ & 0.3 & - & - & 0.5 & 1.4 & 0.5 \\
\hline Strontium & $\mathrm{mCi} / \mathrm{L}$ & -- & -- & 0.1 & 0.6 & 0.6 & -- & - \\
\hline
\end{tabular}


Table 8.2. Chemical and Radiochemical Composition of Industrial Solution II

\begin{tabular}{||l|c|c||}
\hline \multicolumn{1}{|c|}{ Component } & $\begin{array}{c}\text { Measurement } \\
\text { Unit }\end{array}$ & Amount \\
\hline $\mathrm{NaNO}_{3}$ & $\mathrm{~g} / \mathrm{L}$ & 151.1 \\
\hline $\mathrm{CH}_{3} \mathrm{COONa}$ & $\mathrm{g} / \mathrm{L}$ & 43.8 \\
\hline $\mathrm{NaOH}$ & $\mathrm{g} / \mathrm{L}$ & 11.5 \\
\hline $\mathrm{SiO}_{2}$ & $\mathrm{~g} / \mathrm{L}$ & 0.029 \\
\hline Total $\gamma$-activity & $\mathrm{mCi} / \mathrm{L}$ & 10.4 \\
\hline Ruthenium & $\mathrm{mCi} / \mathrm{L}$ & 9.06 \\
\hline Cesium & $\mathrm{mCi} / \mathrm{L}$ & 0.47 \\
\hline Zirconium and niobium & $\mathrm{mCi} / \mathrm{L}$ & 0.14 \\
\hline
\end{tabular}

\subsection{Steps in Cyclic Processing and Removal of Impurities}

Cyclic processing included four main stages: alkaline calcium precipitation, evaporation, crystallization, and sorption purification. Sorption purification of sodium nitrate solutions imposed special requirements on the preceding radiochemical decontamination stages. Among the purposes of the initial three stages was removal of impurities that clisturbed the sorption column operations. Therefore, evaluation of the purification efficiencies, with respect to the individual organic and inorganic impurities, was required.

The concentrations of solid phase impurities, such as heavy metal precipitates remaining in the decantate after alkaline precipitation, were established by their solubilities and by the efficiencies of solid/liquid phase separations. Most of the solid phase impurities could be removed by settling (including centrifugation) and filtration.

Soluble impurities such as sodium chloride were not removed by any purification method and accumulated in the recycle solutions. In this ciase, the concentration of the impurity in the product depended on the amount of impurity retained with the product salts' interstitial liquid. Some of the interstitial impurities could be removed by salt washing. At process equilibrium, the amount of impurity entering a purification cycle must equal the amount removed. For a soluble impurity in an equilibrium cycle, the concentration of impurity held interstitially in the product salt increased by the same factor that the solution volume decreased.

Besides settling, filtration, and salt washing, other mechanisms exist to remove impurities. For example, some organic impurities were removed with water by evaporative stripping. Other impurities were destroyed and removed by oxidation. However, impurities whose concentrations exceeded their solubility limits during crystallization of sodium nitrate were retained with the sodium nitrate product. 
The efficiencies of sorption purifications from various radionuclides were determined by the respective sorbent/solution distribution factors. Sorption column operation depended on the purity of nitrate solutions. Complexing agents and competing ions (for example, calcium in the purification from strontium) decreased the efficiency of sorption and could cause complete loss of sorbent properties.

Because of the deleterious effects of bulk chemical impurities on sorption, their removal was the goal of the first three stages of solution processing (alkaline precipitation, concentration, crystallization). In contrast to cyclic processing of acetate-rich solutions, radiochemical decontamination was only a secondary goal of the initial three steps. As a result, the precipitation stages developed for acetate-rich wastes could be simplified by eliminating the second ruthenium/cesium precipitation step and by conducting only one alkaline calcium precipitation for chemical impurities.

\subsection{Crystallization Purification Factors}

Chromium and nickel hydroxide precipitations at $\mathrm{pH}$ greater than 10 were conducted for genuine waste solutions followed by precipitations of iron hydroxide and nickel potassium ferrocyanide at $\mathrm{pH} 7$ to 9. Purification factors for fresh and stored solutions (whose compositions are given in Table 8.1) are shown in Table 8.3.

The low purification factor for ruthenium was attributed to the formation of poorly adsorbed stable complex compounds with products of acetate and nitrate radiolysis; the well-adsorbed complex was ruthenium nitrosoacetate. To decompose the poorly adsorbed ruthenium, it was proposed to increase the nitric acid concentration used in acetic acid distillation. To increase the purification factor from cesium, the $\mathrm{pH}$ had to be maintained below 9 during ferrocyanide precipitation.

\subsection{Evaporation and Crystallization of Sodium Nitrate}

The influences of evaporation temperature and the presence of surfactants on crystal size were studied for sodium nitrate crystallization. Increasing evaporation temperature from 117 to $121^{\circ} \mathrm{C}$ increased the fraction of small crystals $(0.1$ to $0.25 \mathrm{~mm})$ from 14 to $76 \%$. Small concentrations of surfactants (for example, polyacrylamide up to $6 \mathrm{mg}$ per $\mathrm{kg}$ salt) had no noticeable effect on sodium nitrate crystal size. Increasing surfactant concentration, however, increased the proportion of both the small and large fractions.

Table 8.3. Purification Factors for Fresh and Stored Solution I after Two Precipitations

\begin{tabular}{||l|c|c|c|c|}
\hline \multirow{2}{*}{ Solution } & \multirow{2}{*}{$\begin{array}{c}\text { Initial } \gamma \text {-Activity, } \\
\mathrm{mCi} / \mathrm{L}\end{array}$} & \multicolumn{3}{|c|}{ Purification Factor for } \\
\cline { 3 - 5 } & ${ }^{106} \mathrm{Ru}$ & ${ }^{137} \mathrm{Cs}$ & Total \\
\hline Fresh & $625-2140$ & 5.4 & 12.2 & 5.7 \\
\hline Stored & $60-100$ & 2.5 & 15 & 4.3 \\
\hline
\end{tabular}


A mean decontamination factor of 21 was achieved in sodium nitrate crystallization from industrial solutions. Careful washing of the salt crystals and filtration of the salt solutions increased the purification factor. Despite these steps, solid phase impurities still could contaminate the sodium nitrate product. Solids not removed in prior steps were captured during the crystallization of sodium nitrate. Operational upsets also introduced solid process-origin impurities to the product salt.

In the first case, the solid impurities (primarily silicon, magnesium, and aluminum) could be separated by careful crystallization of sodium nitrate. To attain high product purity, it was necessary to remove these impurities by filtering the salt solution.

Process origin impurities could appear during the evaporation of nitrate solution after precipitation of nickel potassium ferrocyanide, if the solution had insufficient acid concentrations to destroy the ferrocyanide. In this case, the excess nickel potassium ferrocyanide was not decomposed but was incorporated with the accompanying ${ }^{137} \mathrm{Cs}$ in the crystallizing salt.

During cyclic evaporation and crystallization, solid radioactive contaminants carried by the solution or formed by evaporation were trapped in the salt during centrifugation. In this case, the salt layers acted as dense filters, trapping both large and finely dispersed impurities. These solid impurities could not be removed by simple salt washing. To overcome this disadvantage, the salt was washed by a spray jet pressurized to 1.5 atmospheres. Washing decreased the salt's radioactivity 2 - to 5-fold, while filtration decreased the radioactivity 2 - to 3 -fold. 


\subsection{Behavior of Chemical Components at Various Stages in Cyclic Processing of Intermediate-Level Radioactive Wastes}

Intermediate-level radioactive wastes contain a variety of chemical components that can be present over a wide range of concentrations. Because of this, the technology of intermediate-level waste treatment must be flexible and not depend strongly on changes in concentrations of individual components. The effects of the chemical components and their concentrations on waste processing were studied over the concentration ranges anticipated in process operations.

\subsection{Waste Compositions}

Table 9.1 shows the average daily amounts of salts and chemical components discharged as intermediate-level radioactive waste solution. The intermediate-level waste shown in Table 9.1 was produced as a composite of a number of contributing waste streams each having a range of compositions.

The processes to treat the multicomponent intermediate-level radioactive solutions had to be flexible for a number of reasons. First, the waste contained a large number of salts and organic compounds, many of which are strong complexing agents that could affect radionuclide distribution. Second, the concentrations of the bulk waste components in the mixed intermediate level waste varied widely because of the irregular additions of the contributing waste streams. Third, the wastes had high salt concentrations (particularly sodium nitrate), complicating processes for the removal of radionuclides and preventing, by cost, direct discard of the wastes to solidification and long-term disposal.

\subsection{Techniques Applicable to Purification in Cyclic Sodium Nitrate Processing}

Processing must provide salt purification and concentration of the radionuclides despite the complicated waste composition. However, because of the variable solution composition, it was impossible to obtain constant and high purification factors from radionuclides using only precipitation and crystallization techniques. Sorption purification of salt solutions was used to achieve the additional required purification.

\subsection{Behavior of Chemical Components During Processing of Intermediate- Level Radioactive Waste Solutions}

The behaviors and distributions of the chemical waste components in the processing of intermediatelevel waste solutions were studied. Waste components studied were sodium nitrate, sodium carbonate, oxalate salts, fluoride, sulfate, chloride, calcium, potassium, phosphates, and organic compounds. 
Table 9.1. Daily Salt and Impurity Additions to Intermediate-Level Radioactive Waste Solutions

\begin{tabular}{||l|c|}
\hline \multicolumn{1}{|c|}{ Component or Impurity } & Amount, kg \\
\hline $\mathrm{NaNO}_{3}$ & 1700 \\
\hline $\mathrm{HNO}_{3}$ & 4500 \\
\hline $\mathrm{NaOH}$ & 5100 \\
\hline $\mathrm{Na}_{2} \mathrm{CO}_{3}$ & 2200 \\
\hline $\mathrm{C}_{2} \mathrm{O}_{4}^{2-}$ & 165 \\
\hline $\mathrm{F}$ & 82 \\
\hline Fe(III) & 16 \\
\hline Mn(II) & 56 \\
\hline $\mathrm{H}^{+}$ & 40 \\
\hline Sulfonol & Within solubility limits \\
\hline Hexametaphosphate & Within solubility limits \\
\hline Tributyl phosphate & Within solubility limits \\
\hline Syntine (Fischer-Tropsch reaction & Within solubility limits \\
\hline hydrocarbon) & 1.35 \\
\hline Trihydroxyglutaric acid & 0.4 \\
\hline Lactic acid & 30.0 \\
\hline Thiourea & \\
\hline
\end{tabular}

\subsubsection{Sodium Nitrate}

Features of isolation of sodium nitrate by crystallization in cyclic processes have been described in previous sections. To process intermediate-level radioactive waste solutions, the following key operational parameters were identified:

1. The evaporation temperature should be 120 to $121^{\circ} \mathrm{C}$. At this temperature, an optimum balance is obtained between solution volume reduction (oversaturation) and the temperature of the onset of sodium nitrate crystallization.

2. The solutions must remain at temprerature in the evaporators for 3 to 4 hours. This residence time improves destruction of unstable impurities. 
3. The yield of washed sodium nitrate after crystallization in a steam jet-pumped vacuum crystallizer should be allowed to reach 35 to $40 \%$.

4. The crystals must be washed thoroughly to remove entrained mother solution and improve salt purity.

5. Solid materials in the salt solution severely affect crystal purity. Impurities can be removed by filtering the solution through a pearlite bed.

6. The evaporation must be conducted at sufficient acid concentration. Solid impurities (such as carbonates) increase if sodium nitrate solutions are evaporated in neutral or alkaline media.

Using these methods (crystallization of filtered sodium nitrate solution and thorough washing of the salt crystals in a centrifuge), the purification factor from radionuclides and soluble impurities reaches 120 to 150 .

\subsubsection{Sodium Carbonate}

The presence of sodium carbonate in solutions to be treated was undesirable for three reasons. First, carbonate complicated the removal of fluoride and oxalate because it too formed an insoluble compound with calcium. Second, carbonate formed stable soluble complex compounds with zirconium and niobium and, as a consequence, decreased their removal from solution during alkaline precipitation. Third, under alkaline conditions, sodium carbonate precipitated in the evaporation and crystallization steps and contaminated the sodium nitrate product.

Sodium carbonate solubility in saturated sodium nitrate solution at $20^{\circ} \mathrm{C}$ is $58.0 \mathrm{~g} / \mathrm{L}$. Salts produced from solutions containing sodium carbonate hampered sorption purification of sodium nitrate and decreased the filterability of the sodium nitrate in the process centrifuge, disrupting its output. Because of these effects, removal of sodium carbonate was best performed early in the process when solutions were mixed.

\subsubsection{Oxalate Salts}

Oxalate could be removed from intermediate-level waste solutions by three methods: precipitation as slightly soluble calcium oxalate, oxidative decomposition in nitric acid, and co-crystallization with sodium nitrate from neutral or slightly alkaline media.

The following features were observed from study of the behavior of oxalate during calcium precipitation in alkaline conditions.

1. Increasing alkalinity initially decreased calcium oxalate solubility (see Figure 9.1). However, at sodium hydroxide concentrations over $2 \mathrm{~g} / \mathrm{L}$, the solubility of calcium oxalate abruptly increased (Figure 9.2). 


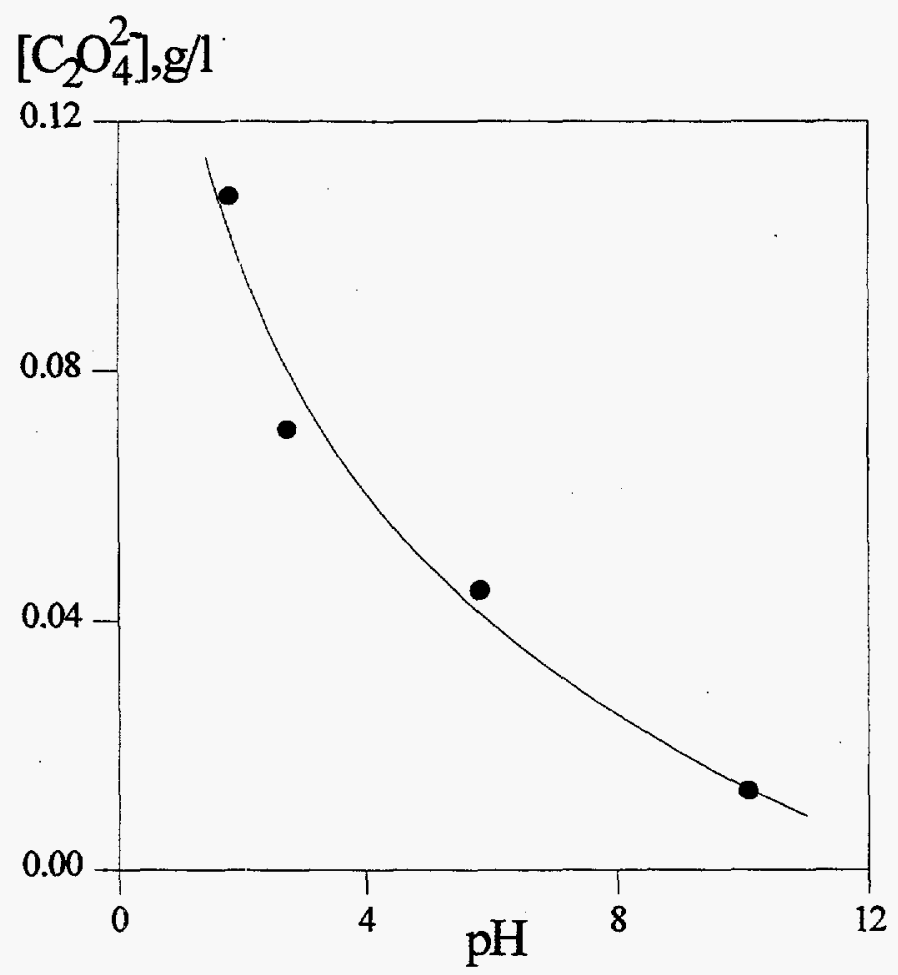

Figure 9.1. Dependence of Calcium Oxalate Precipitation on $\mathrm{pH}$

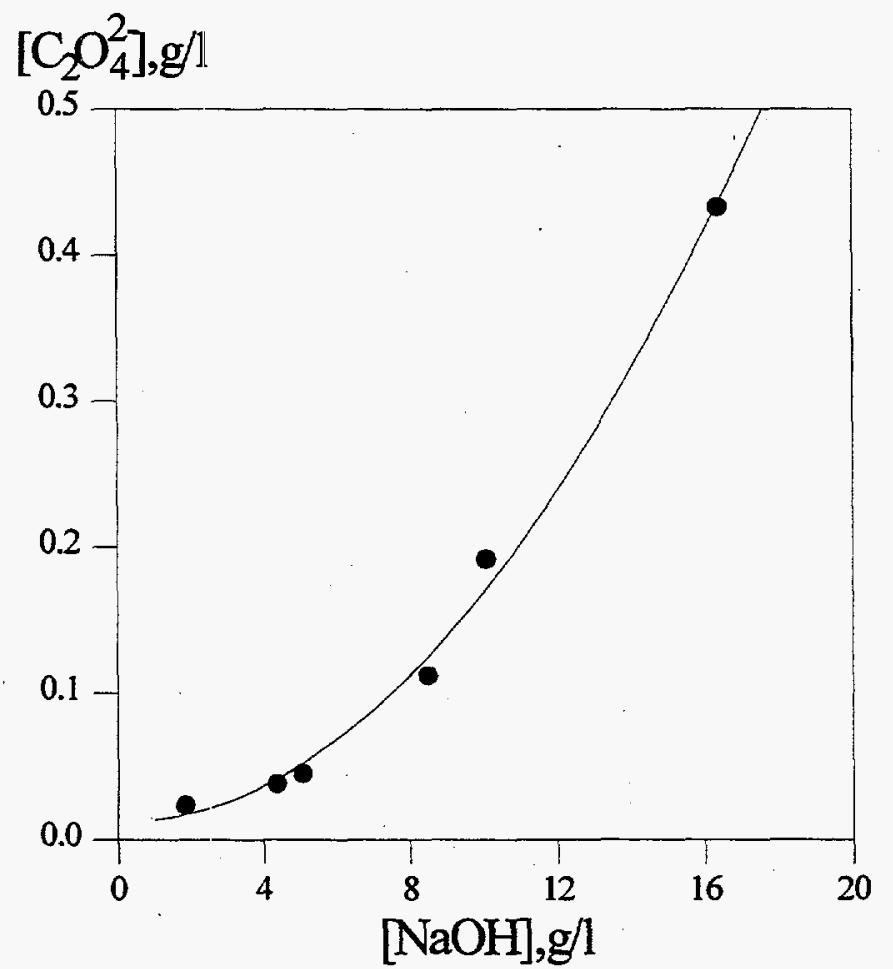

Figure 9.2. Dependence of Calcium Oxalate Precipitation on $\mathrm{NaOH}$ Concentration 
2. A calcium excess of 20 to $50 \%$ over the stoichiometric amount was sufficient to achieve complete oxalate precipitation in the optimal $\mathrm{pH}$ range of 8 to 10 (see Figure 9.3).

Research showed that oxalate could be decomposed by oxidation in hot nitric acid. In tests containing up to $1 \underline{\mathrm{M}}$ nitric acid, the oxidation rate was highest at $0.05 \underline{\mathrm{M}}$ acid. Higher acidity decreased the oxalate decomposition rate.

The oxidation could be accelerated by manganese(II) [Mn(II)] catalyst. The dependence of oxalic acid decomposition on time and $\mathrm{Mn}$ (II) addition is shown in Figure 9.4. To decompose the acid completely, at least 30 minutes were required in the presence of $0.1 \mathrm{~g} / \mathrm{L} \mathrm{Mn}$ (II). In the absence of $\mathrm{Mn}$ (II) but under otherwise similar conditions, total decomposition was achieved only after 8 to 10 hours.

The third method of oxalate removal was crystallization of sodium oxalate with sodium nitrate. This separation could be accomplished only in the complete absence of dissolved calcium. The distribution of sodium oxalate between crystallized salt and mother solution depended both on the oxalate concentration in the evaporated solution and its solubility in the mother solution. The amounts of oxalate removed with the salt and returned to the purification cycle with the mother solution can be calculated based on oxalate concentrations in initial solution and the solubility of sodium oxalate in saturated sodium nitrate solutions. Data on sodium oxalate solubility in saturated sodium nitrate solution are given in Table 9.2.

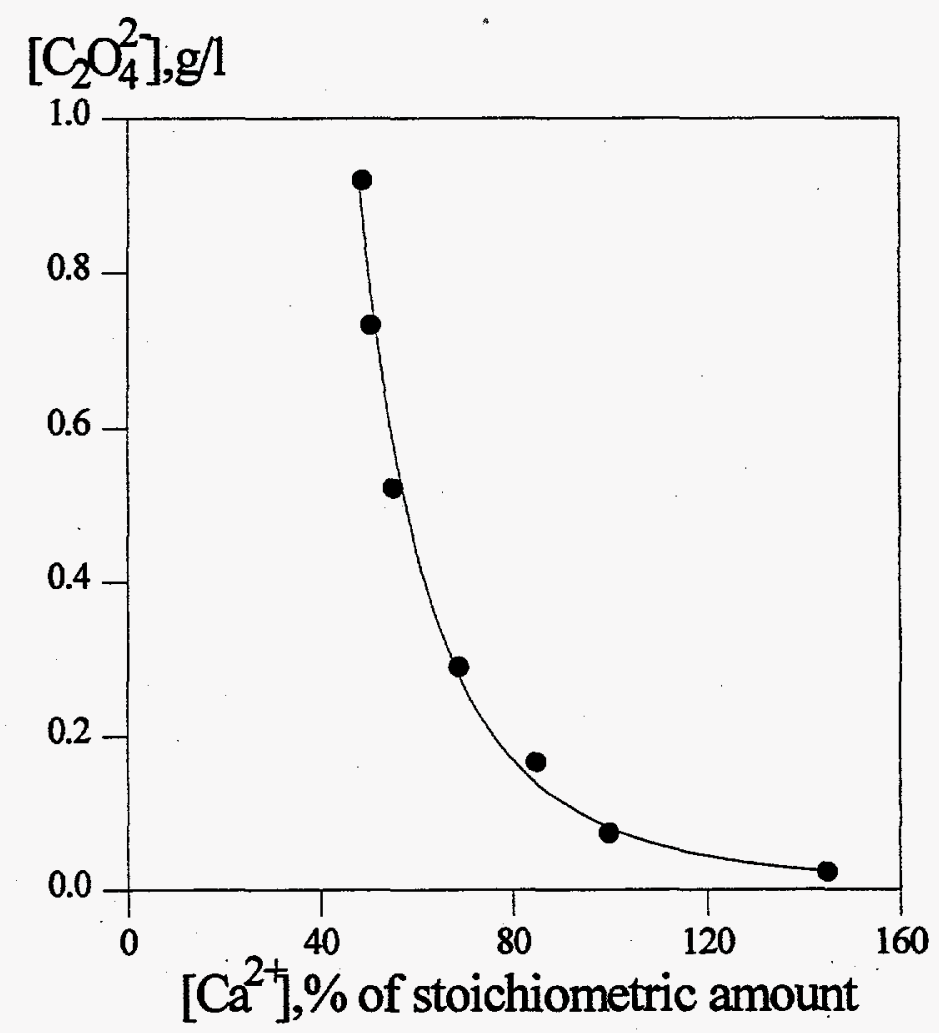

Figure 9.3. Dependence of Calcium Oxalate Precipitation on the Calcium Ion Concentration 


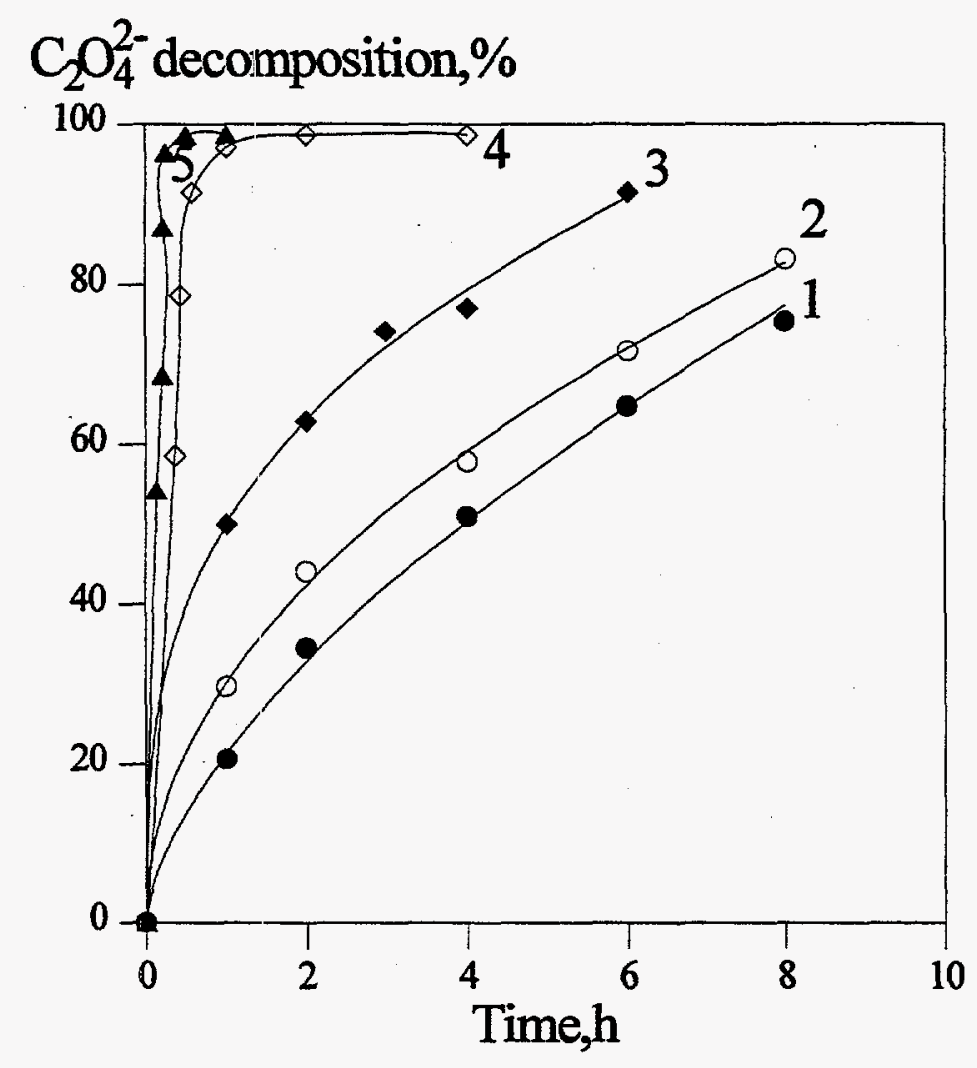

Figure 9.4. Dependence of Oxalic Acid Decomposition on Time at $120^{\circ} \mathrm{C}$, and $0.1 \mathrm{M}$ Nitric Acid at Various Oxalate Concentrations (oxalate, in $\mathrm{g} / \mathrm{L}: 1-0.93,2-3.4,3-4.18,4-2.0$ [solution also contained $\mathrm{Mn}(\mathrm{II})$ at $0.1 \mathrm{~g} / \mathrm{L}$ ], 5-2.0 [solution also contained $\mathrm{Mn}(\mathrm{II})$ at $0.2 \mathrm{~g} / \mathrm{L}$ ])

Table 9.2. Solubility of Sodium Oxalate in Saturated Sodium Nitrate Solutions

\begin{tabular}{|c|c|c|}
\hline $\begin{array}{c}\text { Temperature, } \\
{ }^{\circ} \mathrm{C}\end{array}$ & $\begin{array}{c}\text { Solubility, } \\
\% \text { (by weight } \\
\text { of } \mathrm{C}_{2} \mathrm{O}_{4}{ }^{2-} \text { ) }\end{array}$ & $\begin{array}{c}\text { Calculated } \\
\text { Solubility of } \\
\mathrm{C}_{2} \mathrm{O}_{4}{ }^{2}, \mathrm{~g} / \mathrm{L}\end{array}$ \\
\hline 20 & 0.030 & 0.456 \\
\hline 4.0 & 0.038 & 0.538 \\
\hline 60 & 0.041 & 0.593 \\
\hline 80 & 0.046 & 0.680 \\
\hline 100 & 0.050 & 0.756 \\
\hline 120 & 0.071 & 1.10 \\
\hline
\end{tabular}


The solubility of oxalic acid in acidified sodium nitrate solutions was determined. In the absence of nitric acid, the solubility of oxalate was $0.45 \mathrm{~g} / \mathrm{L}$ at $20^{\circ} \mathrm{C}$. In $0.5 \mathrm{M}$ nitric acid, the solubility of oxalic acid was $35.7 \mathrm{~g} / \mathrm{L}$. Because some oxalate decomposes during evaporation, the residual oxalate entering crystallization might have been entirely in solution.

With alkaline calcium precipitation and complete separation of the solid phase, the residual oxalate concentration in sodium nitrate solution was established by the solubility of calcium oxalate. Calcium oxalate solubility in saturated neutral solutions of sodium nitrate was $0.0047 \mathrm{wt} \%$ at $40^{\circ} \mathrm{C}$ and $0.032 \mathrm{wt} \%$ at $120^{\circ} \mathrm{C}$. Calcium oxalate solubility increased with increasing acidity.

Because of the low solubility of calcium oxalate in saturated sodium nitrate solutions and the oxidative decomposition of oxalate in nitric acid, no process conditions existed to form oxalate crystals and contaminate sodium nitrate.

\subsubsection{Fluoride}

The quantity of fluoride added daily to the waste was $80 \mathrm{~kg}$ (Table 9.1). At a daily sodium nitrate output of 10 tonnes, $8 \mathrm{~g}$ of fluoride could be present with each $\mathrm{kg}$ of salt.

In saturated neutral solutions of sodium nitrate, the solubility of sodium fluoride was found to be virtually independent of temperature and was about $0.16 \mathrm{wt} \%$ with respect to dissolved sodium nitrate (Table 9.3).

Acidification to $3.0 \mathrm{~g} / \mathrm{L}(0.05 \underline{\mathrm{M}})$ nitric acid decreased the solubility of sodium fluoride; at $35 \mathrm{~g} / \mathrm{L}$ $(0.56 \underline{\mathrm{M}})$ nitric acid, sodium fluoride solubility increased slightly (Table 9.4$)$. The decrease in sodium fluoride solubility with increasing acid was due to formation of lower solubility NaF-nHF binary compounds.

Table 9.3. Sodium Fluoride Solubility in Saturated Sodium Nitrate Solutions

\begin{tabular}{||c|c|}
\hline Temperature, ${ }^{\circ} \mathrm{C}$ & $\begin{array}{c}\text { Solubility, } \\
\mathrm{g} \mathrm{NaF} / \mathrm{kg} \mathrm{NaNO}_{3}\end{array}$ \\
\hline 24 & 1.85 \\
\hline 40 & 1.75 \\
\hline 50 & 1.68 \\
\hline 60 & 1.62 \\
\hline 80 & 1.60 \\
\hline 96 & 1.52 \\
\hline 115 & 1.47 \\
\hline
\end{tabular}


Table 9.4. Influence of Acidity on Sodium Fluoride Solubility in Saturated Sodium Nitrate Solution at $20^{\circ} \mathrm{C}$

\begin{tabular}{||c|c|c|}
\hline $\begin{array}{c}\text { Acidity, } \\
\text { g HNO }_{3} / \mathrm{L}\end{array}$ & $\begin{array}{c}\text { Solubility, } \\
\%\end{array}$ & $\begin{array}{c}\text { Solubility, } \\
\mathrm{g} \mathrm{NaF}^{\mathrm{kgg}} \\
\mathrm{NaNO}_{3}\end{array}$ \\
\hline 0 & 0.09 & 1.9 \\
\hline 3.0 & 0.029 & 0.61 \\
\hline 6.0 & 0.032 & 0.68 \\
\hline 7.7 & 0.035 & 0.74 \\
\hline 16.0 & 0.032 & 0.68 \\
\hline 35.0 & 0.041 & 0.87 \\
\hline
\end{tabular}

Based on the data given in Tables 9.3 and 9.4, the behavior of fluoride during evaporation can be evaluated. Those results, given in Table 9.5, show that most incoming fluoride should crystallize and report to the sodium nitrate salt upon evaporation.

The fluoride and nitrate salts were dissolved prior to sorption purification. It was expected that the concentration of fluoride in the filtered sodium nitrate mother solutions after crystallization would be established by the fluoride salt solubility in this medium. However, the fluoride concentrations were lower in solutions prepared by dissolving the product salt than would be predicted by solubility. The lower solubility was attributed to slower kinetics of dissolution of the NaF-nHF salt in the high-nitrate solutions. Therefore, filtration of the product salt solution prior to sorption purification removed a portion of the fluoride impurity. Washing the product salt with saturated sodium nitrate solution did not affect the composition of the wash solution.

Table 9.5. Calculated Fluoride Content in Process Products

\begin{tabular}{||l|c|c|c||}
\hline \multirow{2}{*}{\multicolumn{1}{|c|}{ Stream }} & \multicolumn{3}{|c|}{$\begin{array}{c}\text { Fluoride Concentration, g } \\
\text { Fluoride/kg NaNO }\end{array}$} \\
\cline { 2 - 4 } & $\begin{array}{c}\text { Evaporated } \\
\text { Slurry }\end{array}$ & $\begin{array}{c}\text { Mother } \\
\text { Solution }\end{array}$ & $\begin{array}{c}\text { Solid } \\
\text { Salt }\end{array}$ \\
\hline Total & 8.0 & -- & 6.2 \\
\hline Reporting to supernatant & 1.47 & 1.8 & -- \\
\hline Reporting to saltcake & 6.53 & 0.3 & 6.2 \\
\hline
\end{tabular}


Fluoride also could be removed from the waste solutions by volatilization. About $12 \%$ of the incoming fluoride was removed with the water condensate during evaporation of the acid solutions. Even slight solution acidification (to $\mathrm{pH} 4$ ) caused $0.9 \%$ of the fluoride to volatilize.

Application of alkaline calcium precipitation to the residual fluoride could decrease fluoride concentrations to 0.01 to $0.025 \mathrm{~g} / \mathrm{L}$ if the alkalinity of solution was less than $2 \mathrm{~g} / \mathrm{L}$ but the $\mathrm{pH}$ greater than 7 to 8 . With alkaline calcium precipitation, crystallization of the $200 \mathrm{~g} / \mathrm{L}$ sodium nitrate salt solution should yield 0.05 to $0.125 \mathrm{~g}$ fluoride per $\mathrm{kg}$ of product salt.

The disposition of fluoride also is affected by the solubility of calcium fluoride in the acidic saturated sodium nitrate solutions. Data on calcium fluoride solubility under these conditions are shown in Table 9.6. The solubility of calcium fluoride in concentrated nitrate solutions was considerably higher than the concentration found after alkaline calcium precipitation. Fluoride removal by alkaline calcium precipitation, salt washing, and by the purification afforded by fractional crystallization caused the fluoride concentration in the salt product to be about 100 -fold lower than would be observed solely from the solubility of calcium fluoride in acid.

Table 9.7 shows experimental evidence confirming the predicted purification factors from fluoride and chloride. The observed purification factors are each about 100 over the range 0.25 to $1 \mathrm{~g}$ fluoride per $\mathrm{kg}$ sodium nitrate in the initial solution. At $5 \mathrm{~g}$ fluoride per $\mathrm{kg}$ salt, however, the purification factor for fluoride drops to about 20. Based on these results, the fluoride loading should not be allowed to exceed $1 \mathrm{~g}$ per kg sodium nitrate.

Table 9.6. Calcium Fluoride Solubility in Saturated Sodium Nitrate Solutions

\begin{tabular}{||c|c|c|c|}
\hline $\begin{array}{c}\text { Temperature, } \\
{ }^{\circ} \mathrm{C}\end{array}$ & $\begin{array}{c}{\left[\mathrm{HNO}_{3}\right],} \\
\mathrm{g} / \mathrm{L}\end{array}$ & $\begin{array}{c}{\left[\mathrm{F}^{-}\right],} \\
\mathrm{g} / \mathrm{L}\end{array}$ & $\begin{array}{c}{\left[\mathrm{CaF}_{2}\right],} \\
\mathrm{g} / \mathrm{L}\end{array}$ \\
\hline 20 & 0 & 0.036 & 0.073 \\
\hline 20 & 2.0 & 0.285 & 0.585 \\
\hline 20 & 3.7 & 0.323 & 0.663 \\
\hline 20 & 7.8 & 0.503 & 1.03 \\
\hline 20 & 10.8 & 0.52 & 1.06 \\
\hline 20 & 14.6 & 0.59 & 1.2 \\
\hline 118 & 0 & 0.57 & 1.16 \\
\hline
\end{tabular}


Table 9.7. Purification Factors for Salt from Fluoride and Chloride (initial solution: $200 \mathrm{~g} \mathrm{NaNO}_{3}$ / $\mathrm{L}, 3 \mathrm{~g} \mathrm{HNO}_{3} / \mathrm{L}$, evaporation temperature $118^{\circ} \mathrm{C}$ )

\begin{tabular}{||c|c|c|c|c|c|c|c|c|c||}
\hline \multicolumn{2}{||c|}{ Concentration in Initial Solution } & \multicolumn{3}{c|}{ Concentration in Salt Solution } & \multicolumn{2}{c||}{$\begin{array}{c}\text { Purification } \\
\text { Factors }\end{array}$} \\
\hline $\mathrm{g} / \mathrm{L}$ & $\mathrm{g} / \mathrm{kg}$ salt & $\mathrm{g} / \mathrm{L}$ & $\mathrm{g} / \mathrm{kg}$ salt & $\mathrm{g} / \mathrm{L}$ & $\mathrm{g} / \mathrm{kg}$ salt & $\mathrm{g} / \mathrm{L}$ & $\mathrm{g} / \mathrm{kg}$ salt & $\mathrm{F}^{-}$ & $\mathrm{Cl}^{-}$ \\
\hline 0.05 & 0.25 & 1.49 & 7.45 & 0.0020 & 0.004 & 0.035 & 0.07 & 62.5 & 106 \\
\hline 0.05 & 0.25 & 1.42 & 7.1 & 0.0020 & 0.004 & 0.028 & 0.056 & 62.5 & 126 \\
\hline 0.1 & 0.5 & 1.4 & 7.0 & 0.0020 & 0.004 & 0.035 & 0.07 & 150 & 100 \\
\hline 0.2 & 1.0 & 1.28 & 6.4 & 0.0038 & 0.076 & 0.026 & 0.053 & 125 & 126 \\
\hline 1.0 & 5.0 & -- & -- & 0.1240 & 0.248 & - & - & 20 & - \\
\hline \hline
\end{tabular}

\subsubsection{Sodium Sulfate}

Sulfate concentrations in recycled solutions were established primarily by the low solubilities of compounds such as barium and calcium sulfate. In process solutions not containing barium or calcium, sulfate accumulates in recycle solutions to the concentration established by the solubility of sodium sulfate $(40 \mathrm{~g} / \mathrm{L})$. Barium sulfate precipitates quantitatively. Calcium sulfate solubility data for nitrate solution are presented in Table 9.8 .

Table 9.8. Calcium Sulfate Solubility in Nitrate Solutions

\begin{tabular}{|c|c|c|c|}
\hline \multirow{2}{*}{$\begin{array}{c}{\left[\mathrm{NaNO}_{3}\right]} \\
\mathrm{g} / \mathrm{L}\end{array}$} & \multicolumn{2}{|c|}{$\begin{array}{c}\mathrm{CaSO}_{4} \\
\text { Solubility at } \\
22^{\circ} \mathrm{C}\end{array}$} & \multirow{2}{*}{$\begin{array}{c}\mathrm{CaSO}_{4} \\
\text { Solubility at } \\
99^{\circ} \mathrm{C} \text {, wt } \%\end{array}$} \\
\hline & wt $\%$ & $\mathrm{~g} / \mathrm{L}$ & \\
\hline 0 & 0.204 & 2.04 & 0.155 \\
\hline 50 & 0.52 & 5.30 & -- \\
\hline 100 & 0.56 & 5.90 & - \\
\hline 200 & 0.52 & 5.84 & 0.472 \\
\hline 300 & 0.54 & 6.40 & 0.451 \\
\hline 500 & 0.56 & 7.29 & 0.422 \\
\hline Saturation & 0.55 & 7.61 & -- \\
\hline
\end{tabular}


Acidification of sodium nitrate solutions by nitric acid increases calcium sulfate solubility noticeably. At $20 \mathrm{~g}$ nitric acid per liter, calcium sulfate solubility reaches $16 \mathrm{~g} / \mathrm{L}$. This is about two times higher than its solubility in neutral solution.

\subsubsection{Chloride}

Chloride cannot be separated by precipitation in the cyclic processing of intermediate-level radioactive waste solution. The chloride will be present in the interstitial liquid and be removed with the sodium nitrate product. To define more precisely the conditions for the removal of sodium chloride with sodium nitrate, sodium chloride solubility in saturated sodium nitrate solutions was studied. It was found that the concentrations of both salts are determined by their mutual solubilities. The sodium chloride/nitrate solubility data are shown in Table 9.9 .

As shown in Table 9.9, the relative chloride concentration in saturated sodium nitrate solution decreases with increasing temperature. Even under these conditions, however, the solubility of sodium chloride is very high and prevents application of crystallization to remove chloride. Chloride contamination of the sodium nitrate product is unavoidable.

\subsubsection{Calcium}

Calcium concentrations in the decantate depend on the alkaline precipitation conditions. During alkaline calcium precipitation, the residual dissolved calcium concentration decreases with increasing alkali concentration. Calcium hydroxide precipitates in dilute nitrate solutions at $\mathrm{pHs}$ exceeding 12 . Calcium hydroxide solubility decreases with increasing sodium nitrate concentration. Table 9.10 summarizes the calcium hydroxide solubility in alkaline sodium nitrate solution. The effects of $\mathrm{pH}$ on calcium hydroxide solubility are shown in Table 9.11.

The data in Table 9.11 show that by decreasing $\mathrm{pH}$ from 12 to 6 , calcium concentrations increase from 0.61 to $18 \mathrm{~g} / \mathrm{L}$; further decrease to $\mathrm{pH} 1.5$ to 1.7 increases dissolved calcium to $48.6 \mathrm{~g} / \mathrm{L}$.

Table 9.9. Dependence of Equilibrium $\mathrm{NaCl}$ and $\mathrm{NaNO}_{3}$ Solution Composition on Temperature

\begin{tabular}{||c|c|c|c|}
\hline $\begin{array}{c}\text { Temperature, } \\
{ }^{\circ} \mathrm{C}\end{array}$ & $\begin{array}{c}{[\mathrm{NaCl}],} \\
\mathrm{wt} \%\end{array}$ & $\begin{array}{c}{\left[\mathrm{NaNO}_{3}\right],} \\
\mathrm{wt} \%\end{array}$ & $\begin{array}{c}{[\mathrm{Cl}], \mathrm{g} / \mathrm{kg}} \\
\text { of } \mathrm{NaNO}_{3}\end{array}$ \\
\hline 20 & 13.2 & 31.3 & 253 \\
\hline 40 & 11.6 & 37.9 & 184 \\
\hline 60 & 9.0 & 44.5 & 121 \\
\hline
\end{tabular}


Table 9.10. Solubility of Calcium Hydroxide in Sodium Nitrate Solutions at $20^{\circ} \mathrm{C}$

\begin{tabular}{|c|c|c|}
\hline $\begin{array}{c}{\left[\mathrm{NaNO}_{3}\right],} \\
\mathrm{g} / \mathrm{L}\end{array}$ & $\mathrm{pH}$ & $\begin{array}{c}{\left[\mathrm{Ca}^{2+}\right],} \\
\mathrm{g} / \mathrm{L}\end{array}$ \\
\hline 0 & 12.7 & 1.2 \\
\hline 100 & 12.7 & 1.3 \\
\hline 200 & 12.5 & 1.03 \\
\hline 400 & 12.5 & 0.95 \\
\hline 600 & 12.5 & 0.61 \\
\hline
\end{tabular}

Table 9.11. Solubility of Calcium Hydroxide in Saturated Sodium Nitrate Solutions at Various pH Levels

\begin{tabular}{||c|c|c|}
\hline $\mathrm{pH}$ & $\begin{array}{c}{[\mathrm{NaOH}],} \\
\mathrm{g} / \mathrm{L}\end{array}$ & $\begin{array}{c}{\left[\mathrm{CA}^{2+}\right],} \\
\mathrm{g} / \mathrm{L}\end{array}$ \\
\hline $1.5-1.7$ & - & 48.6 \\
\hline 6.5 & - & 18.0 \\
\hline 12.2 & -- & 0.61 \\
\hline- & 1.36 & 0.324 \\
\hline- & 3.9 & 0.044 \\
\hline
\end{tabular}

These data show that calcium hydroxide formation is favored by increased alkalinity and sodium nitrate concentration during evaporation of alkaline solutions. Under alkaline conditions, calcium hydroxide will precipitate during sodium nitrate crystallization and contaminate the product. Calcium hydroxide does not form during evaporation of acid solutions. In this case, the maximum tolerable concentration of calcium in sodium nitrate salt can be $50 \mathrm{mg}$ per $\mathrm{kg}$ of the salt entering sorption purification.

\subsubsection{Potassium}

Potassium nitrate is very soluble and is removed from the process only in the mother solution entrained interstitially in the sodium nitrate crystalline product. Thus the potassium concentration in the mother solution at cyclic equilibrium increased 33 to 20 times when the solution volume decreased to 3 to $5 \%$ of the initial volume; if the potassium concentration in the initial solution was $4 \mathrm{~g}$ per $\mathrm{kg}$ of sodium nitrate salt, its concentration at cyclic equilibrium reached 132 to $80 \mathrm{~g}$ per $\mathrm{kg}$ of sodium nitrate. These potassium concentrations are considerably below the solubility of potassium nitrate in saturated sodium nitrate solution. 


\subsubsection{Organic and Other Impurities}

Organic impurities such as thiourea and lactic acid can be oxidized during evaporation in nitric acid $(10 \mathrm{~g} / \mathrm{L}$ or $0.16 \mathrm{M})$ at $120^{\circ} \mathrm{C}$ in the presence of $\mathrm{Mn}$ (II) catalyst. Four hours of treatment in the evaporator in the presence of $0.2 \mathrm{~g} \mathrm{Mn}$ (II) per $\mathrm{kg}$ of sodium nitrate decomposes thiourea completely and destroys 25 to $35 \%$ of the lactic acid and other organic compounds. At cyclic equilibrium and with water evaporation, the total concentration of refractory organic impurities increased 3- to 4-fold. Trihydroxyglutaric acid, another organic impurity, forms an insoluble precipitate with calcium and is removed in the alkaline calcium precipitation process.

Other impurities are transformed by hydrolysis. For example, hexametaphosphate $\left(\mathrm{P}_{6} \mathrm{O}_{18}^{6}\right)$ hydrolyzes to phosphate. The phosphate then precipitates as a calcium salt. Sodium dodecylbenzenesulfonate, an anionic detergent known as sulfonol in Russia, was removed from the process solutions by alkaline calcium precipitation. Impurities that were not destroyed, volatilized, or precipitated increased in concentration by the evaporative concentration of the waste solutions.

\subsubsection{Summary}

Based on these studies, and the impurity concentrations found in intermediate-level radioactive solutions, the expected composition of sodium nitrate product prepared by cyclic processing can be calculated (see Table 9.12). The amount of sodium nitrate produced daily was 10 tonnes. The last column of Table 9.12 displays the permissible impurity concentrations tolerated in the process for sorption purification of sodium nitrate. With proper control of purification conditions, acceptable impurity levels could be achieved. 
Table 9.12. Concentrations of Inpurities at Various Stages of Purification of Intermediate-Level Radioactive Waste Solutions

\begin{tabular}{|c|c|c|c|c|c|}
\hline \multirow[b]{2}{*}{ Impurity } & \multirow[b]{2}{*}{$\begin{array}{c}\text { Impurity } \\
\text { Removal Step }\end{array}$} & \multicolumn{4}{|c|}{ [Impurity], g/kg NaNO 3} \\
\hline & & $\begin{array}{c}\text { Initial } \\
\text { Solution } \\
\end{array}$ & Equilibrium & $\begin{array}{l}\text { Filtered } \\
\text { Solution } \\
\end{array}$ & $\begin{array}{l}\text { Maximum } \\
\text { Permitted }\end{array}$ \\
\hline \multirow[t]{2}{*}{$\mathrm{C}_{2} \mathrm{O}_{4}^{2-}$} & $\begin{array}{l}\text { Oxidation in acid } \\
\text { evaporation }\end{array}$ & 16.5 & 16.5 & 0.016 & 0.056 \\
\hline & $\begin{array}{l}\text { Alkaline calcium } \\
\text { precipitation }\end{array}$ & 16.5 & $\leq 0.5$ & 0.026 & 0.056 \\
\hline \multirow[t]{2}{*}{$F^{-}$} & $\begin{array}{l}\text { In solution occluded } \\
\text { by salt }\end{array}$ & 8.2 & 8.2 & 1.2 & 0.15 \\
\hline & $\begin{array}{l}\text { Alkaline calcium } \\
\text { precipitation }\end{array}$ & 8.2 & 0.5 & 0.05 & 0.15 \\
\hline \multirow[t]{2}{*}{$\mathrm{Ca}^{2+}$} & Precipitation at $\mathrm{pH} 12$ & 5.0 & 5.0 & 0.05 & 0.010 \\
\hline & $\begin{array}{l}\text { Precipitation at } 2 \mathrm{~g} \\
\mathrm{NaOH} / \mathrm{L}\end{array}$ & 5.0 & $\leq 1.0$ & $\leq 0.010$ & 0.010 \\
\hline $\mathrm{K}^{+}$ & $\begin{array}{l}\text { In solution occluded } \\
\text { by salt }\end{array}$ & 4.0 & 8.0 & 0.8 & 10.0 \\
\hline $\mathrm{Cl}^{-}$ & $\begin{array}{l}\text { In solution occluded } \\
\text { by salt }\end{array}$ & $0.1-0.3$ & $2-6$ & 0.06 & 10.0 \\
\hline Trihydroxyglutaric acid & Precipitation with $\mathrm{Ca}^{2+}$ & 0.2 & 0 & -- & 0.004 \\
\hline Hexametaphosphate & By precipitation & 7.5 & 0.15 & 0.0015 & -- \\
\hline Thiourea & $\begin{array}{l}\text { Oxidation in acid } \\
\text { evaporation }\end{array}$ & 10.0 & 10.0 & 0 & -- \\
\hline Lactic acid & $\begin{array}{l}\text { Oxidation in acid } \\
\text { evaporation }\end{array}$ & 0.104 & 0.004 & 0.056 & - \\
\hline
\end{tabular}




\subsection{Precipitate Volumes from Processing Intermediate- Level Radioactive Solutions}

One of the primary sources of intermediate-level radioactive waste is equipment decontamination solution. Both alkaline and nitric acid solutions of potassium permanganate, oxalate/oxalic acid, and fluoride are produced. Magnesium, iron, calcium, and organic materials (such as dodecylbenzenesulfonate) also may be present in such solutions.

As shown previously, organics had no noticeable effect on process parameters provided they were not present as solids and did not coat the precipitating and settling solids with an organic layer. If organic impurities coated the precipitates during their formation and mixing, increased volumes of sedimented solids were produced. Precipitates also could be partially floated by droplets of organic products to form a nonsettling layer at the surface.

Difficulties associated with organic contamination could be avoided by excluding organiccontaminated feed solutions or by periodically recycling process solutions that have deleterious concentrations of accumulated organics.

Like calcium, magnesium present in the waste precipitated if the solution was sufficiently alkaline. Data on magnesium hydroxide solubility at various alkalinities are shown in Table 10.1. Solution $\mathrm{pH}$ higher than 10 was required to achieve complete removal of magnesium. The magnesium precipitates were bulky, however, as shown in the data of Table 10.2. If the solution $\mathrm{pH}$ was less than 8 , the magnesium remained in solution and was removed with the sodium nitrate salt in the interstitial liquid.

Table 10.1. Magnesium Hydroxide Solubility in $200 \mathrm{~g} / \mathrm{L}$ Sodium Nitrate Solution at Various pH Levels

\begin{tabular}{||c|c|}
\hline $\mathrm{pH}$ & {$\left[\mathrm{Mg}^{2+}\right], \mathrm{g} / \mathrm{L}$} \\
\hline 7.9 & 8.9 \\
\hline 8.5 & 5.3 \\
\hline 8.7 & 1.2 \\
\hline 9.0 & 0.45 \\
\hline 9.2 & 0.43 \\
\hline 10.0 & 0.11 \\
\hline 11.0 & 0.04 \\
\hline 12.0 & 0.04 \\
\hline
\end{tabular}


Table 10.2. Effect of $\mathrm{Mg}^{2+}$ on Precipitate Volumes $\left(100 \mathrm{~g} \mathrm{NaNO}_{3} \mathrm{~L}\right.$ and $0.2 \mathrm{~g} \mathrm{Fe}^{3+} / \mathrm{L}$ at $\left.90^{\circ} \mathrm{C}\right)$

\begin{tabular}{|c|c|c|}
\hline$\left[\mathrm{Mg}^{2+}\right], \mathrm{g} / \mathrm{L}$ & $\begin{array}{c}{[\mathrm{NaOH}] \text { in }} \\
\text { Decantate, } \mathrm{g} / \mathrm{L}\end{array}$ & $\begin{array}{c}\text { Precipitate } \\
\text { Volume, \% }\end{array}$ \\
\hline 0 & 1.2 & 3.0 \\
\hline 0.1 & 1.3 & 5.2 \\
\hline 0.3 & 1.2 & 7.4 \\
\hline 0.5 & 1.5 & 8.0 \\
\hline
\end{tabular}

In general, precipitate volumes were decided by precipitation conditions and by the concentrations of iron, manganese, and calcium oxalate and fluoride. Experiments were performed to evaluate precipitate volumes based on the amounts of individual components and their sums in various ratios. Precipitation was conducted in alkali at 90 to $95^{\circ} \mathrm{C}$ for iron, manganese, and calcium.

The volume of iron hydroxide obtained by alkaline precipitation varied widely depending on solution composition and precipitation conditions. Iron hydroxide precipitate volumes decreased (relative to iron concentration) as iron concentration increased. The magnitude of this phenomenon at low iron concentrations can be evaluated by comparing volumes of packed precipitates obtained after 24 hours' sedimentation at room temperature as a function of iron concentration (Table 10.3).

Table 10.3. Volumes of Iron and Manganese Hydroxide Precipitates from Solution $\left(10 \mathrm{~g} \mathrm{HNO}_{3} / \mathrm{L}, 0.5 \mathrm{~g} \mathrm{~F}^{-} / \mathrm{L}, 1.0 \mathrm{~g} \mathrm{H}_{2} \mathrm{C}_{2} \mathrm{O}_{4} / \mathrm{L}\right.$, and iron or manganese at $\left.90^{\circ} \mathrm{C}\right)$

\begin{tabular}{|c|c|c|c|c|c|c||}
\hline \multirow{2}{*}{$\begin{array}{c}{\left[\mathrm{Fe}^{3+}\right] \text { or }\left[\mathrm{Mn}^{2+}\right] \text { in }} \\
\text { Initial Solution, } \mathrm{g} / \mathrm{L}\end{array}$} & \multicolumn{2}{|c|}{$\mathrm{Fe}(\mathrm{OH})_{3}$} & $\mathrm{Mn}(\mathrm{OH})_{2}$ & $\mathrm{Fe}^{3+}$ & $\begin{array}{c}\text { Concentration in } \\
\text { Precipitate, } \mathrm{g} / \mathrm{L}\end{array}$ & \multicolumn{2}{c|}{$\begin{array}{c}\text { Precipitate Volume, } \\
\mathrm{mL} / \mathrm{g} \text { Metal }\end{array}$} \\
\cline { 2 - 7 } & 0.8 & 0.4 & 2.6 & 5.0 & 380 & 200 \\
\hline 0.02 & 1.2 & 0.6 & 4.2 & 7.5 & 240 & 120 \\
\hline 0.05 & 1.7 & 0.9 & 5.9 & 11.0 & 170 & 90 \\
\hline 0.1 & 2.1 & 1.4 & 9.5 & 14.0 & 105 & 70 \\
\hline 0.2 & 2.7 & 2.0 & 18.5 & 25.0 & 54 & 50 \\
\hline 0.5 & & &
\end{tabular}


As shown in Table 10.3, manganese behavior was similar to that of iron. It was surmised that the iron and manganese hydroxide precipitate volumes were additive. From the table, it can be seen that increasing metal concentrations from 0.02 to $0.5 \mathrm{~g} / \mathrm{L}$ increased iron precipitate volume seven-fold and manganese precipitate volume five-fold.

Precipitate volumes for calcium hydroxide, oxalate, and fluoride were determined at calcium concentrations as high as $5 \mathrm{~g} / \mathrm{L}$ at 90 to $95^{\circ} \mathrm{C}$ and 24 hours' sedimentation. In all cases, precipitate volumes at calcium concentrations less than $2 \mathrm{~g} / \mathrm{L}$ were less than 3 to $5 \%$ of the initial solution volume. Precipitate volumes at higher calcium concentrations could reach 15 to. 17\%. Alkaline precipitation with all impurities present generally produced 24-hour settled volumes less than 3 to $4 \%$ of total solution volume; in a few cases, volumes were 5 to $6 \%$.

To ensure small precipitate volumes and to optimize alkaline calcium precipitation processing, seeding was used. That is, small amounts of the solid phase to be precipitated were added to the solution. These solids acted as crystallization centers upon which the precipitating solutes deposited. With this technique, most of the precipitation occurred on the seed particles without a noticeable increase in precipitate volume. The rate and completeness of precipitation also increased. Complete solution clarification and maximum packing of precipitates required only two to three hours.

Precipitation stages played only an auxiliary role in the processing of intermediate-level radioactive waste solutions and were primarily intended to pretreat solutions prior to crystallization and sorption. The following stages summarize the crystallization-sorption approach to processing intermediate-level radioactive waste solutions:

1. Alkaline calcium precipitation to remove oxalate, fluoride, trihydroxyglutaric and silicic acids, and heavy metals

2. Evaporation of the decantate under slightly acidic conditions (to prevent precipitate formation during concentration of nitrate salts) and crystallization of sodium nitrate

3. Purification of sodium nitrate solution from radionuclides by use of selective sorbents.

The number of process steps depended on the concentrations of chemical and radiochemical impurities in the feed waste solutions. 


\subsection{Results of Testing Variants for Processing Intermediate-Level Radioactive Waste Solutions by Crystallization and Sorption Techniques}

A large-scale laboratory facility was created to test process variants for crystallization and sorption treatment of intermediate-level radioactive wastes. The facility was designed to verify the operation of all process stages under cyclic conditions and to determine the effects of individual components on process parameters. For example, processing of solutions containing surfactants was planned for this facility. To protect the equipment from corrosion, decantate evaporation for most experiments was not conducted in acid; alkaline media or pHs greater than 2 to 3 were used.

\subsection{Test Facility, Test Objectives, and Solution Process Variants}

The process flowsheet included the following general sequence of engineering stages:

1. Alkaline precipitation

2. Preliminary evaporation to sodium nitrate concentration of 350 to $400 \mathrm{~g} / \mathrm{L}$

3. Secondary evaporation to 1000 to $1150 \mathrm{~g} / \mathrm{L}$

4. Initial crystallization

5. Separation and washing of crystallized salt

6. Dissolution of washed salt and product solution filtration

7. Evaporation of clarified salt solution and recrystallization

8. Dissolution of recrystallized sodium nitrate and sorption purification of salt solution.

A schematic diagram of the test facility is shown in Figure 11.1. The process equipment description follows.

A-1 30-L reactor for alkaline calcium precipitation equipped with a bubbling tube for stirring, thermometer, level indicator, foam alarm, and precipitate level measuring device.

A-2 Charging unit for adding solution to units A-1 and A-3. 


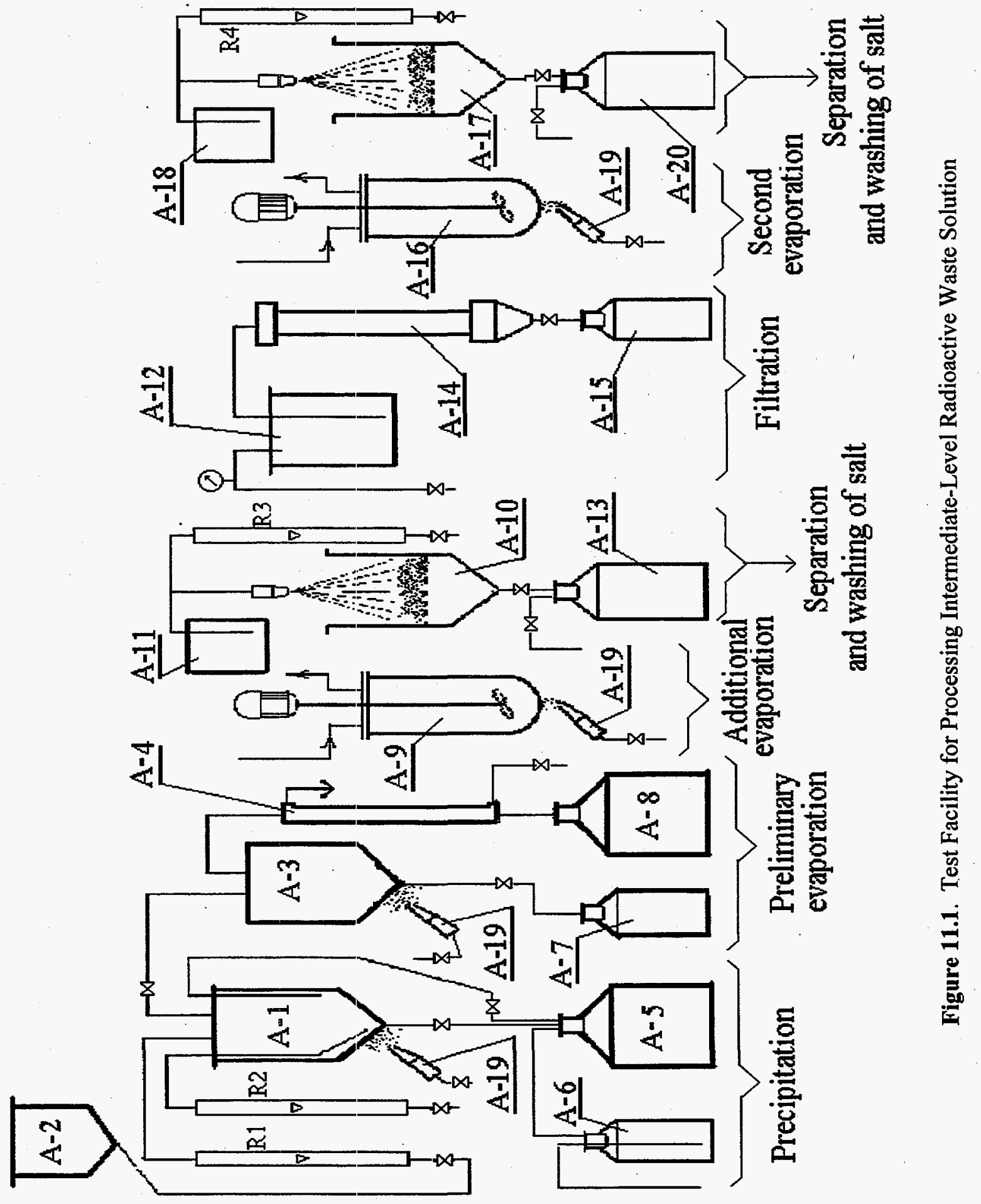



$400 \mathrm{~g} / \mathrm{L}$ sodium nitrate; equipped with cooler, thermometer, and foam alarm.

A-4 Cooler.

A-9 and A-16 Evaporators for secondary concentration and crystallization of solution from A-3.

A-10 and A-17 Nutsch (suction) filters for separating and washing crystalline sodium nitrate. Spraying of washing solution by pressurized air or washing of salt under static conditions was used.

A-11 and A-18 Storage vessels for washing solution.

A-12 Lag storage tank to feed filter A-14.

A-14 Filtering column.

A-19 Flame heaters.

R1 to R4 Rotameters to monitor air consumption and solution flow.

A-5 to A-8, A-13, Volume-measuring vessels.

$A-15$, and $A-20$

The effects of process and feed parameters were investigated in the facility. The influences of sodium dodecylbenzenesulfonate (also known as sulfonol) on processing and radiochemical performance in crystallization and sorption were studied. Conditions for alkaline-side solution evaporation and its effect on salt quality were elucidated. The effects of concentration and crystallization of sodium nitrate on filtration properties of its solutions were also investigated. The influences of solution composition variations on purification factors from radionuclides by sorption columns were determined. The effects of mother solution recycle were investigated. Experiments were performed for five variants of the cyclic processing flowsheet.

Variant 1 was for intermediate-level radioactive waste solutions not containing sulfonol. This variant included several process steps:

1. Alkaline calcium precipitation in a mixture of initial solution and a recycled portion of mother solution (produced after the first crystallization) with an alkali excess of 1 to $2 \mathrm{~g} / \mathrm{L}$.

2. Initial evaporation of the alkaline decantate to a sodium nitrate concentration of 350 to $400 \mathrm{~g} / \mathrm{L}$.

3. Acidification of the concentrated decantate with nitric acid to a 2 to $3 \mathrm{~g} / \mathrm{L}$ excess and evaporative concentration, with oxidation, to a 119 to $120^{\circ} \mathrm{C}$ boiling point. 
4. Crystallization and separation of salt.

5. Salt dissolution and filtration of the salt solution.

6. Second evaporation and crystallization.

7. Sorption purification of the supernatant salt solution (sodium nitrate concentration was $500 \mathrm{~g} / \mathrm{L}$ ).

Partial recycle of process solutions was used to achieve process stability for the varying feed solutions, to adjust salt concentration, and to improve purification. In general, one-third of the crystallization mother solution was recycled. That is, following the first crystallization, one-third of the mother solution was returned to the alkaline precipitation step, and two-thirds were blended with recycle from the second crystallization for acidification prior to the first crystallization. Following the second crystallization, one-third of the mother solution returned to the first crystallization (in the oxidation unit), and two-thirds returned to the second crystallization.

Variant 2 was the same as variant 1 but had sulfonol and other impurities added. Variant 3 was the same as variant 2 except the first crystallization was performed either in a slightly alkaline medium (pH 8 to 10 ; variant $3 \mathrm{a}$ ) or in a slightly acid medium ( $\mathrm{pH} 2$ to 3 ; variant $3 \mathrm{~b}$ ); the second crystallization in both cases was performed at $\mathrm{pH} 6$ to 8 . Variant 4 was the same as variant 3 but without sulfonol present. Variant 5 was the same as variant 4 but with sulfonol included and $100 \%$ recycling of mother solution. The effects of acid concentration on crystallization behavior also were determined. The experimental conditions for the process variants are summarized in Table 11.1.

Model (simulant) solutions were used to test the five variants of cyclic crystallization and sorption processing. Compositions of the model solutions are presented in Table 11.2. For experiments with sulfonol (variants 2,3, and 5), a blend of $10 \mathrm{~L}$ of solution 1, $0.45 \mathrm{~L}$ of solution 2, and $0.15 \mathrm{~L}$ of solution 4 was used. About $15 \mathrm{~L}$ of intermediate-level radioactive waste solution were treated in each experimental cycle.

\subsection{Results of Process Variant Tests}

Results of the tests performed with the assorted process and solution variants are given in the following subsections.

\subsubsection{Variant 1 Results}

Ten process cycles were conducted with variant 1. A total salt purification factor of 150 was achieved. 
Table 11.1. Experimental Conditions for Process Test Variants

\begin{tabular}{|c|c|c|c|c|c|c|}
\hline \multirow[b]{2}{*}{ Variant } & \multicolumn{3}{|c|}{$\mathrm{pH}$} & \multirow[b]{2}{*}{ Recycle, $\%$} & \multirow[b]{2}{*}{ Filtration } & \multirow{2}{*}{$\begin{array}{c}\text { Sulfonol } \\
\text { and } \\
\text { Impurities }\end{array}$} \\
\hline & $\begin{array}{c}\text { Alkaline } \\
\text { Precipitation }\end{array}$ & $\begin{array}{c}\text { First } \\
\text { Evaporation }\end{array}$ & $\begin{array}{c}\text { Second } \\
\text { Evaporation }\end{array}$ & & & \\
\hline 1 & $1-2 \mathrm{~g} \mathrm{NaOH} / \mathrm{L}$ & $2-3 \mathrm{~g} \mathrm{HNO}_{3} / \mathrm{L}$ & pH $6-7$ & 33 & $\begin{array}{l}\text { After first } \\
\text { cryst. }\end{array}$ & No \\
\hline 2 & $1-2 \mathrm{~g} \mathrm{NaOH} / \mathrm{L}$ & $2-3 \mathrm{~g} \mathrm{HNO}_{3} / \mathrm{L}$ & $\mathrm{pH} 6-7$ & 33 & $\begin{array}{l}\text { After first } \\
\text { cryst. }\end{array}$ & Yes \\
\hline $3 a$ & $1-2 \mathrm{~g} \mathrm{NaOH} / \mathrm{L}$ & $\mathrm{pH} 8-10$ & pH $6-8$ & 33 & $\begin{array}{l}\text { After first } \\
\text { cryst. }\end{array}$ & Yes \\
\hline $3 b$ & $1-2 \mathrm{~g} \mathrm{NaOH} / \mathrm{L}$ & $\mathrm{pH} 2-3$ & pH $6-8$ & 33 & $\begin{array}{l}\text { After first } \\
\text { cryst. }\end{array}$ & Yes \\
\hline 4 & $1-2 \mathrm{~g} \mathrm{NaOH} / \mathrm{L}$ & $\mathrm{pH} 8-10$ & $\mathrm{pH} 2-3$ & 33 & $\begin{array}{l}\text { After second } \\
\text { cryst. }\end{array}$ & No \\
\hline 5 & $1-2 \mathrm{~g} \mathrm{NaOH} / \mathrm{L}$ & $\mathrm{pH} 8-10$ & $\mathrm{pH} 1.5-3$ & 100 & No & Yes \\
\hline
\end{tabular}

\subsubsection{Variant 2 Results}

Seven experimental cycles of variant 2 were performed. The volume of solids collected from alkaline calcium precipitation over all seven cycles was $6 \mathrm{~L}$ after 24 hours' sedimentation at $20^{\circ} \mathrm{C}$, representing about $5.6 \%$ of the treated solution volume.

The alkaline decantate (remaining after settling and removal of the calcium precipitate) was initially evaporated at 104 to $105^{\circ} \mathrm{C}$, mixed with recycle mother solution from the first crystallization and acidified (allowing oxidation reactions to occur), evaporated further, and crystallized. In all cases, the initial alkaline evaporation proceeded quietly without foaming. Ammonia was completely removed with the condensate. During alkaline concentration, a small amount of calcium carbonate formed. The alkalinity of the evaporated solution almost always was less than that of the solution before evaporation. This phenomenon was attributed to the presence of calcium hydroxide and its subsequent conversion to calcium carbonate by absorption of atmospheric carbon dioxide. A small amount of calcium carbonate scale appeared on the surface of the evaporator; the scale could be dissolved with weak nitric acid. 
Table 11.2. Solution Composition for Preparation of Model Solutions

\begin{tabular}{|c|c|c|c|c|}
\hline \multirow[b]{2}{*}{ Component } & \multicolumn{4}{|c|}{ Solution Concentration, $\mathrm{g} / \mathrm{L}$} \\
\hline & Solution 1 & Solution 2 & Solution 3 & Solution 4 \\
\hline $\mathrm{NaNO}_{3}$ & 60 & - & - & -- \\
\hline $\mathrm{NaOH}$ & - & -- & 50 & -- \\
\hline $\mathrm{HNO}_{3}$ & 12 & 250 & - & - \\
\hline$F^{-}$ & 0.2 & 250 & -- & -- \\
\hline $\mathrm{C}_{2} \mathrm{O}_{4}^{2-}$ & 1.2 & 8.0 & -- & -- \\
\hline $\mathrm{Fe}^{3+}$ & 0.25 & 0.7 & -- & -- \\
\hline $\mathrm{Cl}^{-}$ & 0.02 & 1.7 & - & -- \\
\hline $\mathrm{Mn}^{2+}$ & 0.2 & 0.2 & -- & - \\
\hline $\mathrm{KMnO}_{4}$ & -- & - & 1.5 & -- \\
\hline $\mathrm{Ca}^{2+}$ & - & 8.5 & -- & 100 \\
\hline $\mathrm{Mg}^{2+}$ & -- & 8.0 & - & -- \\
\hline $\mathrm{Ba}^{2+}$ & - & 1.0 & -- & - \\
\hline $\mathrm{Cr}^{3+}$ & -- & 0.2 & -- & - \\
\hline $\mathrm{Ni}^{2+}$ & -- & 0.1 & -- & -- \\
\hline $\mathrm{Si}$ & -- & 0.3 & -- & -- \\
\hline $\mathrm{Al}^{3+}$ & - & 0.2 & -- & -- \\
\hline $\mathrm{Pb}^{2+}$ & - & 0.2 & - & - \\
\hline $\mathrm{NH}_{4}^{+}$ & -- & 10.0 & - & -- \\
\hline $\mathrm{K}^{+}$ & - & 0.1 & -- & - \\
\hline Hexametaphosphate & 0.15 & - & - & - \\
\hline Sulfonol & 0.5 & -- & - & - \\
\hline Tributyl phosphate & 0.02 & -- & - & -- \\
\hline Lactic acid & 0.4 & - & -- & - \\
\hline
\end{tabular}


Feed solution for the first crystallization was prepared by mixing two-thirds parts of the concentrated alkaline solution with one-third parts of mother solution from the first crystallization. This mixture was acidified to a nitric acid concentration of 1 to $3 \mathrm{~g} / \mathrm{L}$ and evaporated to 119 to $120^{\circ} \mathrm{C}$. Salt crystallization occurred by natural (unforced) cooling of the solution to room temperature with constant mechanical stirring. The product salt crystals were washed with an amount of distilled water equivalent to $40 \%$ of the salt weight. Despite the acid medium, a solid phase containing calcium and sulfonol decomposition products formed during evaporation. The filtration rate was very low.

The sodium nitrate from the first crystallization was dissolved and filtered. The clarified solution was blended with double its volume of mother solution from the second crystallization and crystallized without further acidification. The salt from the second crystallization was washed and redissolved in water. The salt solution then was purified by sorption. Despite the filtration performed after the first crystallization, the salt produced from the second crystallization had a noticeable amount of slime. At least 24 hours were required to settle the slime. Table 11.3 shows concentrations of impurities found in the salt solutions and product after the second crystallization.

As seen in Table 11.3, concentrations of solid phase impurities formed in the second crystallization ranged from 0.2 to $0.5 \mathrm{~g}$ per kilogram of salt. This was about the same amount of solid impurity as was observed in the first crystallization. Thus, in the presence of sulfonol, filtration of the salt solution after the first crystallization did not guarantee the production of a salt product free of solid phase impurities after the second crystallization.

Table 11.3. Concentrations of Impurities in Salt Solutions after Second Crystallization for Variant 2

\begin{tabular}{||c|c|c|c||}
\hline \multirow{2}{*}{$\begin{array}{c}\text { Cycle } \\
\text { Number }\end{array}$} & \multicolumn{3}{|c|}{ Impurity Concentration } \\
\cline { 2 - 4 } & $\mathrm{Ca}^{2+}, \mathrm{mg} / \mathrm{L}$ & Sulfonol, g/L & Solid Phase, g/kg Salt \\
\hline 1 & 10 & 0.24 & 0.48 \\
\hline 2 & 10 & 0.22 & 0.44 \\
\hline 3 & 10 & 0.24 & 0.48 \\
\hline 4 & 10 & 0.3 & 0.60 \\
\hline 5 & 10 & 0.08 & 0.16 \\
\hline 6 & 10 & 0.10 & 0.20 \\
\hline 7 & 10 & 0.10 & 0.20 \\
\hline
\end{tabular}




\subsubsection{Variant 3 Results}

No foam was observed in the initial evaporation of feed solutions in variant 3 tests. In the first experimental series, the concentrated solution (one-third parts) was blended with two-thirds parts of the initial crystallization mother solution from the preceding cycle to give a solution with $\mathrm{pH}$ of 8 to 10 . The blended solution was evaporated to 119 to $120^{\circ} \mathrm{C}$; the salt was crystallized, filtered, washed, and dissolved.

Increased amounts of solid-phase impurities (compared with variant 2) were observed in product salts prepared by crystallization in this slightly alkaline medium. The impurities were primarily calcium hydroxide and carbonate produced during evaporative concentration. Increasing alkalinity to $2 \mathrm{~g} / \mathrm{L}$ further increased solid phase concentrations in the dissolved salt to $2 \mathrm{~g} / \mathrm{L}$ or $4 \mathrm{~g}$ per kilogram of dry salt.

The second crystallization was conducted at $\mathrm{pH} 6$ to 8 . In results similar to variant 2, sulfonol (from 0.1 to $0.3 \mathrm{~g} / \mathrm{L}$ ) was found in solution after the second crystallization. The calcium concentration also increased to $40 \mathrm{mg} / \mathrm{L}$. In tests at higher alkalinities, calcium concentrations reached 80 to $130 \mathrm{mg} / \mathrm{L}$. With these high calcium concentrations, the solution could not be purified from strontium without a preliminary calcium precipitation step. Based on these experiments, to prevent the formation of calcium carbonate and its contamination of the salt, the second evaporation and crystallization must be conducted in an acidic medium.

A second set of experiments was conducted by variant 3 in which the $\mathrm{pH}$ of the first crystallization was 2 to 3 . The solution produced by dissolving salt from the first crystallization contained a relatively high concentration of solid phase $(0.5$ to $0.7 \mathrm{~g} / \mathrm{L})$. This level was comparable to that found in experiments with variant 2 at $\mathrm{pH} 8$ to 9 . The clarified salt solution was mixed with double its volume of mother solution from the second crystallization and, without further acidification, evaporated and crystallized. The resulting concentrated $\mathrm{pH} 6$ to 7 salt solutions contained 0.01 to $0.04 \mathrm{~g}$ calcium/L.

\subsubsection{Variant 4 Results}

Solutions were processed by variant 4 to evaluate filtration and solid-phase impurity behaviors in the absence of sulfonol. The first crystallization was conducted at $\mathrm{pH} 8$ to 10 and the second at $\mathrm{pH} 2$ to 3 . The salt solution was filtered only after the second crystallization. Alkaline precipitation and preliminary evaporation were performed under the same conditions used for the previous variants. The concentrations of calcium and solid-phase impurities found in the salt solutions after the second crystallization are shown in Table 11.4 as a function of $\mathrm{pH}$.

The relatively high amount of solid-phase impurity (up to $0.6 \mathrm{~g} / \mathrm{L}$ ) found in the salt solution prepared after the second crystallization was attributed to precipitates carried from the first crystallization. The salt solution prepared from the first crystallization was not filtered. Impurities also may have been introduced in the recycled mother solutions from the second crystallization. 
Table 11.4. Concentrations of Calcium and Solid Phase in Solutions after Second Crystallization at Various $\mathrm{pH}$ for Variant 4

\begin{tabular}{|c|c|c|}
\hline $\begin{array}{c}\text { Solution pH for Second } \\
\text { Evaporation }\end{array}$ & $\begin{array}{c}{\left[\mathrm{Ca}^{2+}\right] \text { in Salt }} \\
\text { Solution, } \mathrm{g} / \mathrm{L}\end{array}$ & $\begin{array}{c}\text { Solid Phase } \\
\text { Concentration, } \mathrm{g} / \mathrm{L}\end{array}$ \\
\hline 2.0 & 0.02 & 0.25 \\
\hline 2.8 & 0.01 & 0.19 \\
\hline 1.9 & 0.01 & 0.23 \\
\hline 3.0 & 0.04 & 0.22 \\
\hline 3.0 & 0.08 & 0.60 \\
\hline 1.5 & 0.01 & 0.20 \\
\hline 2.8 & 0.02 & 0.13 \\
\hline 2.0 & 0.02 & 0.21 \\
\hline
\end{tabular}

\subsubsection{Variant 5 Results}

The variant 5 series of experiments was conducted to evaluate the effects of $100 \%$ recycling of mother solutions and the presence of sulfonol. Properties of solutions prepared after the first and second crystallizations are given in Table 11.5. Using a medium more acid than in other variants (nitric acid at 3 to $4 \mathrm{~g} / \mathrm{L}$ ) produced salts with lower levels of calcium and solid phase impurities (Table 11.6).

The data in Tables 11.5 and 11.6 show that $100 \%$ recycling of mother solution and further acidification of salt solution before the second crystallization decreased solid-phase impurity concentrations in the salt by more than an order of magnitude. However, because of the presence of sulfonol in solution, the filter pores still clogged quickly.

\subsubsection{Summary of Variant Results}

A summary of data obtained for all experimental variants is given in Table 11.7. It was found that with sulfonol present a fine colloid suspension formed. The colloid clogged filter pores and prevented purification from solid phases by filtration. Without filtration, salt quality was highest with $100 \%$ recycling of the mother solutions. Filtration could be avoided if the first crystallization was conducted in weak acid solution ( $\mathrm{pH} 2$ to 5). Under such conditions calcium compounds did not precipitate, and equipment corrosion was negligible. 
Table 11.5. Solution Characteristics after First and Second Crystallizations in Variant 5

\begin{tabular}{||c|c|c|c|c|c||}
\hline \hline $\begin{array}{c}\text { Crystallization } \\
\text { Stage }\end{array}$ & $\begin{array}{c}\text { Solution } \mathrm{pH} \text { at } \\
\text { Evaporation }\end{array}$ & $\begin{array}{c}\text { Salt Weight, } \\
\mathrm{kg}\end{array}$ & $\begin{array}{c}\text { Salt Solution } \\
\text { Volume, } \mathrm{L}\end{array}$ & $\begin{array}{c}\left.\mathrm{CCa}^{2+}\right], \\
\mathrm{g} / \mathrm{L}\end{array}$ & [Solid Phase], g/L \\
\hline \multirow{3}{*}{ First } & 9.1 & 2.24 & 2.8 & 0.07 & 0.27 \\
\cline { 2 - 6 } & 9.0 & 2.15 & 2.4 & 0.10 & 0.37 \\
\cline { 2 - 6 } & 9.0 & 2.25 & 2.6 & 0.06 & 0.31 \\
\hline \multirow{3}{*}{ Second } & 9.6 & 2.30 & 2.8 & 0.17 & 0.30 \\
\cline { 2 - 6 } & 3.0 & 1.0 & 1.0 & 0.03 & 0.07 \\
\cline { 2 - 6 } & 2.3 & 0.95 & 0.9 & 0.02 & 0.14 \\
\cline { 2 - 6 } & 2.0 & 1.05 & 1.1 & 0.02 & 0.19 \\
\cline { 2 - 6 } & 1.5 & 1.0 & 1.0 & 0.02 & 0.18 \\
\hline
\end{tabular}

Table 11.6. Concentration of Impurities after Second Crystallization in Variant 5 Using Increased Nitric Acid

\begin{tabular}{||c|c|c||}
\hline $\begin{array}{c}{\left[\mathrm{HNO}_{3}\right] \text { Before }} \\
\text { Evaporation, } \mathrm{g} / \mathrm{L}\end{array}$ & $\begin{array}{c}{\left[\mathrm{Ca}^{2+}\right] \text { in Salt }} \\
\text { Solution, g/L }\end{array}$ & $\begin{array}{c}\text { Solid Phase } \\
\text { Concentration, } \mathrm{g} / \mathrm{L}\end{array}$ \\
\hline 4.1 & 0.01 & 0.050 \\
\hline 4.4 & 0.01 & 0.024 \\
\hline 3.7 & 0.01 & 0.040 \\
\hline
\end{tabular}


Table 11.7. Summary of Results for Variants for Processing Intermediate-Level Radioactive Waste Solutions

\begin{tabular}{|c|l|c|c|c|c|c|c||}
\hline \multirow{2}{*}{ Variant } & & \multicolumn{2}{|c|}{$\begin{array}{c}\text { [Solid Phase] in Salt, } \\
\mathrm{mg} / \mathrm{kg} \text { Salt }\end{array}$} & \multicolumn{2}{|c|}{$\begin{array}{c}\text { Impurity] in Salt, } \\
\mathrm{mg} / \mathrm{kg} \text { Salt }\end{array}$} & $\begin{array}{c}\text { Specific } \\
\text { Load on } \\
\text { Filter, } \\
\mathrm{m}^{3} / \mathrm{m}^{2}\end{array}$ & $\begin{array}{c}\text { Precip. } \\
\text { Volume, } \\
\%\end{array}$ \\
\cline { 2 - 8 } & & $\begin{array}{c}\text { Second } \\
\text { Cryst. }\end{array}$ & $\mathrm{Ca}^{2+}$ & Sulfonol \\
\hline 1 & $\begin{array}{l}\text { No sulfonol; } \\
\text { recycle }\end{array}$ & $30-50$ & $<20$ & $<20$ & - & $>40$ & 2.0 \\
\hline 2 & $\begin{array}{l}\text { With sulfonol; first } \\
\text { evap. in acid }\end{array}$ & $60-80$ & $300-500$ & $<20$ & 0.40 & $<5$ & 5.6 \\
\hline $3 \mathrm{a}$ & $\begin{array}{l}\text { With sulfonol; first } \\
\text { evap. at pH 8-10; } \\
\text { second evap. pH 7-8 }\end{array}$ & $1000-1600$ & $500-600$ & $40-250$ & $200-300$ & 5 & 5.6 \\
\hline $3 \mathrm{~b}$ & $\begin{array}{l}\text { With sulfonol; first } \\
\text { evap. at pH 2.5; second } \\
\text { evap. pH 6-7 }\end{array}$ & $1000-1500$ & $400-600$ & $20-40$ & $300-500$ & 5 & 4.7 \\
\hline 4 & $\begin{array}{l}\text { No sulfonol; 33\% } \\
\text { mother solution recycle }\end{array}$ & - & $400-500$ & $20-40$ & -- & $>20$ & 5.0 \\
\hline 5 & $\begin{array}{l}\text { With sulfonol; 100\% } \\
\text { mother solution recycle }\end{array}$ & $500-600$ & $150-300$ & $40-50$ & $200-300$ & $<5$ & 5.0 \\
\hline
\end{tabular}

\subsection{Influence of Accumulated Impurities in Sodium Nitrate on Its Purification by Sorption}

Impurities were found to accumulate in process solutions because of recycle of mother solutions. Some of the impurities could affect radionuclide sorption. To investigate the potential problems posed by impurities, samples of sodium nitrate prepared after the second crystallization were obtained from the first through the twentieth cycles. The samples were dissolved in water to a sodium nitrate concentration of $500 \mathrm{~g} / \mathrm{L}$. Ruthenium-106 nitrosonitrate, ${ }^{137} \mathrm{Cs}$, and ${ }^{90} \mathrm{Sr}$ were added to portions of these solutions. The distribution coefficients $\left(\mathrm{K}_{d} \mathrm{~s}\right)$ on sulfide, ferrocyanide, and pyrolusite sorbents under static conditions were determined for each sample. The $\mathrm{K}_{d} \mathrm{~s}$ were calculated based on experimental measurements according to the formula:

$$
\mathrm{K}_{\mathrm{d}}=\left[\left(\mathrm{A}_{0}-\mathrm{A}\right) / \mathrm{A}\right](\mathrm{V} / \mathrm{m})
$$


where $A_{o}$ is the specific activity of initial solution, $A$ is the specific activity of the equilibrium solution, $V$ is the solution volume in $\mathrm{mL}$, and $\mathrm{m}$ is the sorbent weight in grams.

The sorption tests required $\mathrm{pH}$ control ( $\mathrm{pH} 4$ to 5 for sulfide and ferrocyanide sorbents; $1 \mathrm{~g}$ sodium hydroxide per liter for pyrolusite, $\mathrm{MnO}_{2}$ ). Solution/sorbent contact of 6 hours at $80^{\circ} \mathrm{C}$ gave the sorbents opportunity to form complex compounds with the impurities (particularly nitrosoruthenium). Calcium and barium were precipitated from solution by addition of sodium carbonate $(0.6 \mathrm{~g} / \mathrm{L})$ to form the respective carbonate salts prior to sorption on pyrolusite.

The experimental data are presented in Table 11.8. These data show that 20 successive crystallization cycles (including recycling of one-third of the mother solution from the first crystallization to alkaline precipitation and one-third of the second crystallization's mother solution to the $120^{\circ} \mathrm{C}$ concentration step) did not increase or decrease ${ }^{106} \mathrm{Ru} \mathrm{K} \mathrm{K}_{d}$ s. A 1.5- to 3-fold $\mathrm{K}_{d}$ decrease was observed in the later cycles for ${ }^{137} \mathrm{Cs}$ sorption compared with the first two cycles. However, no obvious further trend of decreasing $\mathrm{K}_{d}$ was observed with increasing number of cycles. Distribution factors for both ${ }^{106} \mathrm{Ru}$ and ${ }^{137} \mathrm{Cs}$ were high.

Strontium sorption generally decreased with an increasing number of cycles. Despite this, the $K_{d}$ was above 1,000 in several cases. Decrease in strontium sorption may have been caused by insufficient removal of calcium and barium carbonate in the preliminary precipitation treatment.

Further studies were conducted on the possible influence of various impurities on sorption purification from radionuclides under dynamic (column sorption) conditions. To this end, sodium nitrate solutions obtained from all 20 cycles were blended to give a solution of the following composition: sodium nitrate $(500 \mathrm{~g} / \mathrm{L})$, calcium $(0.03 \mathrm{~g} / \mathrm{L})$, potassium $(0.02$ to $0.03 \mathrm{~g} / \mathrm{L})$, reductants $(0.03$ gram-equivalents $/ \mathrm{L}$, calculated with respect to $\mathrm{KMnO}_{4}$ consumption), and sulfonol $(0.27 \mathrm{~g} / \mathrm{L})$. Plutonium-239 was introduced to the composite solution to study its removal by each of the three sorbents. Preliminary removal of calcium and barium from solution was performed by precipitation with sodium phosphate.

The volume of sorbent loaded to each column was $1 \mathrm{~mL}$. Solution flow rate was about two column volumes per hour and was maintained by a special device. Each sorption column was run for 45 days (2,000 column volumes). Dynamic column experiments were performed in which the concentrations of the radionuclide of interest were compared before and after the column. The respective ratio of these concentrations is defined as the decontamination factor, DF.

Results of tests with the solution mixture showed that in 1,230 column volumes, the DF from ${ }^{106} \mathrm{Ru}$ gradually decreased from 1,790 to 130 . Further processing to 1,850 column volumes gave another $2-$ to 3-fold decrease in DF. 
Table 11.8. Sorption of Radionuclides Under Static Conditions from Sodium Nitrate Solutions $(500 \mathrm{~g} / \mathrm{L})$ Obtained from Various Crystallization Cycles

\begin{tabular}{|c|c|c|c|c|c|}
\hline \multicolumn{3}{|c|}{ Impurity Concentrations } & \multicolumn{3}{|c|}{ Distribution Factors for } \\
\hline $\begin{array}{l}\text { Calcium, } \\
\mathrm{mg} / \mathrm{L}\end{array}$ & $\begin{array}{l}\text { Sulfonol, } \\
\text { mg/L }\end{array}$ & $\begin{array}{c}\text { Reductants }\left(\mathrm{KMnO}_{4}\right. \\
\text { consumption), g-equiv. } / \mathrm{L}\end{array}$ & Ruthenium & Cesium & Strontium \\
\hline$<10$ & 0 & - & $3.4 \times 10^{4}$ & $1.4 \times 10^{5}$ & $8.0 \times 10^{3}$ \\
\hline$<10$ & 240 & 0.03 & $4.3 \times 10^{4}$ & $1.4 \times 10^{5}$ & $3.6 \times 10^{3}$ \\
\hline$<10$ & 240 & 0.03 & $4.0 \times 10^{4}$ & $4.2 \times 10^{4}$ & $0.7 \times 10^{3}$ \\
\hline$<10$ & 300 & 0.03 & $4.2 \times 10^{4}$ & $4.2 \times 10^{4}$ & $0.7 \times 10^{3}$ \\
\hline$<10$ & 80 & 0.03 & $5.0 \times 10^{4}$ & $4.2 \times 10^{4}$ & $9.0 \times 10^{3}$ \\
\hline$<10$ & 100 & 0.03 & $4.1 \times 10^{4}$ & $4.2 \times 10^{4}$ & $9.0 \times 10^{3}$ \\
\hline$<10$ & - & -- & $4.0 \times 10^{4}$ & $7.7 \times 10^{4}$ & $0.4 \times 10^{3}$ \\
\hline 138 & 100 & 0.03 & $5.6 \times 10^{4}$ & $6.6 \times 10^{4}$ & $0.4 \times 10^{3}$ \\
\hline 20 & 160 & 0.04 & $8.0 \times 10^{4}$ & $8.8 \times 10^{4}$ & $3.3 \times 10^{3}$ \\
\hline 20 & 290 & 0.03 & $3.9 \times 10^{4}$ & $8.3 \times 10^{4}$ & $3.3, \times 10^{3}$ \\
\hline 20 & 330 & 0.06 & $4.1 \times 10^{4}$ & $6.0 \times 10^{4}$ & $0.3 \times 10^{3}$ \\
\hline 260 & 66 & 0.03 & $4.5 \times 10^{4}$ & $8.6 \times 10^{4}$ & $0.3 \times 10^{3}$ \\
\hline 78 & 135 & 0.03 & $3.3 \times 10^{4}$ & $7.0 \times 10^{4}$ & $0.3 \times 10^{3}$ \\
\hline 36 & 95 & 0.03 & $3.1 \times 10^{4}$ & $7.1 \times 10^{4}$ & $0.3 \times 10^{3}$ \\
\hline 18 & 380 & -- & $3.4 \times 10^{4}$ & $6.0 \times 10^{4}$ & $0.5 \times 10^{3}$ \\
\hline 20 & 140 & 0.03 & $3.4 \times 10^{4}$ & $6.8 \times 10^{4}$ & $1.2 \times 10^{3}$ \\
\hline 40 & 200 & 0.03 & $3.4 \times 10^{4}$ & -- & $1.2 \times 10^{3}$ \\
\hline 20 & 290 & 0.03 & $3.9 \times 10^{4}$ & $7.9 \times 10^{4}$ & $0.3 \times 10^{3}$ \\
\hline 10 & 240 & 0.04 & $3.9 \times 10^{4}$ & $9.8 \times 10^{4}$ & $0.3 \times 10^{3}$ \\
\hline
\end{tabular}


The DF from ${ }^{137} \mathrm{Cs}$ on ferrocyanide sorbent after 1,802 column volumes averaged 4,000 with no clearly decreasing trend. However, the DF was about 2 to 4 times lower than that observed for pure sodium nitrate solution.

An average $\mathrm{DF}$ of 6 was obtained for strontium removal by coprecipitation with barium phosphate. Passing the clarified solution through a pyrolusite column increased the DF to 5,000 after 900 column volumes. Complete regeneration of the pyrolusite column was possible by treatment with nitric acid. The DF decreased to 900 after subsequent passage of 923 column volumes.

Sorption of ${ }^{239} \mathrm{Pu}$ occurred on ferrocyanide and sulfide sorbents; the DFs were 10 and 3 , respectively. Initial solution portions had slightly higher DFs. Decreased purification after 1,800 column volumes was not observed. Coprecipitation of ${ }^{239} \mathrm{Pu}$ with bulk phosphate precipitates increased with increasing amounts of precipitate. With the pyrolusite column, the DF stabilized at about 30 to 70 after 300 column volumes. The total DF achieved for ${ }^{239} \mathrm{Pu}$ was about $10^{5}$.

\subsection{Behavior of Sulfonol in Sodium Nitrate Solutions}

The influences of sulfonol on technological and radiochemical parameters for sodium nitrate purification were evaluated. The solubility of sulfonol was found to decrease as the sodium nitrate concentration increased and the sulfonol coagulated to form a fine dispersion. The completeness of coagulation, however, depended on sodium nitrate concentration. At low sodium nitrate concentrations, sulfonol was present partially as a stable colloid. The amount of dispersed colloid increased with decreasing sodium nitrate concentration. In other words, the coagulating effect of sodium nitrate increased with increasing concentration. Data supporting these conclusions are given in Table 11.9.

Table 11.9. Influence of Sodium Nitrate Concentration on Sulfonol Concentration

\begin{tabular}{|c|c|c|c|c||}
\hline \multirow{2}{*}{} & \multicolumn{4}{|c|}{ [Sulfonol] } \\
\cline { 2 - 5 } & \multicolumn{2}{|c|}{ Solution } & \multicolumn{2}{c|}{ Solid } \\
\cline { 2 - 5 } & $\mathrm{g} / \mathrm{L}$ & $\mathrm{wt} \%$ & $\mathrm{~g} / \mathrm{L}$ & $\mathrm{wt} \%$ \\
\hline 0 & 5.0 & 100 & 0 & 0 \\
\hline 100 & 2.6 & 52 & 1.06 & 21 \\
\hline 200 & 1.7 & 34 & 2.4 & 48 \\
\hline 500 & 0.9 & 18 & 3.4 & 68 \\
\hline 640 & 0.2 & 4 & 4.7 & 94 \\
\hline
\end{tabular}


The amount of sulfonol itself introduced to solution also influenced sulfonol's solubility. For instance, the steady-state solubilities of sulfonol in $100 \mathrm{~g} / \mathrm{L}$ sodium nitrate solution were 0.05 and $2.25 \mathrm{~g} / \mathrm{L}$ at initial sulfonol concentrations in the feed solution of 0.01 and $5 \mathrm{~g} / \mathrm{L}$, respectively. Coagulation of sulfonol in salt solutions was slow, and the rate decreased with increasing sodium nitrate concentration. The change in sulfonol concentration with time in room temperature sodium nitrate solution is shown in Figure 11.2. Apparent equilibrium occurred in 1 to 2 hours at sodium nitrate concentrations of 200 and $500 \mathrm{~g} / \mathrm{L}$, respectively.

The effect of cations on the behavior of sulfonol was investigated during alkaline precipitation at various concentrations. It was found that iron and calcium had virtually no effect on sulfonol concentration in the decantate from alkaline precipitation.

Because sulfonol was not removed completely by alkaline precipitation, coagulation and increased sulfonol concentrations both occurred during cyclic processing. Sulfonol contaminated the salt during crystallization and again passed to the salt solution for the second crystallization. Results of experiments on sulfonol distribution between mother and salt solutions are shown in Table 11.10. As shown in the table, a considerable part of the sulfonol was present in coagulated form in the first crystallization. Despite filtration of the salt solution, the content of sulfonol appearing in the second crystallization was $0.32 \mathrm{~g} / \mathrm{kg}$ salt; this amount originated from the $0.8 \mathrm{~g} / \mathrm{kg}$ remaining after the first crystallization. Formation of solid phase sulfonol contaminant during the second crystallization was not observed. However, experiments on a larger scale showed that sulfonol accumulated in cyclic processing and that even repeated crystallization did not prevent solid phase formation in salt solutions.

\section{[Sulfonol],mg/}

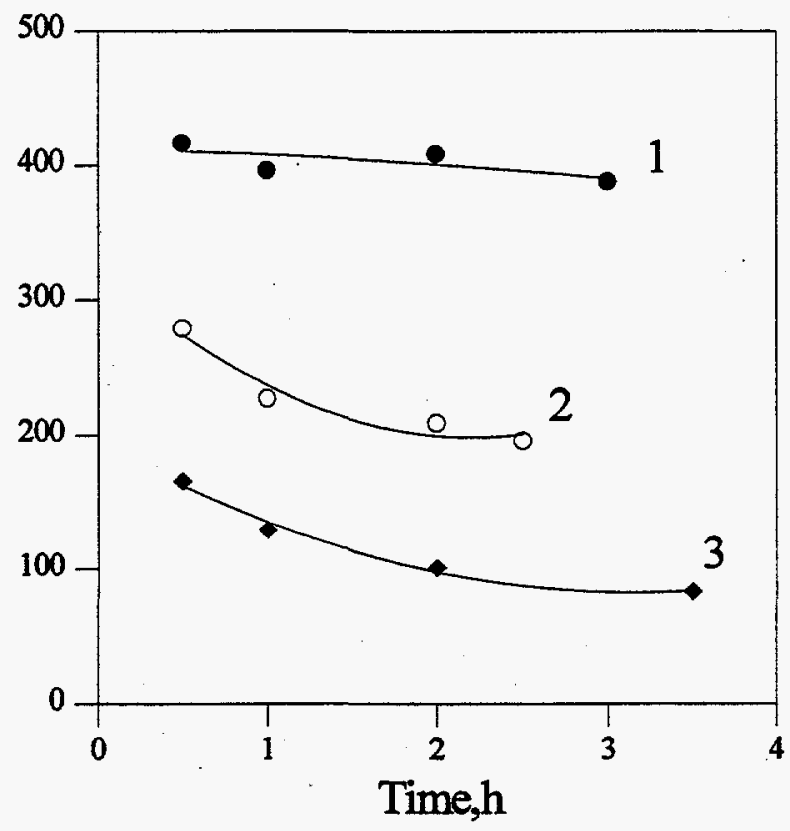

Figure 11.2. Sulfonol Solubility in Room Temperature Sodium Nitrate Solution as a Function of Time at Various Sodium Nitrate Concentrations (in $\mathrm{g} \mathrm{NaNO}_{3} / \mathrm{L}: 1-100,2-200,3-500$ ) 
Table 11.10. Behavior of Sulfonol During Sodium Nitrate Evaporation and Crystallization $\left(100 \mathrm{~g} \mathrm{NaNO}_{3} / \mathrm{L}, 5 \mathrm{~g}\right.$ sulfonol/kg salt)

\begin{tabular}{|c|c|c|}
\hline \multirow{2}{*}{ Product } & \multicolumn{2}{|c|}{ [Sulfonol], g/kg Salt } \\
\cline { 2 - 3 } & First Cryst. & Second Cryst. \\
\hline Mother solution & 1.12 & 0.62 \\
\hline Salt solution & 0.8 & 0.32 \\
\hline Solid phase & 3.08 & -- \\
\hline
\end{tabular}

Special experiments were conducted with solutions containing various sulfonol concentrations to evaluate the influence of sulfonol on sodium nitrate crystal size. Sulfonol at $0.1 \mathrm{~g} / \mathrm{L}$ had no effect on crystal size. However, increasing its concentration to $1 \mathrm{~g} / \mathrm{L}$ increased the fraction of small crystals. Further increase in sulfonol concentration to $5 \mathrm{~g} / \mathrm{L}$ had virtually no additional influence on sodium nitrate crystal size distribution. The solid phase precipitating from solutions containing sulfonol filtered poorly and seriously affected filtration operations.

\subsection{Filtration of Sodium Nitrate Solutions}

One requirement for preparation of a pure salt by crystallization is the absence of solid impurities. Because of this requirement, special attention was paid to solution filtration. Particle size analysis of filtercollected precipitates showed that fine, disperse, almost colloid fractions that did not settle even over long periods were responsible for clogging the pearlite filters. Apparently, the suspensions were produced from sulfonol. Three approaches were tested to improve solution clarification.

1. The filtration unit was relocated from its place after the first crystallizer to after the second crystallizer. In addition, $100 \%$ recycling of mother solutions was tested from the first crystallization to the precipitation unit and from the second crystallization to the first crystallization. The second crystallization was conducted at $\mathrm{pH} 2$ to 3 .

2. This approach was the same as the first method except that the second crystallization was conducted in a strongly acid medium.

3. Experiments were conducted according to conditions described for variant 4 (Section 11.2.4). That is, the first crystallization was performed at $\mathrm{pH} 8$ to 10 , the second at $\mathrm{pH} 2$ to 3 , solution was filtered after the second crystallization, and one-third mother solution recycle was used.

Salt solutions prepared by methods 1 and 2 filtered poorly. Increasing filtration pressure to 3 atmospheres had no noticeable effect, indicating high precipitate compressibility. Data on filtration through pearlite are shown in Figure 11.3. The mean filtration rate at all pressures did not exceed 1.8 to 


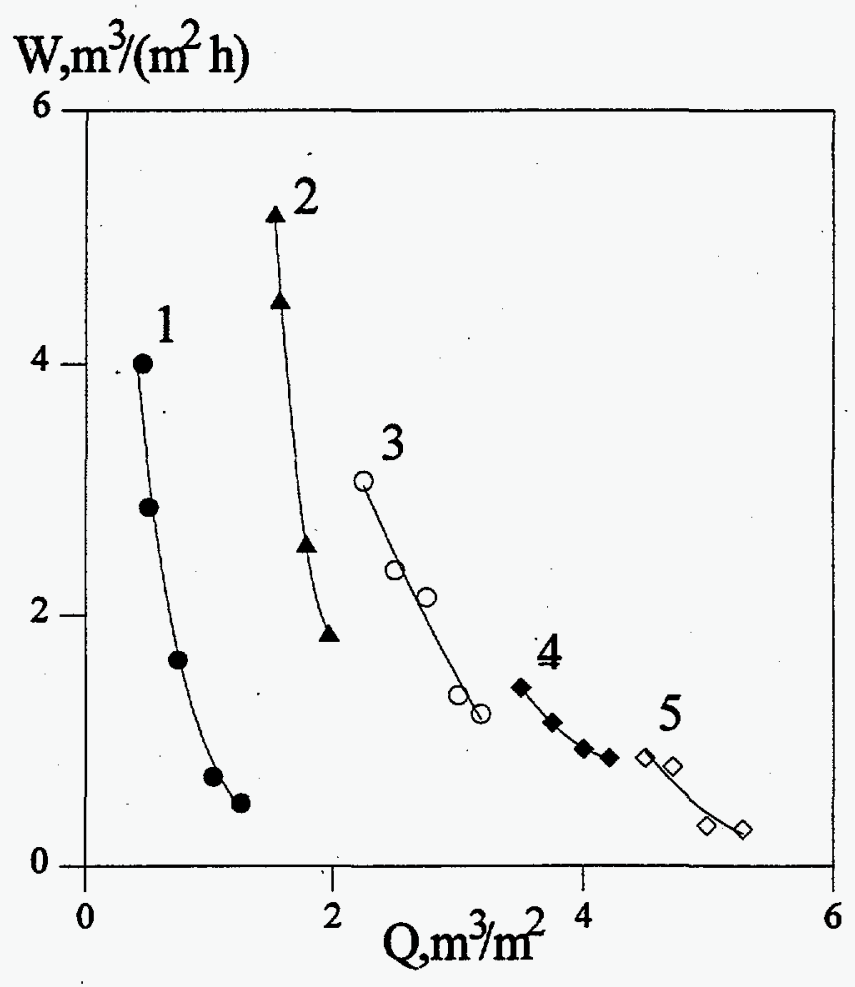

Figure 11.3. Filtration of Sodium Nitrate Solutions Containing Sulfonol Through a Pearlite Filter at Various Pressures (in atmospheres: $1-0.05,2-0.5,3-1.0,4-2.0,5-3.0$ )

$2.0 \mathrm{~m}^{3} /\left(\mathrm{m}^{2}-\mathrm{h}\right)$. The rate decreased rapidly with time, reaching $0.8 \mathrm{~m}^{3} /\left(\mathrm{m}^{2}-\mathrm{h}\right)$ at 3 atmospheres pressure and total specific load on the filter of $5 \mathrm{~m}^{3} / \mathrm{m}^{2}$. The origin of these phenomena was the behavior of sulfonol in crystallization and sorption processing. The influence of sulfonol was confirmed by experiments without sulfonol (Figure 11.4). In the absence of sulfonol (method 3), even at 0.05 atmospheres differential filtration pressure, the rate at $15 \mathrm{~m}^{3} / \mathrm{m}^{2}$ specific loading decreased only a factor of two compared with no loading [from 5.3 to $2.5 \mathrm{~m}^{3} /\left(\mathrm{m}^{2}-\mathrm{h}\right)$ ].

Because of the difficulties with filtration, experiments were conducted combining solution clarification with calcium precipitation. Sodium nitrate solutions containing sulfonol were clarified with sodium phosphate after the second crystallization. Sedimentation for 24 hours produced transparent decantates free of calcium phosphate and solid impurities. The precipitate volume was less than $1 \%$ of the salt solution volume. 


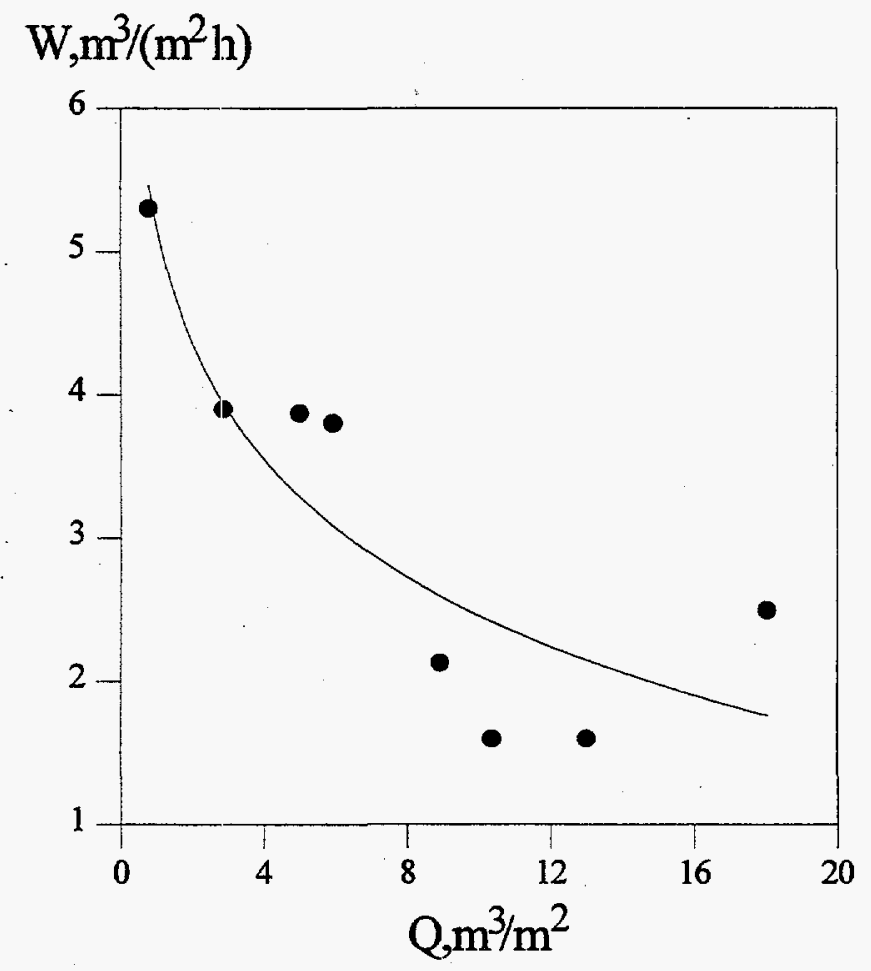

Figure 11.4. Filtration of Sodium Nitrate Solution Without Sulfonol Through a Pearlite Filter 


\subsection{Conclusions}

Detailed research and development were conducted at the Institute of Physical Chemistry of the Russian Academy of Sciences to separate decontaminated acetate and nitrate salts and acetic acid from industrial radioactive wastes. The goal of the work was to decrease the waste volume.

Initial studies demonstrated practical methods to process, by closed cyclic flowsheets, liquid radioactive wastes containing sodium acetate and nitrate at weight concentration ratios greater and less than one. In tests using laboratory-scale glass equipment, salt yields for individual crystallization steps were 50 to $60 \%$. At steady state cyclic conditions, the yields approached $100 \%$. The purity of the separated sodium acetate was 88 to $95 \%$ without washing, and that of sodium nitrate was 96 to $98 \%$ after washing. The activity of the separated crystals was 2 to $3 \%$ of the activity of the initial liquid radioactive waste. Studies were conducted in a pilot-scale facility of metal construction with solutions predominantly composed of sodium acetate. A process technology was developed that used a tubular rotating crystallizer.

Research with genuine radioactive wastes led to development of several variants of cyclic processes to purify the separated salt products from aluminum, silicic acid, ${ }^{137} \mathrm{Cs},{ }^{90} \mathrm{Sr}$, and ${ }^{106} \mathrm{Ru}$. The behavior of sulfate was investigated during acetic acid evaporation and sodium nitrate crystallization. The solubility of sodium sulfate in sodium nitrate solution also was determined. Impurities were identified and their behaviors were studied at the various cyclic processing stages (alkaline calcium precipitation, evaporation, crystallization, sorption purification). Techniques were developed to remove sodium nitrate salt impurities (sodium carbonate, oxalate salts, fluoride, chloride, sulfate, calcium, potassium, ammonium, some organic compounds, and detergents).

An overall method was developed to process intermediate level radioactive waste solutions. Purification factors were determined from zirconium, niobium, rare earth elements, cesium, strontium, ruthenium, and plutonium. Several variants of crystallization and sorption processing for purification of liquid radioactive wastes were tested in a large-scale laboratory facility. Research and development to treat liquid intermediate-level radioactive wastes identified processes that could achieve high decontamination factors through sodium nitrate crystallization and selective purification of inorganic sorbents.

Sulfonol (sodium dodecylbenzenesulfonate) present in the waste formed finely dispersed suspensions in sodium nitrate solutions produced after the second crystallization. These suspensions prevented effective filtration for solution clarification before sorption. A combined solution clarification and precipitation with calcium and barium was proposed for application before strontium sorption. Residual chemical impurities contained in solution and held interstitially in the twice-crystallized sodium nitrate created no noticeable effect on sorption removal of ${ }^{90} \mathrm{Sr},{ }^{106} \mathrm{Ru},{ }^{137} \mathrm{Cs}$, and ${ }^{239} \mathrm{Pu}$. 
At present, research on the application of crystallization and sorption processes for treatment of liquid radioactive wastes from nuclear power plants is being performed at the Institute of Physical Chemistry. Studies to create new selective inorganic sorbents and to develop sorption equipment are under way. Solid/liquid separation apparatus, techniques to remove precipitates from equipment, and processes for thermal treatment, packaging, and purification of gaseous wastes are being developed. 


\section{Distribution}

No. of

Copies

Offsite

2 Office of Scientific and Technical Information

$6 \quad$ Institute of Physical Chemistry

Russian Academy of Sciences

31 Leninsky Prospekt

Moscow, Russia 117915

Attn: V. B. Krapukhin (2)

E. P. Krasavina (2)

A. K. Pikaev (2)

U.S. Department of Energy

12800 Middlebrook Road

Trevion II Building

Germantown MD 20874-1290

Attn: J. Mathur

U.S. Department of Energy

Oak Ridge Operations Office

200 Administration Road

Oak Ridge, TN 37830

Attn: J. Harness

3 Oak Ridge National Laboratory

P. O. Box 2008

Oak Ridge, TN 37831

Attn: J. T. Bell

C. P. McGinnis

J. S. Watson

Savannah River Technical Center

P. O. Box 616

Aiken, SC 29808

Attn: M. C. Thompson
No. of

Copies

Waste Policy Institute

555 Quince Orchard Road, Suite 600

Gaithersburg, MD 20878

Attn: Ian Tasker

John Swanson

1318 Cottonwood Drive

Richland, WA 99352

Thomas Albert and Associates, Inc.

34931 U. S. Highway 19 North

Suite 205

Palm Harbor, FL 34684

Attn: T. E. Albert

Onsite

7 DOE Richland Operations Office

T. L. Aldridge

K8-50

S. T. Burnum

A2-45

J. A. Frey

K8-50

M. J. Glasper

K8-50

J. P. Hanson

K8-50

C. S. Louie

B4-56

B. A. Mauss

K8-50

32 PHMC Team

W. C. Allan

R3-15

J. N. Appel

H6-37

G. S. Barney

T5-12

W. B. Barton

R2-12

J. Bourges

T6-07

D. R. Bratzel

S7-14

K. G. Carothers

R2-11

A.-M. F. Choho

Distr.1 
No. of

Copies

D. W. Edmonson

J. S. Garfield

D. W. Hendrickson

D. L. Herting (3)

J. O. Honeyman

J. R. Jewett

R. A. Kirkbride

M. J. Klem

M. J. Kupfer

S. L. Lambert

G. T. MacLean

W. C. Miller

R. M. Orme

J. C. Person

D. A. Reynolds

E. J. Slaathaug

J. P. Sloughter (3)

D. J. Swanberg

D. J. Washenfelder

Central Files
No. of

Copies

T6-07

H5-49

B4-51

T6-07

G3-21

T6-07

H5-27

H5-27

H5-49

H5-27

H5-61

H5-25

H5-27

T6-07

R2-11

H5- 49

H5-49

$\mathrm{HO}-50$

S7-40

A3-88

\section{Pacific Northwest National Laboratory}

S. Q. Bennett

W. F. Bonner (3)

K7-90

N. G. Colton

K9-14

C. H. Delegard (5)

K8-93

T. A. Fryberger

P7-25

W. L. Kuhn

K2-20

Information Release (5)

K8-93

K1-06 